\title{
HINDERSON AYRES
}

Validacão do ezcore de condição corgoral e seu impacto na eficiéncia reprodutiva de vacas Nelore (Bos indicus) inseminadas em tempo fixo 


\section{HENDERSON AYRES}

Validação do escore de condição corporal e seu impacto na eficiência reprodutiva de vacas

Nelore (Bos indicus) inseminadas em tempo fixo

São Paulo

2008 


\section{HENDERSON AYRES}

DEDALUS - Acervo - FMVZ

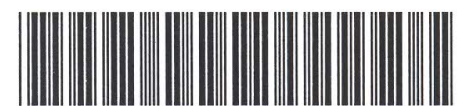

11300031913

Validação do escore de condição corporal e seu impacto na eficiência reprodutiva de vacas Nelore (Bos indicus) inseminadas em tempo fixo

Dissertação apresentada ao Programa de PósGraduação em Reprodução Animal da Faculdade de Medicina Veterinária e Zootecnia da Universidade de São Paulo para a obtenção do título de Mestre em Medicina Veterinária

Departamento:

Reprodução Animal

Área de concentração:

Reprodução Animal

Orientador:

Prof. Dr. Pietro Sampaio Baruselli

São Paulo 2008

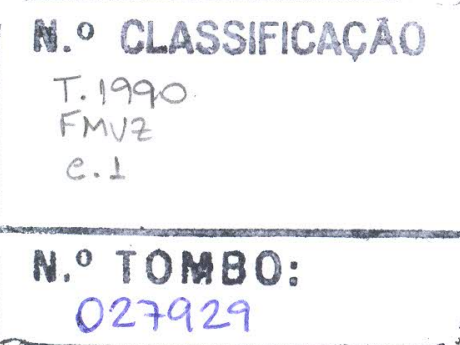


Autorizo a reprodução parcial ou total desta obra, para fins acadêmicos, desde que citada a fonte.

DADOS INTERNACIONAIS DE CATALOGAÇÃO-NA-PUBLICAÇÃO

(Biblioteca Virginie Buff D’Ápice da Faculdade de Medicina Veterinária e Zootecnia da Universidade de São Paulo)

T.1990

FMVZ

Ayres, Henderson

Validação do escore de condição corporal e seu impacto na eficiência reprodutiva de vacas Nelore (Bos indicus) inseminadas em tempo fixo / Henderson Ayres. - São Paulo : H. Ayres, 2008.

$136 \mathrm{f}$ : : il.

Dissertação (mestrado) - Universidade de São Paulo. Faculdade de Medicina Veterinária e Zootecnia. Departamento de Reprodução Animal, 2008.

Programa de Pós-Graduação: Reprodução Animal.

Área de concentração: Reprodução Animal.

Orientador: Prof. Dr. Pietro Sampaio Baruselli.

1. Vacas Nelore. 2. Condição corporal. 3. Espessura da gordura subcutânea. 4. Eficiência reprodutiva. I. Título. 


\section{UNIVERSIDADE DE SÃO PAULO Faculdade de Medicina Veterinaria e Zootecnia Assistência Acadêmica \\ Comissão Bioética}

\section{CERTIFICADO}

Certificamos que o Projeto intitulado "Efeito da quantidade de gordura subcutânea da condição e do peso corporal durante o pré e pós-parto na atividade ovariana pós-parto e na eficiência reprodutiva de vacas Nelores (Bos indicus) inseminadas em tempo fixo", protocolo n $738 / 2005$, utilizando 600 bovinos, sob a responsabilidade do Prof. Dr. Pietro Sampaio Baruselli, está de acordo com os princípios éticos de experimentação animal da Comissão de Bioética da Faculdade de Medicina Veterinária e Zootecnia da Universidade de São Paulo e foi aprovado "ad referendun".

(We certify that the Research "Effect of amount of subcutaneous fat,corporal weight and score condition, during pre and post partum, on post partum ovarian activity and reproductive efficiency of Nelore cows (Bos indicus) inseminated at fixed time", protocol number 738/2005, under the responsibility of Prof. Dr. Pietro Sampaio Baruselli, utilizing 600 bovines, agree with Ethical Principles in Animal Research adopted by Bioethic Commission of the Faculty of Veterinary Medicine and Zootechny of University of São Paulo and was approved "ad referendun", meeting).

São Paulo, 30 de setembro de 2005

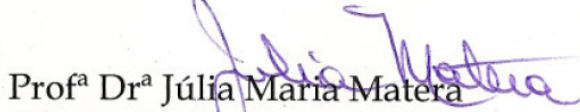

Presidente da Comissão de Bioética

FMVZ/USP 
Nome: AYRES, Henderson

Título: Validação do escore de condição corporal e seu impacto na eficiência reprodutiva de vacas Nelore (Bos indicus) inseminadas em tempo fixo

Dissertação apresentada ao Programa de PósGraduação em Reprodução Animal da Faculdade de Medicina Veterinária e Zootecnia da Universidade de São Paulo para a obtenção do título de Mestre em Medicina Veterinária

Data:

1

Prof. Dr.

Assinatura:

Prof. Dr.

Assinatura:

Prof. Dr.

Assinatura:
Instituição:

Julgamento:

Instituição:

Julgamento:

Instituição:

Julgamento: 
Aos meus queridos pais, José e Maria, pelo apoio em todas as minhas decisões e ações.

Aos meus irmãos, Peterson e Arley pela amizade e apoio.

Aos meus sobrinhos queridos Peterson e Beatriz.

A minha namorada Roberta pelo apoio, carinho, companheirismo e compreensão incondicionais.

Dedico 


\section{AGRADEÇO}

À Deus por me dar forças, ajudar e me guiar na vida.

Ao meu grande amor Roberta, pelo companheirismo, dedicação e por ter entrado na minha vida e a transformado (Grandes Papers). Obrigado pela ajuda na confecção desta dissertação, sem você tenho certeza que ela não sairia.. TE AMO!!!

Aos meus QUERIDOS Pais que me proporcionaram uma base familiar, ensinamentos, e sempre me apoiaram em todas as minha decisões.

Ao meu irmão PETERSON pela confiança incondicional na pessoal que sou e por muitas vezes acreditar mais em mim do que eu mesmo.

Ao meu irmão ARLEY por me mostrar que na vida tudo é conseqüência de um trabalho e força de vontade e, principalmente mostrar "que o mundo dá voltas".

Às minhas cunhadas TÂNIA E LUCIANA o apoio e a alegria de formarmos uma maravilhosa família.

Aos meus queridos sobrinhos PETISHHO E BIA pela alegria que trouxeram a nossa casa e vida. AMO VOCÊS!!!

Ao PROF. DR. PIETRO SAMPAIO BARUSELLI pelo exemplo de pessoa, de trabalho e de dedicação. Com você pude aprender muito sobre a vida, o trabalho e o contato pessoal. Obrigado pela amizade nascida e desculpe-me se faltei em algum momento como orientado ou pessoa, mas meu intuito sempre foi procurar o caminho certo.

À todos os professores do Departamento de Reprodução Animal (VRA) pelos ensinamentos, dedicação e amizade. Em especial ao PROF. DR. RENATO CAMPANARUT BARNABE pela sinceridade, carisma e exemplo de dedicação; ao PROF. DR. MARIO BINELLI pelo exemplo de cientista e pela confiança depositada na minha pessoa; a PROF. DRA. MARIA HELENA .... pela amizade e coração de mãe; ao PROF. DR. JOSÉ 


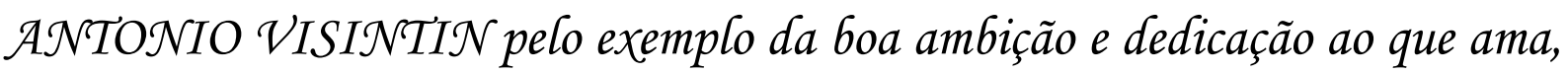
sem esquecer da sombra (Prof. DRA. Camila Infantosi Vannucchi).

Ao Prof Dr. Ed Hoffmann Madureira pela amizade, ensinamentos, disponibilidade para discussão e pelas boas risadas proporcionadas em churrascos e momentos de descontração.

À todos os funcionários do VRA pelo apoio e eficiência, sem vocês a pesquisa não seria possivvel, em especial à DONA SILVIA pelo exemplo de vida e serenidade.

À Saulo da Luz e Silva pela disponibilidade e apreço em todos os momentos que necessitei.

Às secretárias HARUMI SHIRAISHI e THAÍS SOTO pela amizade e ajuda incondicional em todos os momentos que sempre necessitei de vocês e, principalmente pela amizade construída nesse longos e bons anos de VRA que podemos conviver juntos, obrigado meninas.

Ao quase irmão JOSÉ EDUARDO, Gardenal, pelo companheirismo em horas boas e ruins, e por ter me proporcionado descobrir o que é a amizade verdadeira.

À todos os veterinários de campo com quem passei desde 1999, tenho certeza que aprendi um pouco com cada um.

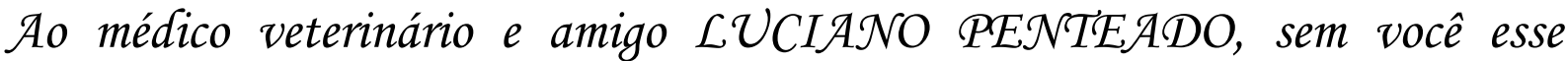
trabalho não seria possível.

Aos amigos Nélcio Antônio Tonizza de Carvalho (Cabecinha de Macaco) amigo incondicional e que traz alegria onde esta; Everton Luiz Reis (Cabeção) pela amizade e de profissional, Manoel Francisco de Sá Filho (Mané, Gaúcho, Burchecha de (Burdoge) por ter me ensinado muito no meu inicio na pós e por ter sido sempre um amigo; José Ribamar de Souza Torres Júnior (Preto, Índio Veio) pela amizade, alegria e ajuda, pois sem você este trabalho não teria sido feito por inteiro; Lindsay Unno Gimenes (Japinha, não, não, aí não!!!) pela amiga e companheira que é; Alexandre Henrily de Souza (Cabecinha de 
Neném) obrigado pela confiança empregada em mim, tenho certeza que você foi importantíssimo para a minha formação como profissional e pessoa, proporcionando a possibilidade de poder conhecer novas pessoas e lugares e, pelo exemplo de responsabilidade profissional e de membro de uma família; Gabriel Crepaldi pelas suas ponderações, ajudas e companherismo, José Nélio Sales (Znlogan) pela pessoa humildade (no melhor sentido da palavra) e pronta a ajudar, Marcio Leão Ferraz pelo convívio (infelizmente pocuo, porém proveitoso), Alessandra Teixeira, a mais nova nariguda, a todos que junto formamos uma família, "Os $\mathcal{N}$ arigudinhos".

À todos os estagiários que contribuíram para a realização de nossos trabalhos.

Ao MÁRCILIO por ser um amigo disposto a ajudar, ensinar e discutir a qualquer momento. $\mathcal{N a ̃ o ~ e s q u e c e n d o ~ d o s ~ n o s s o s ~ c h u r r a s c o s . ~}$

Ao Febém pela amizade e dedicação, ainda maior no seu mandato de vicepresidente, tesoureiro e churrasqueiro (quantas funções).

Ao Ira, Luís e Belau, amigos sem os quais muitos de nossos churrascos não teriam saido, obrigado moçada!!!

À todos os amigos do VRA (Alê, Mazza, Rê, Fabiola, Cris, Li, Gi, Weber, Camila, Zeca, Paulo, Rodriguinho...), valeu galera.

À PRISCILA do LDH pela paciência e realização das dosagens de progesterona dos nossos experimentos.

Aos amigos da sexagésima quinta turma GUGA, LEDA, FUD $\hat{E} \mathcal{N C I O}$, CHAVES, B1, SUVACO e TULIPA, nunca vou esquecer os anos que passamos juntos.

À AGROPECUARIA CAFÈ $\mathcal{N O}$ BULE, por ter aberto as portas para a realização desse e outros muitos experimentos. $E$ todos os funcionários (Leandro, Camila, Sâmia, Jairo, Zé, Carlinhos, cozinheiras), pois sem vocês

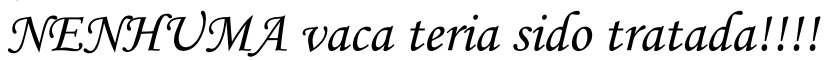


À INTERTVT, pelo financiamento de diversos experimentos e, em especial à MARCO DALALIO, CHIQUINHHO, TIAGO e JULIANO, pessoas com quem pude trabalhar e aprender sempre algo novo.

À empresa $\mathcal{N}$ utricell-Campinas pela grande ajuda durante a parte experimental ao fornecer a probe de carcaça

À todas as empresas que trabalham em conjunto com nosso grupo de pesquisa, sem elas não seria possível produzir.

À FAPESP - Fundação de Amparo a Pesquisa do Estado de São Paulo, pelo indispensável suporte financeiro concedido através da bolsa de Mestrado. (Processo: 05/57425-7).

Obrigado ao Mela e Preta, Alê, Ivo, Rato Branco, Mauri, Luis e Ro e todos os amigos do remo que souberam entender, compreender e a aceitar as minhas muitas ausências nos treinos, porém sempre deixei claro que nunca deixei de treinar!!!! Esse é um esporte que como diria o "TIO": "te prepara para encarar qualquer desafio na sua

Agradeço a todos que souberam conviver de forma harmoniosa com as minhas ausências e que nunca deixaram de me apoiar nas minhas decisões.

Em ESPECIAL as minha queridas amigas VACAS, sejam elas as leiteiras ou de corte, as gringas ou Grasileiras, pois sem vocês testa dissertação e diversas pesquisa não poderiam ter sido realizadas. Desculpa por algum incômodo.

Enfim, à todos aqueles com quem convivi e pude tirar palavras e ensinamentos proveitosos. Peço desculpas se omiti algum nome, pois ainda tem muitos que deveriam estar aqui e, tenham certeza que o que importa é a gratidão presente dentro de cada um e não a simples escrita de um nome.

\section{OBRIGADO A TODOS!}


"Uma reunião em que todos os presentes estão absolutamente de acordo é uma reunião perdida."

Albert Einstein

Conhecimento entra pela "porta do fundo"...

Pietro Sampaio Baruselli 


\section{RESUMO}

AYRES, $H$. Validação do escore de condição corporal e seu impacto na eficiência reprodutiva de vacas Nelore (Bos indicus) inseminadas em tempo fixo. [Validation of body condition score and its impact on reproductive efficiency of Nelore (Bos indicus) cows fixed-time inseminated]. 2009136 f. Dissertação (Mestrado em Medicina Veterinária) Faculdade de Medicina Veterinária e Zootecnia, Universidade de São Paulo, São Paulo, 2009.

A presente dissertação foi dividida em 2 Capítulos. O objetivo do Capítulo 1 foi determinar a relação entre as variáveis: peso vivo (PV), avaliação do escore de condição corporal (ECC) e espessura da gordura subcutânea na garupa (EGPU) mensurada por ultra-sonografia. 266 vacas Nelores foram avaliadas quanto ao ECC, a EGPU e PV, em cinco momentos distintos: M1) no momento da desmame; M2) ao parto, M3) no dia da sincronização; M4) aos 82 dias e M5) aos 112 dias pós-parto. Foi atribuído um ECC para cada vaca na escala 1 a 5 (MACIEL, 2006). Para a obtenção das imagens ultra-sonográficas para mensuração EGPU, foi utilizado um transdutor linear com freqüência de 3,5 $\mathrm{MHz}$. As imagens ultra-sonográficas obtidas foram congeladas e imediatamente analisadas. As relações entre ECC e as mensurações de EGPU foram investigadas utilizando modelos de regressão. Para a análise de semelhança entre os cinco modelos foi utilizado o proc MIXED do SAS. As correlações entre variáveis foram analisadas com o proc CORR do SAS. O ECC foi capaz de predizer a EGPU de vacas Nelores em diferentes momentos do ciclo de criação. Ainda, foi demonstrado que o ECC apresentou alta correlação $(r=0,82$ a 0,93$)$ e relação $\left(R^{2}=0,73\right.$ a 0,92) com a EGPU. Porém, tanto o ECC, quanto a EGPU apresentam baixa correlação e baixíssima relação com o peso. No Capítulo2, o objetivo foi determinar o impacto do ECC, da EGPU, do PV e de suas variações nos 5 momentos descritos acima na eficiência reprodutiva (ER) de vacas Nelore submetidas à IATF e repasse com o touro e determinar o(s) momento(s) de avaliação com maior impacto na ER. Foram utilizados os mesmas animais do Capítulo 1. No dia 0 , todos os animais receberam implante auricular de Norgestomet, reutilizado e a aplicação de 2,0 mg de benzoato de estradiol (D42). Oito dias após (D50), os implantes foram retirados e foi administrado 400 UI de eCG e PGF. No dia seguinte (D51), foi administrado $1,0 \mathrm{mg}$ de Benzoato de estradiol. Os animais foram inseminados 56 horas após a retirada do implante (D52). Após 10 dias da inseminação, houve a introdução de touros. O diagnóstico de gestação foi realizado aos 30 e 60 dias após à IATF. Os animais foram avaliados quanto ao PV, ECC e EGPU com a mesma metodologia do Capítulo 1. A ER foi avaliada pela taxa de concepção à IATF aos 82 e aos 112 dias pósparto e a taxa de prenhez acumulada até 82 dias pós-parto. Os dados binomiais foram analizados com o proc GLIMMIX do SAS. Os modelos de regressão foram gerados através do Guide Data Analysis do SAS. As correlações entre variáveis foram analisadas com o proc 
CORR do SAS. Os resultados apontam que vacas com maior ECC, EGPU e ganho destas medidas entre desmame-parto apresentaram melhor ER e a avaliação do peso apresentou baixa correlação com a ER. Porém, a menor perda de ECC e gordura subcutânea entre parto-sincronização não melhorou a ER. Avaliação do ECC e a EGPU no momento do parto demonstraram ter o maior impacto na ER de vacas Nelore submetidas à IATF e repasse com touro. Porém, mais estudos são necessários para confirmar os dados deste estudo.

Palavras-chave: Vacas Nelore. Condição corporal. Espessura da gordura subcutânea. Eficiência reprodutiva 


\section{SUMMARY}

AYRES, $H$. Validation of body condition score and its impact on reproductive efficiency of Nelore (Bos indicus) cows fixed-time inseminated [Validação do escore de condição corporal e seu impacto na eficiência reprodutiva de vacas Nelore (Bos indicus) inseminadas em tempo fixo]. 2008136 f. Dissertação (Mestrado em Medicina Veterinária) Faculdade de Medicina Veterinária e Zootecnia, Universidade de São Paulo, São Paulo, 2008.

The present study was divided in two Chapters. The objective of the first Chapter was to determine the relationship among the variables: body weight (BW), body condition score $(B C S)$ and back fat thickness (BFT), measured by ultrasonography. Two hundred and six Nelore cows had their BW, BCS and BFT evaluated at five different moments: M1) weaning; M2) parturition, M3) synchronization; M4) 82 days post-partum and M5) 112 days postpartum. A BCS value was attributed for each cow following a 1 to 5 points scale (MACIEL, 2006). Ultrasound images for BFT measurement were obtained using a $3.5 \mathrm{MHz}$ linear transducer. Images were immediately analyzed as soon as they were formed and frozen. The relationship between BCS and BFT values was investigated by regression models. The analysis of similarity among the five obtained models was performed using the proc MIXED from SAS and the correlations among variables were analyzed with proc CORR from SAS. The BCS was able to predict BFT in Nelore cows in all different moments evaluated. Also, it was shown that BCS presented high correlation $(r=0.82$ to 0.93$)$ and relationship $\left(R^{2}=0.73\right.$ to 0.92 ) with BFT. However, both BCS and BFT showed poor correlation and extremely pour relationship with $\mathrm{BW}$. On Chapter 2, the objective of the study was to determine the impact of $\mathrm{BCS}, \mathrm{BFT}$ and $\mathrm{BW}$, and their variations in that five previously cited moments, on reproductive efficiency (RE) of Nelore cows submitted to FTAI followed by exposition to clean-up bulls. Also, this work aimed to determine the moment(s) of evaluation that presented greater impact on RE. The same animals used on Chapter 1 were used here. All animals received a norgestomet ear implant (previously used for 9 days) associated to $2.0 \mathrm{mg}$ of estradiol benzoate (D42). Eight days after (D50), the implants were removed and $400 \mathrm{IU}$ of eCG plus PGF were administered. On the following day (D51), cows received $1.0 \mathrm{mg}$ of estradiol benzoate and all animals were inseminated 56 hours after implant withdrawal (D52). Ten days after insemination females were exposed to clean-up bulls. Pregnancy diagnosis was performed 30 and 60 days post-FTAI. All animals had their BW, BCS and BFT measured using the same methods described on Chapter 1. Reproductive efficiency was evaluated considering pregnancy per $\mathrm{Al}$ at 82 and 112 days post-partum and cumulative pregnancy until 82 days post-partum. Binomial data were analyzed using the proc GLIMMIX from SAS, regression models were generated via Guide Data Analysis from SAS, and correlations among variables were analyzed with proc CORR from SAS. The obtained results evidenced 
that cows with higher BCS and BFT and greater gain of these measures during the interval weaning-partum presented better RE. However, the decreased loss of BCS and BFT between parturition and synchronization did not increase the RE. Also, BW evaluation showed poor correlation with RE. The evaluation of BCS and BFT at partum demonstrated that these parameters had great impact on RE of Nelore cows submitted to FTAl followed exposition to bulls. However, more studies are demanded in order to reaffirm the results obtained in this particular study.

Key-words: Nelore cows. Body condition. Back fat thickness. Reproductive efficiency. 


\section{LISTA DE FIGURAS}

Figura 1 - Modelo simplificado do crescimento de folículos desde a emergência até a ovulação (Wiltbank et al., 2002).

Figura 2 - Diagrama esquemático dos momentos de coleta de dados..

Figura 3 - Diagrama esquemático do local de mensuração da espessura da gordura subcutânea vista lateral $(A)$ e vista superior (B; adaptado SCHRODER; STAUFENBIEL, 2006).

Figura 4 - Imagem ultra-sonográfica do local de mensuração da espessura da gordura subcutânea (A) e corte longitudinal do Gluteus medius e Bíceps femoris (B; adaptado de SAINZ; ARAÚJO; 2002).

Figura 5 - Gráfico de dispersão do escore de condição corporal e a raiz quadrada da espessura da gordura subcutânea.

Figura 6 - Representação esquemática do tratamento hormonal.

Figura 7 - Representação gráfica da probabilidade de ciclicidade no início do protocolo de sincronização em função do escore de condição corporal no momento da sincronização $(P=0,04)$ em vacas Nelore (Bos indicus).

Figura 8 - Representação gráfica da probabilidade de ciclicidade no início do protocolo de sincronização em função da data do parto $(P=0,0001)$ em vacas Nelore (Bos indicus).

Figura 9 - Representação gráfica da probabilidade de concepção à IATF aos 60 dias de gestação (112 dias pós-parto) em função do escore de condição corporal próximo ao parto $(P=0,02)$ em vacas Nelore $(B o s$ indicus)......

Figura 10 - Representação gráfica da probabilidade de prenhez acumulada aos 82 dias pós-parto em função do sexo do bezzero $(P=0,06)$ de vacas Nelore (Bos indicus).

Figura 11 - Representação gráfica da probabilidade de prenhez acumulada aos 82 dias pós-parto em função do escore de condição corporal no desmame ( $P=0,01)$ em vacas Nelore (Bos indicus).

Figura 12 - Representação gráfica da probabilidade de prenhez acumulada aos 82 dias pós-parto em função do escore de condição corporal ao parto $(P=0,0007)$ em vacas Nelore (Bos indicus) 
Figura 13 - Representação gráfica da probabilidade de prenhez acumulada aos 82 dias pós-parto em função do escore de condição corporal aos 112 dias pós-parto $(P=0,048)$ em vacas Nelore (Bos indicus).....

Figura 14 - Representação gráfica da probabilidade de prenhez acumulada aos 82 dias pós-parto em função da diferença de escore de condição corporal entre o parto e a sincronização $(P=0,03)$ em vacas Nelore (Bos indicus).

Figura 15 - Representação gráfica da probabilidade de prenhez acumulada aos 82 dias pós-parto em função da espessura da gordura subcutânea no desmame $(P=0,03)$ em vacas Nelore (Bos indicus).

Figura 16 - Representação gráfica da probabilidade de prenhez acumulada aos 82 dias pós-parto em função da espessura da gordura subcutânea ao parto $(P=0,003)$ em vacas Nelore (Bos indicus).

Figura 17 - Representação gráfica da probabilidade de prenhez acumulada aos 82 dias pós-parto em função do peso da vaca no desmame $(P=0,01)$ em vacas Nelore (Bos indicus).

Figura 18 - Representação gráfica da probabilidade de prenhez acumulada aos 82 dias pós-parto em função da diferença de peso entre o desmame e o parto $(P=0,006)$ em vacas Nelore (Bos indicus).

Figura 19 - Representação gráfica da probabilidade de perda de gestação à IATF (entre 30 e 60 dias de gestação) em função do escore de condição corporal aos 82 dias $(P=0,046)$ em vacas Nelore (Bos indicus).

Figura 20 - Representação gráfica da probabilidade de perda de gestação à IATF (entre 30 e 60 dias de gestação) em função do escore de condição corporal aos 112 dias pós-parto $(P=0,02)$ em vacas Nelore (Bos indicus).

Figura 21 - Representação gráfica da probabilidade de perda de gestação à IATF (entre 30 e 60 de gestação) em função da diferença de espessura da gordura subcutânea entre o desmame e o parto $(P=0,046)$ em vacas Nelore (Bos indicus).

Figura 22 - Representação gráfica da evolução do escore de condição corporal segundo cada classe e o momento de classificação em vacas Nelore (Bos indicus): (A) no desmame; (B) próximo ao parto; (C) na sincronização. 
Figura 23 - Gráfico de dispersão e reta de regressão do escore de condição corporal e taxa de prenhez acumulada aos 82 dias pós-parto em vacas Nelore (Bos indicus): (A) escore de condição corporal no desmame; (B) escore de condição corporal próximo ao parto; (C) escore de condição corporal na sincronização. 


\section{LISTA DE TABELAS}

Tabela 1 - Número de observações, médias, erros padrão e valores mínimos e máximos do escore de condição corporal (ECC), da espessura da gordura subcutânea (EGPU, $\mathrm{cm}$ ) e do peso vivo $(\mathrm{kg})$ de vacas Nelore (Bos indicus) avaliadas em diferentes momentos experimentais (desmame, parto, sincronização, diagnóstico de gestação aos 82 e aos 112 dias)

Tabela 2 - Coeficiente de correlação de Pearson ( $r$ ) entre os escores de condição corporal (ECC) e as espessuras da gordura subcutânea (EGPU; $n=266$ ) encontrados em vacas Nelore (Bos indicus) avaliadas em diferentes momentos experimentais (desmame, parto, sincronização, diagnóstico de gestação aos 82 e aos 112 dias)

Tabela 3 - Número de animais $(\mathrm{N})$ e valores do coeficiente de regressão $\left(R^{2}\right)$, de.F e de $P$ (nível de significância) obtidos nos diferentes modelos testados para ECC e EGPU de vacas Nelore (Bos indicus) avaliadas em diferentes momentos experimentais (desmame, parto, sincronização, avaliação aos 82 e aos 112 dias pósparto).

Tabela 4 - Freqüência de ocorrência de cada escore de condição corporal em vacas Nelore (Bos indicus) avaliadas em diferentes momentos experimentais (desmame, parto, sincronização, avaliação aos 82 e aos 112 dias pós-parto)

Tabela 5 - Freqüência de ocorrência de cada espessura da gordura subcutânea (EGPU) em vacas Nelore (Bos indicus) avaliadas em diferentes momentos experimentais (desmame, parto, sincronização, avaliação aos 82 e 112 dias)

Tabela 6 - Número de observações, médias, desvios padrão e valores mínimos e máximos da idade (ao desmame), intervalo entre partos, intervalo entre o desmame e o parto e dias pós-parto das vacas Nelore (Bos indicus) mantidas no experimento. 
Tabela 7 - Número de observações, médias, erros padrão e valores mínimos e máximos do escore de condição corporal (ECC), da espessura da gordura subcutânea (EGPU; $\mathrm{cm}$ ) e do peso vivo $(\mathrm{kg})$ de vacas Nelore (Bos indicus) avaliadas em diferentes momentos experimentais (desmame, parto, sincronização, avaliação aos 82 e aos 112 dias pós-parto)

Tabela 8 - Taxa de ciclidade, taxa de concepção à IATF aos 30 e 60 dias de gestação, taxa de prenhez acumulada aos 82 dias pós-parto e taxa de perda de gestação entre 30 e 60 dias de gestação de vacas Nelore (Bos indicus)

Tabela 9 - Valores de $P$ de para o efeito de cada variável analisada sobre as taxas de ciclicidade, concepção à IATF aos 82 e 112 dias pós-parto (equivalente a 30 e 60 dias de gestação, respectivamente), prenhez acumulada aos 82 dias pós-parto e perda de gestacional entre 30 e 60 dias de gestação de vacas Nelore (Bos indicus)

Tabela 10 - Escore de condição corporal no momento da sincronização de acordo com a etapa de sincronização (primeira vs segunda) e o status ovariano de vacas Nelore (Bos indicus)

Tabela 11 - Escore de condição corporal no início da sincronização de acordo com a etapa de sincronização (primeira vs segunda) e o status ovariano (efeito principal)

Tabela 12 - Diferença de escore de condição corporal entre o desmame e o parto em vacas Nelore (Bos indicus)

Tabela 13 - Diferença de escore de condição corporal entre o parto e a sincronização em vacas Nelore (Bos indicus). 


\section{LISTA DE ABREVIATURAS E SIGLAS}

$12^{\mathrm{a}}$

$13^{a}$

$17 \beta$-estradiol

BE

BF

BHBA

B-mode

CE

$\mathrm{CIDR}^{\circledR}$

$\mathrm{CL}$

$\mathrm{cm}$

CORR

$\mathrm{CSH}$

$\mathrm{DIB}^{\circledR}$

E2

ECC

EGPU

EGS

EGSU

EM

Desm

Diag

$\mathrm{FSH}$

$\mathrm{GH}$

GM

$\mathrm{GnRH}$

hCG

IA

IATF

IGF -1 décima segunda

décima terceira

17-beta-estradiol

Benzoato de estradiol

Bíceps Femoral

beta hidroxibutirato

Módulo B

Cipionato de Estradiol

control internal drug relise

Corpo Lúteo

centimetro

correlação

composto de simetria heterogênea

dispositivo intravaginal bovino

estrógeno

escore de condição corporal

espessura da gordura subcutânea na garupa

Espessura da Gordura de Cobertura

espessura da gordura subcutânea na área de lombo

estação de monta

desmame

diagnóstico

hormônio folículo estimulante

hormônio do crescimento

Glúteo Médio

hormônio liberador de gonadotrofina

gonadotrofina coriônica humana

inseminação artificial

inseminação artificial em tempo fixo

fator de crescimento semelhante ao crescimento 1 


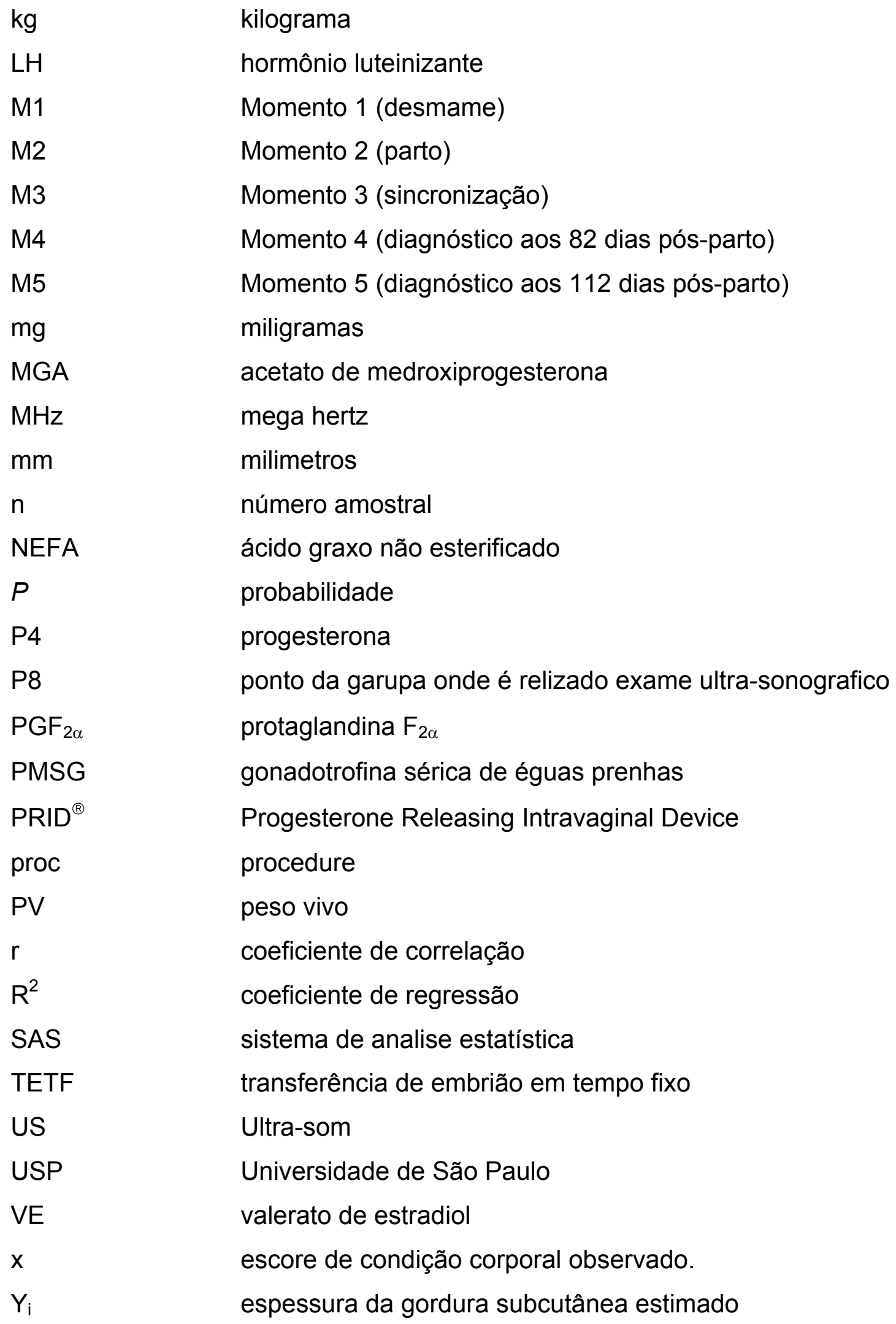




\section{LISTA DE SÍMBOLOS}

$\begin{array}{ll}\circledR & \text { marca registrada } \\ \% & \text { porcentagem } \\ \sqrt{E G P U} & \text { raiz quadrada da espessura da gordura subcutânea predito } \\ \% & \text { porcentagem } \\ \alpha & \text { Letra grega alfa } \\ \beta & \text { Letra grega beta } \\ \gamma & \text { Letra grega gama } \\ \delta & \text { Letra grega omega } \\ \tau & \text { Letra grega tau } \\ \beta_{i} & \text { elemento de primeiro grau } \\ \gamma_{i} & \text { elemento de segundo grau } \\ \delta_{i} & \text { elemento de terceiro grau } \\ \alpha_{i} & \text { intercept } \\ < & \text { menor que } \\ = & \text { igual } \\ > & \text { maior que } \\ \pm & \text { mais ou menos } \\ \leq & \text { menor e igual a }\end{array}$




\section{SUMÁRIO}

1 INTRODUÇÃO

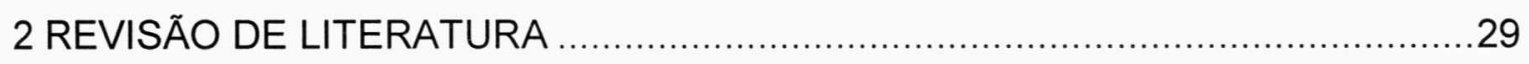

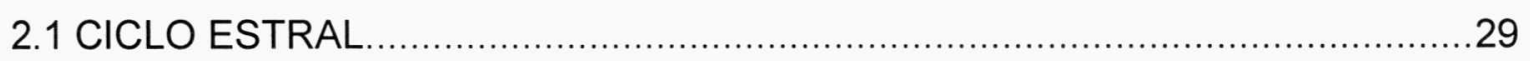

2.2 ANESTRO

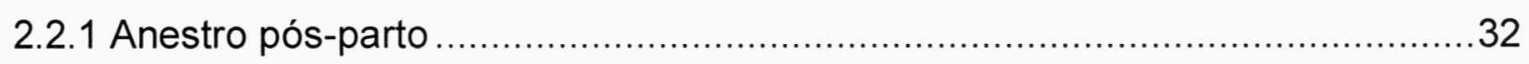

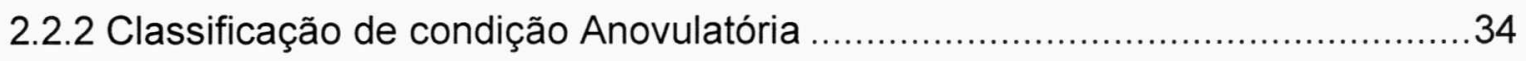

2.3 CONTROLE FARMACOLÓGICO DO CICLO ESTRAL DE FÊMEAS BOVINAS

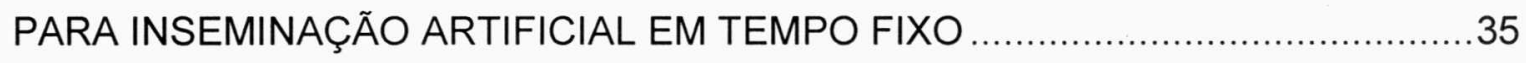

2.3.1 Tratamento com $\mathrm{PGF}_{2 \propto}$ para sincronização do estro ........................................35

2.4 CONTROLE DA DINÂMICA FOLICULAR PARA REALIZAÇÃO DA

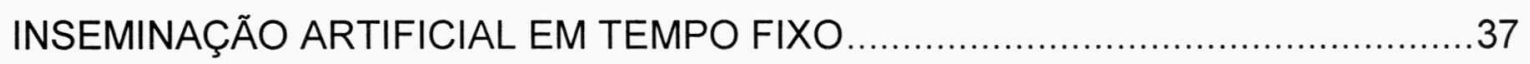

2.4. 1 Sincronização da emergência de nova onda de crescimento folicular com

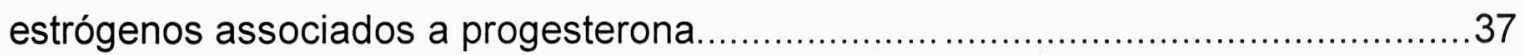

2.4.2 Controle da fase progesterônica do ciclo estral - Prostaglandina $F_{2 \alpha} \ldots \ldots \ldots \ldots . . . .39$

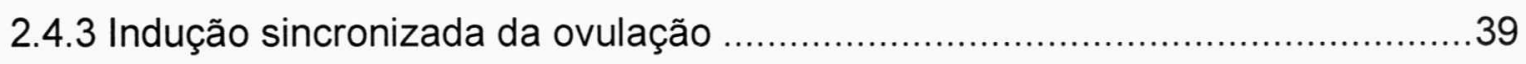

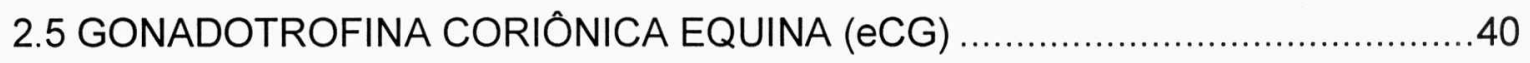

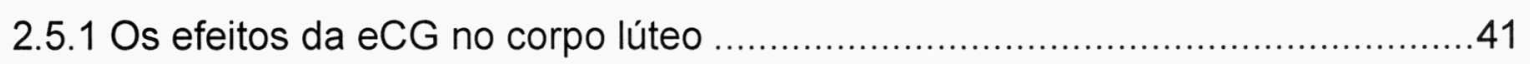

2.5.2 Uso da gonadotrofina coriônica equina (eCG) em programas de IATF ............42

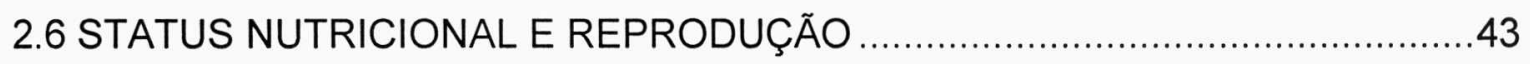

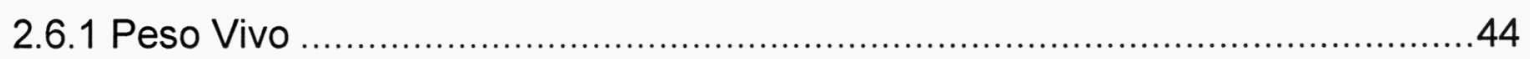

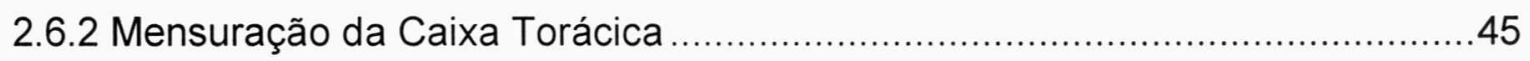

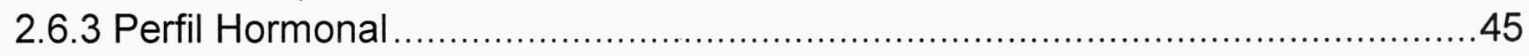

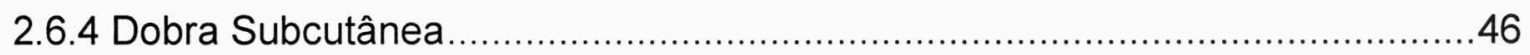

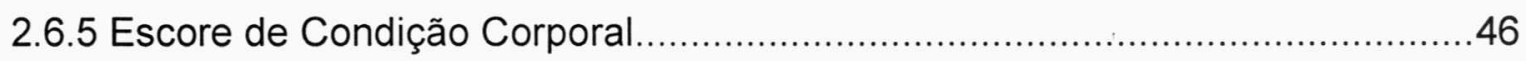

2.6.6 Mensuração da Espessura da Gordura Subcutânea na Garupa (EGPU) ........47

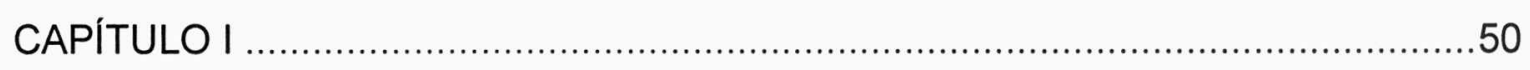

Validação do escore de condição corporal na escala em vacas Nelore .....................50

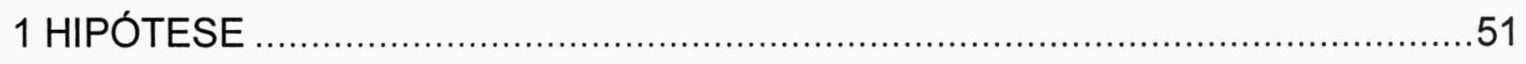

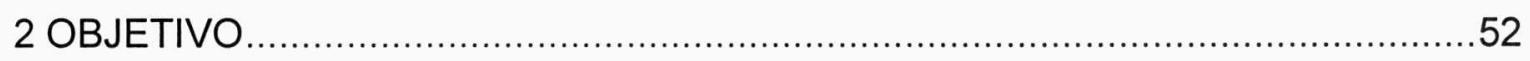

3 MATERIAIS E MÉTODO

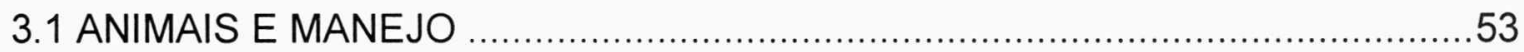


3.2 AVALIAÇÃO DA CONDIÇÃO CORPORAL E DA ESPESSURA DA GORDURA

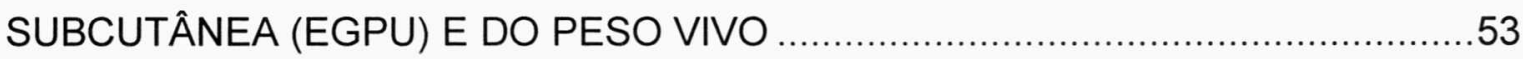

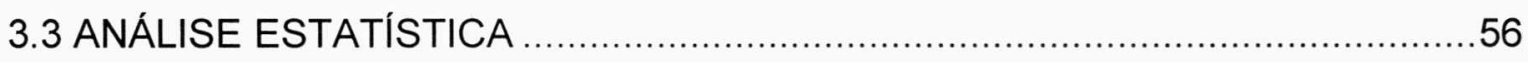

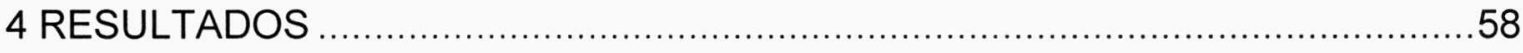

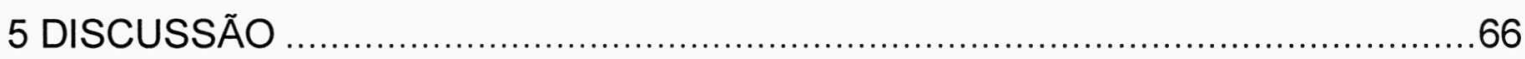

6 CONCLUSÃO

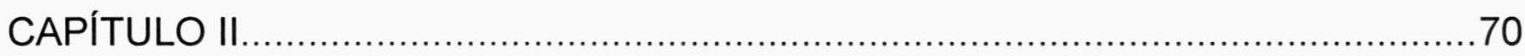

Efeito do Escore de condição Corporal, da Espessura da Gordura Subcutânea e do

Peso na Eficiência Reprodutiva de vacas Nelore .................................................70

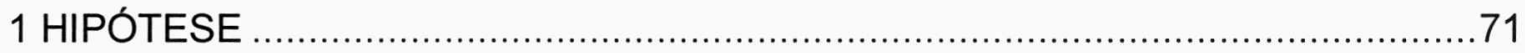

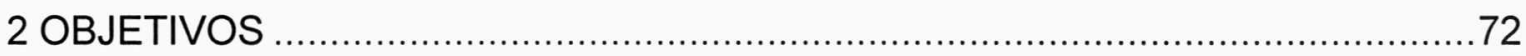

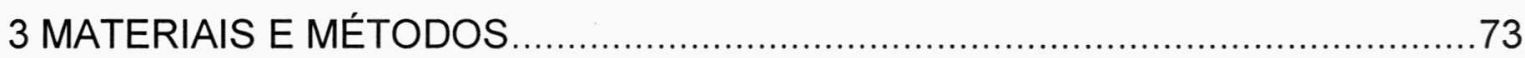

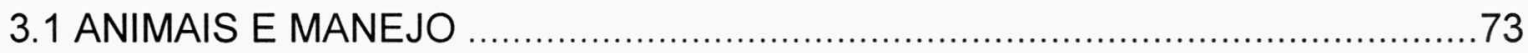

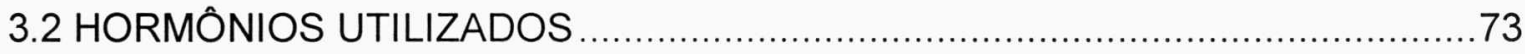

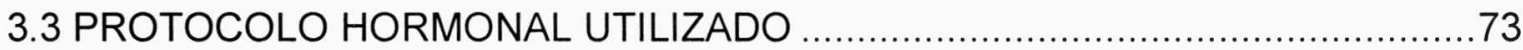

3.4 AVALIAÇÃO DO PESO, DA CONDIÇÃO CORPORAL E DA ESPESSURA DA GORDURA SUBCUTÂNEA (EGPU)

3.5 AVALIAÇÃO DA ATIVIDADE OVARIANA PÓS-PARTO, DA TAXA DE CONCEPÇÃO À IATF, DA EFICIÊNCIA REPRODUTIVA DURANTE A ESTAÇÃO

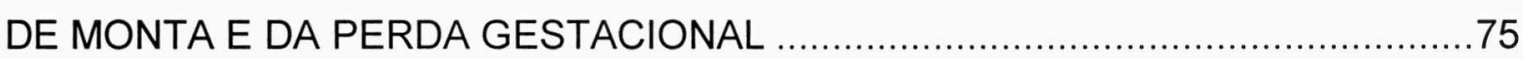

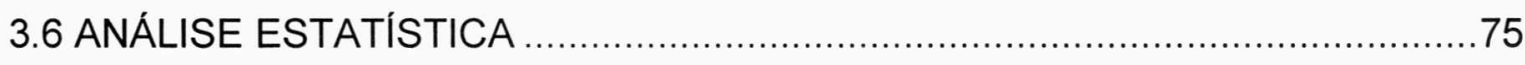

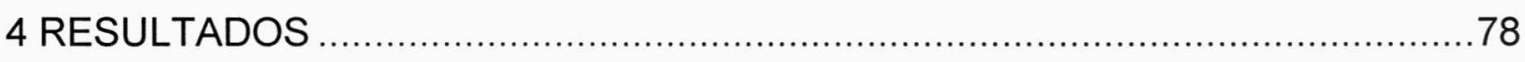

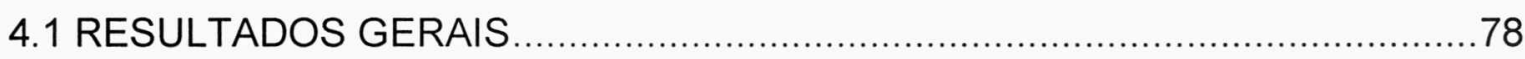

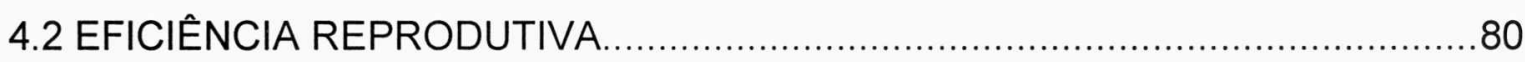

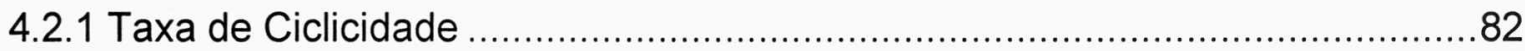

4.2.2 Taxa de concepção à IATF (30 dias de gestação) …………….....................84

4.2.3 Taxa de concepção á IATF (60 dias de gestação) ……..................................84

4.2.4 Taxa de Prenhez Acumulada (até 82 dias pós-parto; IATF com repasse de touro)

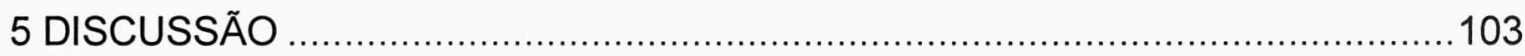

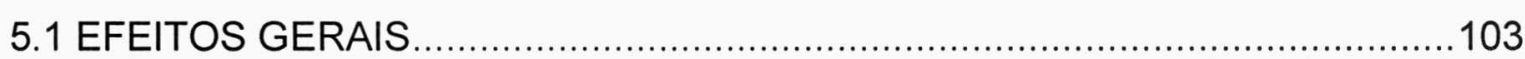

5.2 EFEITOS EM PERÍODOS ESPECÍFICOS .....................................................105

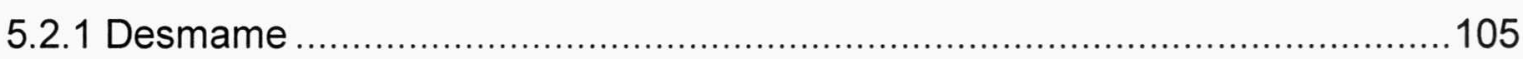

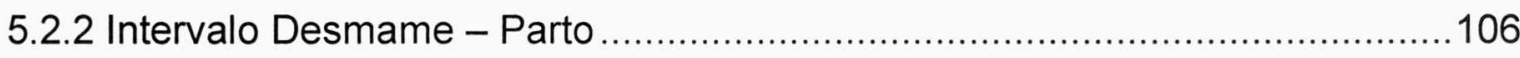


5.2.3 Parto

106

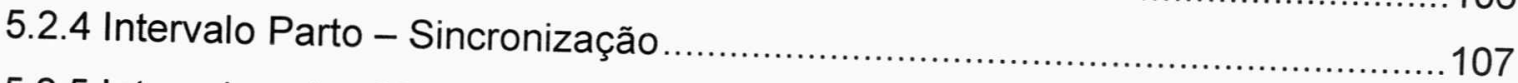

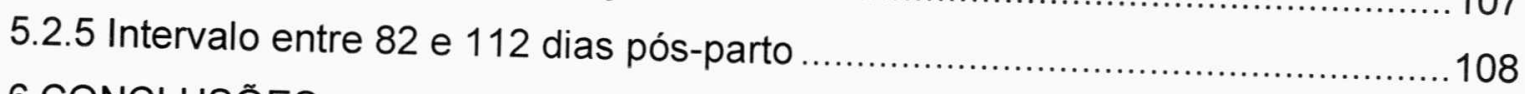

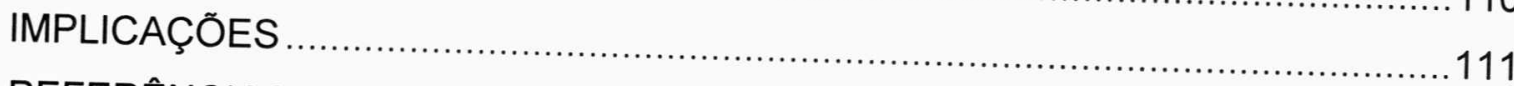

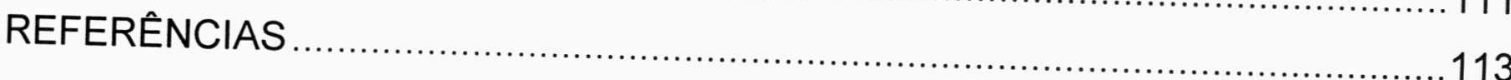




\section{INTRODUÇÃO}

O Brasil apresentou em 2007 crescimento econômico de 5,4\% em relação ao ano anterior, sendo que boa parte desse desenvolvimento resultou do potencial de expansão da agropecuária do país (IBGE, 2008). Nesse contexto, a bovinocultura colaborou significamente, tendo apresentado aumento expressivo nos índices de produtividade.

Em nosso território, o rebanho de bovinos de corte é representado principalmente pela raça Nelore (Bos indicus) e seus cruzamentos, que perfazem cerca de $80 \%$ dos 170 milhões de cabeças de gado. Somente em 2007, as exportações de carne superaram U\$ 4 bilhões, totalizando 2,4 milhões de toneladas de equivalente de carcaça (crescimento de 10\% em relação ao de 2006) exportadas, - que perfaz $30,6 \%$ do volume mundial. A Austrália é o segundo maior país exportador de carne bovina, sendo responsável por $19 \%$ do volume global (CNA, 2007).

Em todo o mundo, a inseminação artificial (IA) teve grande impacto na constituição genética da população de bovinos, tornando possível a multiplicação de material genético superior em condições adversas de manejo e ambiente (CARVALHO, 2004). Entretanto, a baixa eficiência na detecção do cio nessa espécie constituiu-se em fator limitante para a utilização dessa biotécnica, causando impacto negativo no desempenho reprodutivo de rebanhos inseminados artificialmente. Assim, uma das alternativas para superar o problema da detecção de cio foi o desenvolvimento de tratamentos que sincronizassem o crescimento folicular e a ovulação (BARUSELLI et al., 2006).

A sincronização da ovulação implica na manipulação do ciclo estral para obtenção de grande número de fêmeas aptas a serem inseminadas em tempo prédeterminado (Inseminação Artificial em Tempo Fixo - IATF). Idealmente, esse sistema deve proporcionar o maior número possível de fêmeas prenhes de uma única IA e, dessa forma, diminuir a duração da estação de monta e concentrar a estação de nascimentos. Além disso, vacas que parem no início da estação de parição têm um período maior para a involução uterina e para a retomada da atividade cíclica ovariana (DUNN; KALTENBACH, 1980). 
Deve-se salientar também, que para a obtenção de satisfatória eficiência reprodutiva é indispensável o bom manejo da propriedade, uma vez que as características reprodutivas são de baixa herdabilidade e, conseqüentemente, bastante influenciadas pelo meio e, principalmente, pelo manejo nutricional (VASCONCELOS, 1999). Estima-se que aproximadamente $80 \%$ da variação na fertilidade ocorram devido à fatores ambientais, dos quais mais de $50 \%$ são explicados pela nutrição (LOTTHAMMER, 1991). Nesse contexto, sabe-se que vacas que parem magras (sem reservas) e que perdem muito peso nos primeiros meses pós-parto, entram em prolongado período de anestro (CANFIELD; BUTLER, 1990).

Adicionalmente, a literatura (MONTIEL; AHUJA, 2005) aponta o hipotálamo como a área pela qual os fatores externos (como o status nutricional) e internos são integrados para regular o eixo endócrino reprodutivo. Assim, estímulos hipotalâmicos, como a severidade e duração da restrição alimentar, afetariam a resposta hipofisária e, consequentemente, ovariana, promovendo alterações importantes de ordem reprodutiva. Essas informações evidenciam, mais uma vez, que a alimentação equilibrada mostra-se fundamental tanto para a fertilidade quanto para a saúde dos animais.

O escore de condição corporal (ECC) é uma ferramenta que pode ser utilizada para monitorar e determinar o status nutricional e metabólico de cada animal no rebanho, porém trata-se de uma medida subjetiva. Assim, uma ferramenta mais objetiva que pode ser utilizada para tal função é a análise da espessura da gordura subcutânea (EGS) por ultra-sonografia, uma vez que a gordura corporal indica a reserva de energia, a qual é utilizada para manutenção de saúde, função reprodutiva e capacidade de produção (EDMONSON et al., 1989).

A ultra-sonografia para análise da EGS tem sido utilizada em avaliação de carcaças e, tem mostrado alta correlação $(r=0,86$ a 0,90) entre a medida no animal vivo e post-morten (PERKINS et al. 1992, GRIFFIN et al., 1999, GREINER et al., 2003). Portanto, o uso dessa tecnologia se mostra um método de alta acurácia para avaliar a quantidade de gordura, ou seja, a reserva corporal dos animais. 


\section{REVISÃO DE LITERATURA}

\section{$2.1 \quad$ CICLO ESTRAL}

O ciclo estral em bovinos apresenta duração média de 17 a 25 dias (SIROIS; FORTUNE, 1988), com semelhanças entre as fêmeas zebuínas e taurinas (VACA et al., 1985; FORTUNE, 1988; BARROS et al., 1995). Ele é regido por interações e antagonismos endocrinológicos de hormônios secretados pelo hipotálamo, hipófise, gônadas e útero (MACMILLAN; BURKE, 1996). Neste intervalo, o desenvolvimento folicular se apresenta como um processo dinâmico que envolve o crescimento e a atresia de folículos antrais, em um processo fisiológico e endocrinológico que se assemelha ao movimento de ondas (PIERSON; GHINTER, 1984).

Com o advento da tecnologia da ultra-sonografia, Pierson e Ginther (1987) comprovaram a teoria de que o crescimento dos folículos se dava em forma de ondas, normalmente variando entre duas ou três ondas de crescimento folicular entre ciclos (PIERSON; GINTHER, 1988; SÁVIO et al., 1988; SIROIS; FORTUNE, 1988). Cada onda de crescimento folicular é dividida em 4 fases: emergência, seleção, dominância e atresia ou ovulação (GINTHER; KASTELIC; KNOPF, 1989; DISKIN; AUSTIN; ROCHE, 2002).

A emergência de uma onda é caracterizada por um repentino crescimento de mais de 20 pequenos folículos, detectados por ultra-sonografia, com diâmetro de 2 a $4 \mathrm{~mm}$ (GINTHER; KASTELIC; KNOPF, 1989; CARVALHO et al., 2004), sendo estimulada pela secreção de hormônio folículo estimulante (FSH) pela hipófise (ADAMS et al., 1992). O número de picos desse hormônio corresponde exatamente ao número de ondas foliculares em um animal (ADAMS et al., 1992). A seleção, ou desvio, se caracteriza pelo momento em que um folículo passa a apresentar maior taxa de crescimento que os outros (GINTHER, 2000; DISKIN; AUSTIN; ROCHE, 2002); até então, a taxa de crescimento folicular era semelhante para todos os folículos (GINTHER, 2000). A partir do desvio fica estabelecida a dominância folicular, período durante o qual ocorre o crescimento contínuo do folículo 
dominante, enquanto os folículos subordinados diminuem sua taxa de crescimento e entram em atresia (GINTHER et al., 2001). Durante a dominância há queda das concentrações de FSH e aumento da secreção de LH, sendo que, nessa fase, o folículo selecionado passa a ser LH dependente (GINTHER et al., 1996).

Caso ocorra a luteólise, a concentração plasmática de progesterona (P4) entrará em declínio e proporcionará condições favoráveis para que o presente folículo dominante cresça rapidamente e torne-se folículo pré-ovulatório (BINELLI et al., 2001; RATHBONE et al., 2001). O folículo pré-ovulatório produzirá concentrações relativamente elevadas de estrógeno (E2), que será secretado na circulação sangüínea (NISWENDER et al., 2000). Este, agora por um sistema de retroalimentação positiva, atuará no hipotálamo estimulando a liberação de $\mathrm{GnRH}$ (FORTUNE, 1994). O GnRH será liberado no sistema hipotalâmico-porta-hpofisário, atingindo a hipófise e levando à liberação do pico pré-ovulatório de LH e ocorra a ovulação (BINELLI et al., 2001).

O aumento do tamanho do CL ocorre gradualmente e ao redor do quinto dia após a ovulação quantidades de P4 podem ser detectadas na circulação (NISWENDER et al., 2000). Depois de atingida a capacidade máxima, a produção de P4 se estagna até em torno do dia 16-17 do ciclo estral (RATHBONE et al., 2001), momento em que poderá ou não ocorrer nova luteólise.

Caso o concepto esteja presente no útero entre os dias 14 e 17, e ocorra secreção adequada de interferon- $\tau$ (proteína secretada pelo trofoderma do concepto que é responsável pelo reconhecimento materno da gestação), não ocorrerá a liberação de protaglandina $\mathrm{F}_{2 \alpha}\left(\mathrm{PGF}_{2 \alpha}\right)$ e a $\mathrm{P} 4$ continuará a ser secretada, mantendo a prenhez (NORTHEY; FRENCH, 1980; RATHBONE et al., 2001). Caso exista comprometimento na produção de interferon- $\tau$ ou ausência de feto nesse período, ocorrerá a liberação de $\mathrm{PGF}_{2 \alpha}$, com conseqüente luteólise e queda dos níveis plasmáticos de $\mathrm{P} 4$, proporcionando condições favoráveis para o término do crescimento folicular e ovulação (BINELLI et al., 2001; RATHBONE et al., 2001).

Wiltbank et al. (2002) propuseram um modelo simplificado para explicar o crescimento folicular desde a emergência até à ovulação (Figura 1). 


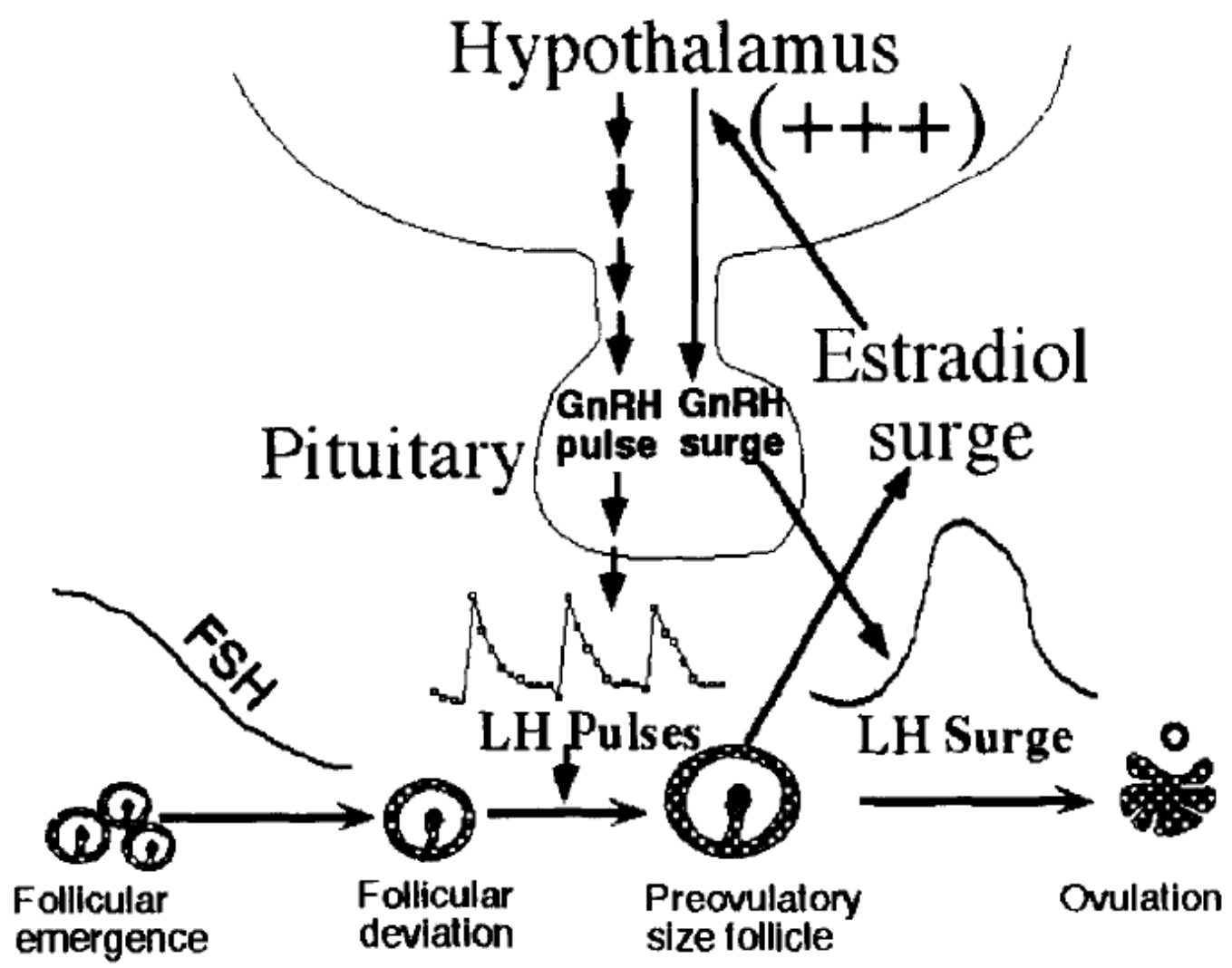

Fonte: (WILTBANK et al., 2002)

Figura 1 - Modelo simplificado do crescimento de folículos desde a emergência até a ovulação

Existem dados indicativos de que seja necessário conhecer características como número de ondas de crescimento folicular, população folicular no início da onda, diâmetro do folículo dominante e subordinado, diâmetro folicular no momento da divergência, características do estro (duração, período de manifestação e sua relação com o metabolismo), diâmetro do corpo lúteo, concentração de progesterona produzida pelo $\mathrm{CL}$ e concentrações séricas de progesterona, para que se possa implantar eficientes programas reprodutivos, levando-se sempre em consideração as diferenças fisiológicas existentes entre Bos indicus e Bos taurus. 


\subsection{ANESTRO}

Anestro é o estado de aclicidade ovariana, refletido pela completa inatividade sexual sem manifestação de estro (FALLAS et al., 1987) e anovulação acompanhada de concentrações de progesterona menores que $0,5 \mathrm{ng} / \mathrm{ml}$ (ARREGUÝN et al., 1997). A condição de anestro é associada à presença de ovários estáticos e lisos, pois, apesar do desenvolvimento folicular ocorrer, nenhum dos folículos que inicia o crescimento chega a maturar e, conseqüentemente, ovular (MORO et al., 1994). Um período de anestro de duração variável é observado tanto em vacas de leite, quanto em vacas de corte no pós-parto.

\subsubsection{Anestro pós-parto}

No terço final da gestação as concentrações de gonadotrofinas são muito baixas devido ao efeito da retroalimentação negativa da progesterona e do estrogênio sobre o eixo hipotalâmico-hipofisário. No entanto, após o parto, as concentrações de FSH aumentam drasticamente dentro de 5 dias (RHODES et al., 2003), levando ao surgimento da primeira onda folicular (revisto por WILTBANK et al., 2002). Assim, um folículo dominante começa a crescer em torno de 10 a 14 dias pós-parto (SAVIO et al., 1988; MURPHY et al., 1990). Este primeiro folículo dominante pode (1) tornar-se totalmente maduro e ovular, (2) tornar-se atrésico e ser substituído por um ou mais folículos dominante subseqüentes ou, ainda, (3) continuar a crescer e tornar-se cístico (WILTBANK; GÜMEN; SARTORI, 2002). A ovulação de um folículo dominante ocorre somente quando a produção de estradiol pelo folículo é suficiente para promover um pico pré-ovulatório de LH na presença de baixas concentrações circulantes de progesterona. Porém, isto apenas irá ocorrer quando o estoque de LH estiver completamente restabelecido (YAVAS; WALTON, 200).

Yavas e Walton (2000) sugerem que dentro de 15 a 30 dias pós-parto os estoques de LH já estão restabelecidos, e que o estado nutricional e a 
amamentação podem ser os fatores mais importantes na inibição da ovulação pósparto. Alguns outros fatores como a presença do bezerro, idade da vaca, números de partos, efeito macho (presença de touro), atraso da involução uterina, e distocias influenciam a duração do anestro pós-parto (MORROW et al., 1969; MACMILLAN; CLAYTON, 1980; OYEDIPE et al., 1982; PETERS, 1984; GALINA; ARTHUR, 1989; GALINA et al., 1989), sendo este mais marcante em gado de corte do que de leite (GALINA; ARTHUR, 1989; GALINA et al., 1989).

Mesmo após o restabelecimento do estoque de LH na hipófise anterior, o vínculo entre a mãe o e o bezerro pode afeta a duração do anestro pós-parto, uma vez que reduz a liberação de GnRH e a secreção de LH (WILLIAMS, 1990). Essas alterações fisiológicas podem afetar a maturação final do folículo dominante e a ovulação. Além disso, durante o ato de amamentar, a estimulação dos órgãos do sentido maternos como o olfato, a visão, a audição e o estímulo tátil pode, também, induzir a ocorrência dessas alterações fisiológicas em vacas de corte no pós-parto (WILLIAMS et al., 1996).

Quanto à nutrição, sabe-se que animais criados em regiões tropicais apresentam comprometimento na atividade ovariana pós-parto devido ao inadequado conteúdo energético fornecido pelas pastagens. Dessa maneira, a energia ingerida pelo animal é priorizada para funções vitais de manutenção e de produção de leite, em detrimento das funções reprodutivas (revisado em MONTIEL; AHUJA, 2005). Efeitos resultantes do comprometimento nutricional são a supressão na liberação de $\mathrm{GnRH}$ e conseqüente diminuição na freqüência dos pulsos de LH (SCHILLO, 1992), reduzindo o diâmetro máximo do folículo dominante e a duração da onda de crescimento folicular (RHODES et al., 1995; WILTBANK et al., 2002). De acordo com esses achados, pode-se inferir que a avaliação do status nutricional e da nutrição do rebanho são, de fato, importantes ferramentas do manejo reprodutivo (MONTIEL; AHUJA, 2005). 


\subsubsection{Classificação de condição Anovulatória}

Três categorias de anestro foram recentemente definidas por Wiltbank et al. (2002). Com auxílio da ultra-sonografia, estes autores definiram os padrões de desenvolvimento folicular e as condições de anovulação, como se segue:

1) Anovulação com crescimento folicular não avançando além da fase de emergência - pode ser observado em animais sujeitos à severas restrições alimentares, especialmente em Bos indicus. Esta condição resulta na ausência de quaisquer folículos maiores que $8 \mathrm{~mm}$ de diâmetro e está associada com a ausência de liberação de LH (JOLLY et al., 1995; RHODES et al., 1995).

2) Anovulação com crescimento folicular até diâmetro inferior ao ovulatório - observa-se crescimento folicular, porém os folículos alcançam diâmetros inferiores ao ovulatório. Essa condição é detectada em vacas no puerpério, que exibem prolongado intervalo entre o parto e a primeira ovulação, sendo comum em vacas com bezerros ao pé e/ou mantidas à pasto (baixa nutrição; MURPHY et al., 1990; MCDOUGALL et al., 1995). Nesse caso, observa-se baixa liberação de LH e aumento da sensibilidade do hipotálamo ao feedback negativo do estradiol na liberação de gonadotrofinas (GARCIA-WINDER et al., 1984; MCDOUGALL et al., 1995).

3) Anovulação com desenvolvimento folicular maior que o diâmetro ovulatório - observa-se desenvolvimento de folículos até diâmetros superiores ao ovulatório (condição anovulatória cística). Pode ser observado em vacas de leite, mas é incomum em vacas de corte. Esta categoria de anestro abrange uma variedade de condições fisiológicas, podendo estar associado a ausência ou excesso de comportamento sexual. Ainda, pode ocorrer maior liberação de LH e insensibilidade ao feedback positivo do estradiol (WILTBANK et al., 2002). 


\subsection{CONTROLE FARMACOLÓGICO DO CICLO ESTRAL DE FÊMEAS BOVINAS PARA INSEMINAÇÃO ARTIFICIAL EM TEMPO FIXO}

A manipulação da reprodução animal é provavelmente tão antiga quanto à domesticação. Desde que o homem começou a trabalhar com os animais, foi exercida profunda influência no comportamento natural e reprodutivo das espécies. $\mathrm{O}$ uso de tecnologias na reprodução, em particular a inseminação artificial, tem sua importância aumentada pela necessidade de atender à crescente demanda da aceleração do melhoramento genético de rebanhos.

Nesse contexto, a inseminação artificial em tempo fixo, sem a necessidade da detecção do estro (BARUSELLI et al., 2006), depende de bons programas de sincronização da onda folicular, cujo alvo é o controle preciso do início da onda de crescimento folicular (emergência) e da ovulação,

\subsubsection{Tratamento com $\mathrm{PGF}_{2 \propto}$ para sincronização do estro}

A PGF $2 \propto$ foi descoberta no início da década de 70 como um potente agente luteolítico (MCCRACKEN, 1972). A partir de então, esta substância e seus análogos têm sido os agentes farmacológicos mais utilizados nos tratamentos para sincronização do estro em fêmeas bovinas (ODDE, 1990; LARSON; BALL, 1992).

Os regimes de sincronização de estro utilizando prostaglandinas e seus análogos estão baseados na sincronização da fase progesterônica do ciclo estral, sendo seu sucesso dependente da presença de um CL, já que a ação da luteolisina é provocar a regressão morfológica e funcional dessa estrutura (RATHBONE et al., 2001) e, assim, a queda dos níveis endógenos de P4. Dessa forma, pode-se dizer que a resposta ao tratamento com $\mathrm{PGF}_{2 \propto}$ é influenciada pela maturidade do $\mathrm{CL}$. O CL maduro possuí um sistema de retroalimentação positiva que resulta na produção intraluteínica de $\mathrm{PGF}_{2 \propto}$, possibilitando a continuidade do processo luteolítico iniciado por uma única aplicação exógena de PGF $_{2 \propto}$ (WILTBANK, 1997; OKUDA; 
MIYAMOTO; SKARZYNSKI, 2002). Tratamentos realizados até o dia 5 do ciclo estral (CL não maduro) não induzem efetivamente a luteólise (REFSAL; SEGUIN, 1980; PARFET et al., 1989).

Após a luteólise, o estro e a ovulação são distribuídos ao longo de seis dias e são influenciados não apenas pela responsividade do $\mathrm{CL}$, mas também pelo estágio de desenvolvimento do folículo dominante (KASTELIC; GINTHER, 1991). Kastelic, Knopf e Ginther (1990) constataram que, quando o tratamento com PGF $2 \propto$ é realizado no dia 5 do ciclo estral - momento em que o folículo dominante da primeira onda ainda está em fase de crescimento - o intervalo entre a aplicação e a ovulação é de 3 dias. No entanto, se o tratamento é realizado no dia 12 do ciclo estral quando o folículo dominante da segunda onda encontra-se no início da fase de crescimento - a ovulação ocorre 4,5 dias após a aplicação. Bovinos tratados no dia 8 do ciclo estral freqüentemente apresentam ovulação do folículo dominante da primeira onda folicular 2 dias após a aplicação de PGF $2 \alpha$. Entretanto, ocasionalmente pode ocorrer a ovulação do segundo folículo dominante 6 dias após o tratamento.

As taxas de manifestação de estro após a administração de PGF $_{2 \propto}$ possuem alta variabilidade, principalmente quando se compara animas de origem taurina e zebuína (70 a 90\% e 47 a 60\%, respectivamente; TANABE; HANN, 1984; MORENO et al., 1986; LAVERDIERE et al., 1995). Com o intuito de melhorar a eficiência da sincronização do cio com $\mathrm{PGF}_{2 \propto}$ foram desenvolvidos protocolos com duas aplicações seqüenciais, intervaladas de 11 a 14 dias (JACKSON et al., 1979).

Essas informações sustentam que o sucesso da aplicação da PGF $_{2 \propto}$ depende da presença do CL funcional em fase específica do ciclo estral (diestro). Além disso, observa-se que o estro e a ovulação não são precisamente sincronizados devido à variações do estágio de desenvolvimento folicular no momento da regressão do corpo lúteo. Também, a alta variabilidade das respostas ao tratamento com $\mathrm{PGF}_{2 \propto \mathrm{e}}$ o fato de animais criados a pasto em condições tropicais apresentarem alta incidência de anestro (ausência de $\mathrm{CL}$ ) têm comprometido a eficiência do tratamento (YAVAS; WALTON, 2000).

Assim, torna-se necessário o emprego de métodos que controlem 0 desenvolvimento luteínico e folicular para sincronizar o crescimento dos folículos e a ovulação. Além disso, em animais que se apresentam em anestro é necessária a 
utilização de protocolos que induzam ciclicidade para permitir o emprego de biotecnologias (IATF e TETF) que dispensem a detecção de cio (BÓ; BARUSELLI; MARTINEZ, 2003).

\subsection{CONTROLE DA DINÂMICA FOLICULAR PARA REALIZAÇÃO DA INSEMINAÇÃO ARTIFICIAL EM TEMPO FIXO}

Um eficiente sincronização da ovulação para IATF depende da induzição da emergência de uma nova onda de crescimento folicular sincronizada, do controle da duração do crescimento folicular e da fase luteínica, da sincronização da retirada da fonte de $\mathrm{P} 4$ exógena (dispositivo) e endógena $\left(\mathrm{PGF}_{2 \alpha}\right)$ e da indução da ovulação sincronizada em todos os animais tratados.

\subsubsection{Sincronização da emergência de nova onda de crescimento folicular com estrógenos associados a progesterona}

A P4 e os progestágenos são substâncias que podem ser administradas por via oral $(M G A)$, via implantes subcutâneos $\left(\right.$ SyncroMateB ${ }^{\circledR}$, Crestar $^{\circledR}$ ) ou via dispositivos intravaginais $\left(\mathrm{PRID}^{\circledR}, \mathrm{CIDR}^{\circledR}, \mathrm{DIB}^{\circledR}, \mathrm{PRIMER}^{\circledR}\right.$, entre outros). Esses compostos têm sido utilizados por períodos prolongados desde a década de 60 , com o intuito de permitir a regressão espontânea do $C L$ e consequente sincronização do estro entre 2 e 4 dias após a remoção da fonte de P4/progestágeno (RATHBONE et al., 2001). Esses tratamentos longos (14 a 21 dias) são efetivos para sincronizar o estro, no entanto a fertilidade dessa ovulação é reduzida (HANSEL; MALVEN; BLACK, 1961; WILTBANK et al., 1965), uma vez que induz-se a ovulação de

folículos persistentes (ODDE, 1990) e, portanto, contendo oócitos envelhecidos (REVAH; BUTLER, 1996).

$O$ estradiol (E2), por sua vez, foi originalmente incorporado à programas de sincronização de estro utilizando $\mathrm{P} 4$, com o objetivo de causar a lise do CL 
(FANNING et al., 1992). No entanto, relatos posteriores demonstraram que a progesterona associada ao estradiol foi responsável pela regressão dos folículos em crescimento e sincronia de uma nova onda folicular (BÓ et al., 1991, 1993, 1994, 1995; CACCIA; BÓ, 1998).

Os E2 têm sua ação modulada pela presença ou não de $P 4$, seja ela endógena ou exógena. Assim, quando os E2 são administrados na presença de P4, essa associação causa a diminuição dos níveis circulantes de FSH (pelo E2) e LH (pela P4), provocando a regressão dos folículos gonadotróficos dependentes. Então, após a metabolização e a diminuição das concentrações plasmáticas de $E 2$, verificase o surgimento de um pico de FSH e a emergência de uma nova onda de crescimento folicular. O mecanismo responsável pela supressão do crescimento folicular induzida pelo E2 parece ser mais sistêmico que local (BÓ et al., 2000).

O 17ß-estradiol produzido pelo folículo na ausência de P4 leva à liberação de GnRH pelo hipotálamo, estimulando a produção de LH pela hipófise e culminando na ovulação (RATHBONE et al., 2001). Assim, a administração de E2 durante a fase folicular do ciclo estral associada ao E2 endógeno (folículos) leva a um efeito ovulatório. Por isso, é importante que elevados níveis de P4 estejam presentes no momento do início do tratamento para evitar um pico pré-ovulatório de LH (BÓ et al., 1994).

Existem diferentes ésteres de estradiol: $17 \beta$-Estradiol, Benzoato de estradiol $(B E)$, Valerato de estradiol (VE) e Cipionato de Estradiol (CE). O VE (BÓ et al., 1995b) e o CE (COLAZO; KASTELI; MAPLETOFT, 2003), na presença de P4, causam a regressão dos folículos antrais presentes no ovário, no entanto a meia vida longa desses ésteres, pela baixa solubilidade em água, leva a um atraso e a uma alta dispersão do dia da emergência da onda de crescimento folicular. Já o BE (SÁ FILHO et al., 2004) e o 17ß-estradiol (BÓ et al., 1995b) apresentam meia vida mais curta, induzindo a emergência sincronizada de uma nova onda de crescimento folicular em um grupo de animais tratados.

Quanto às doses desses hormônios foi encontrado que vacas tratadas com CIDR e 2,5 mg de BE tiveram a emergência da onda folicular mais sincronizada do que aquelas que receberam $5 \mathrm{mg}$ (CACCIA; BÓ, 1998). Da mesma forma, a utilização de $2 \mathrm{mg}$ de VE resultou na emergência mais precoce e sincronizada da 
onda folicular do que o tratamento com a dose de $5 \mathrm{mg}$ desse mesmo estrógeno (MAPLETOFT et al., 2004).

Portanto, ficou evidenciado que o intervalo entre o tratamento e a emergência da onda folicular é dependente tanto da preparação (tipo de estrógeno), quanto da dose de estradiol empregada.

\subsubsection{Controle da fase progesterônica do ciclo estral - Prostaglandina $\mathbf{F}_{2 \alpha}$}

Preconiza-se a aplicação de $\mathrm{PGF}_{2 \propto}$ no momento da retirada da fonte de P4/progestágenos para indução da luteólise e queda dos níveis endógenos de P4, propiciando condições favoráveis à ovulação. O mecanismo de ação da $\mathrm{PGF}_{2 \propto}$ já foi descrito anteriormente nessa dissertação.

\subsubsection{Indução sincronizada da ovulação}

Os fármacos utilizados para a indução da ovulação podem atuar por retroalimentação positiva na liberação pulsátil de LH (E2 e GnRH) ou diretamente nos receptores de LH das células da granulosa dos folículos (hCG e LH). Esses indutores quando administrados isoladamente não são capazes de sincronizar adequadamente a ovulação para a IATF. No entanto, quando associados a protocolos com P4/progestágenos, E2 e $\mathrm{PGF}_{2 \propto}$, induzem a ovulação sincronizada do folículo dominante presente no final do tratamento, possibilitando o emprego da IATF.

Para a indução da ovulação, a fase em que se encontra o folículo é fator determinante. Martinez et al. (1999) avaliaram a eficiência da administração de $\mathrm{GnRH}$ e LH em cada fase da onda de crescimento folicular em novilhas. Os tratamentos foram realizados no dia 3 (crescimento), 6 (estática inicial) e 9 (estática final) do ciclo estral. Os autores verificaram que animais que apresentavam folículos grandes (fase de crescimento ou platô inicial) tiveram as melhores respostas ao 
tratamento para se induzir a ovulação (VASCONCELOS et al., 1999; SARTORI et al., 2001).

Segundo Clarke (1989), a resposta folicular ao tratamento com GnRH deve-se à liberação de LH por estímulo direto desse hormônio. Sendo assim, a concentração plasmática de P4 proveniente da fase luteínica não afeta essa resposta, uma vez que é hipofisária, e a retroalimentação negativa da P4 sobre a liberação de LH ocorre em nível hipotalâmico. Por outro lado, Cruz, Valle e Kesler (1997) e Rubianes et al. (1997) observaram que a aplicação de GnRH 30 ou 48 horas após a aplicação de $\mathrm{PGF}_{2 \alpha}$ induziu um pico de LH com maior amplitude do que quando aplicado no início ou no meio da fase luteínica. Esse resultado indica que, possivelmente, além do estágio de desenvolvimento folicular, as concentrações hormonais que precedem o pico de LH são importantes na determinação da resposta ovulatória.

\subsection{GONADOTROFINA CORIÔNICA EQUINA (eCG)}

A gonadotrofina coriônica eqüina foi descrita pela primeira vez em 1930 por Cole e Hart. Esses autores relataram a presença de uma substância de ação gonadotrófica no soro de éguas e outros eqüídeos prenhes, que ganhou o nome de gonadotrofina sérica de éguas prenhas (PMSG). Mais especificamente, a PMSG é um hormônio glicoprotéico secretado pelos cálices endometriais de éguas gestantes. Allen e Moor (1972) observaram que sua produção era realizada pela placenta materna e concluíram que uma melhor terminologia para esta glicoproteína seria gonadotrofina coriônica eqüina (eCG). Estes mesmos pesquisadores descobriram que a eCG é produzida pelas células trofoblásticas presentes nos cálices endometriais de éguas prenhes.

A eCG, assim designada, é composta de duas subunidades ( $\alpha$ e $\beta$ ) e têm ação de LH e FSH na mesma molécula (GOSPODAROWICS, 1972; LEGARDINIER et al., 2005). Essas ações podem ser também observadas em outras espécies (WARD; MOORE, 1979). Em eqüinos, o pico de liberação de eCG ocorre ao redor dos 60 dias de gestação, no entanto o aumento na liberação desse hormônio já se dá ao redor de 40 dias, perdurando até aproximadamente os 130 dias de gestação 
(MURPHY; MARTINUK, 1991). A ação da eCG ocorre via indução da ovulação ou luteinização de folículos, causando aumento da progesterona circulante em eqüinos (URWIN; ALLEN, 1982) e, desta forma, auxiliando a manutenção da gestação. Porém, a quantidade de eCG circulante varia bastante conforme a raça do animal, a sua idade e conforme a presença de gestações gemelares (MURPHY; MARTINUK, 1991). Ainda, as concentrações de ácido siálico e carboidrato presentes na molécula de eCG podem variar bastante de eqüino para eqüino, conforme o estágio de gestação e conforme o tecido no qual foi coletado a molécula de eCG (MURPHY; MARTINUK, 1991).

A eCG é uma molécula que possuí grande quantidade de carboidratos (aproximadamente $45 \%$ de sua massa) principalmente a $\mathrm{N}$-acetil neuramina (ou ácido siálico), primordialmente presente na subunidade $\beta$ da molécula de eCG, 0 que proporciona uma grande meia vida a este composto químico (WARD; MOORE, 1979; MURPHY; MARTINUK, 1991). Martinuk et al. (1991), utilizando uma enzima chamada neuraminidase, retiraram diferentes porcentagens de ácido siálico da molécula de eCG, e assim demostraram que a meia vida da molécula era alterada. Outro fator que colabora para longa meia vida da eCG é o fato da molécula ter carga elétrica negativa, o que dificulta a sua filtração glomerular (LEGARDINIER et al., 2005).

Estes fatores explicam a longa meia-vida da eCG quando aplicada em bovinos (cerca de 40h; MENZER et al., 1979).

\subsubsection{Os efeitos da eCG no corpo lúteo}

A eCG parecer ter função luteotrófica em eqüinos e outras espécies (como os bovinos; SOUZA, 2008), sendo possível verificar aumentos nas concentrações circulantes de progesterona após o aumento natural ou por via de administração exógena da eCG (MURPHY; MARTINUK, 1991). Esses dados foram confirmados por Daels et al. (1998), que demonstraram a ação luteotrófica da eCG durante a gestação de éguas. 
A estrutura da eCG é muito parecida com a estrutura do LH eqüino (BOUSFIELD et al., 1996). Apesar dessa similaridade, a eCG apresenta tanto função de FSH quanto de LH em eqüinos e em outras espécies (GONZALEZ-MENICO et al., 1979; WARD; MOORE, 1979). Acredita-se que atividade biológica LH da molécula de eCG esteja intimamente ligada com a quantidade de ácido siálico nela presente, pois a utilização de enzimas que digerem o ácido siálico promoveu aumento da ação LH (SOUZA, 2008).

\subsubsection{Uso da gonadotrofina coriônica equina (eCG) em programas de IATF}

Recentemente a eCG têm sido incorporada em protocolos para IATF em vacas de corte (CAVALIERI et al., 1997) e leite (SOUZA, 2008), sendo o tratamento com eCG altamente recomendado quando uma grande proporção dos animais se encontra em anestro (HUMBLOT et al., 1996; BARUSELLI et al., 2004, RODRIGUES et al., 2004a). Existem muitos relatos de aumentos na fertilidade após a incorporação da eCG em protocolos para IATF, principalmente em vacas de corte (BARUSELLI et al., 2004). A melhora na taxa de concepção em animais que recebem a eCG na retirada do dispositivo intravaginal de $\mathrm{P} 4$, provavelmente, está relacionada ao aumento da taxa de ovulação de animais em anestro e aos maiores níveis de progesterona circulante no diestro (BARUSELLI et al., 2004).

Porém nenhum destes autores demonstram efeito satisfatório da eCG em animais em condições nutricionais desfavoráveis (ECC< 2,5, escala de 1 a 5), demonstrando desta forma a importância de um adequado manejo nutricional para a obtenção de bons resultados em programas de IATF utilizando esse hormônio. 


\subsection{STATUS NUTRICIONAL E REPRODUÇÃO}

Uma das mais importantes habilidades da vaca é a capacidade de utilizar suas reservas energéticas corpóreas em períodos de balanço energético negativo. Nas fêmeas, existe necessidade de adequada quantidade de reservas de energia (gordura corporal) para suprir o metabolismo basal, o crescimento, a lactação, a manutenção da saúde e, ainda, a função reprodutiva (WRIGHT et al., 1987; EDMONSON et al., 1989). Inúmeros trabalhos científicos mostram que as vacas apresentam elevada demanda energética no período pós-parto. Assim, durante o final da gestação, quantidades suficientes de energia devem ser armazenadas nos tecidos corporais, na tentativa de suprir o balanço energético negativo pós-parto.

A ingestão insuficiente de energia está correlacionada com baixo desempenho reprodutivo, atraso na idade à puberdade, atraso no intervalo da primeira ovulação e cio pós-parto e redução nas taxas de concepção e de prenhez em vacas de corte e de leite (SANTOS, 2004). Por outro lado, vários estudos mostram que dietas altamente energéticas diminuem a resposta aos protocolos de superovulação, diminuem a produção embrionária e alteram a expressão de genes importantes para o desenvolvimento embrionário. O mecanismo pelo qual isto ocorre ainda não está claro, mas acredita-se que esteja relacionado com a produção de oócitos com qualidade comprometida (DUNNE et al., 1999; YAAKUB et al., 1999).

A estimativa da condição nutricional das vacas através da avaliação de escores de condição corporal (ECC) é uma prática descrita desde o início do século passado. O status ou balanço nutricional de um animal, avaliado através do ECC, reflete as reservas corporais disponíveis. Assim, como parte do manejo, o registro ECC é uma tentativa de avaliar a magnitude do déficit energético do animal.

Em gado de corte, a nutrição pré-parto refletida pelo ECC no parto, é o maior determinante da duração do anestro pós-parto (DUNN; KALTENBACH, 1980; DZIUK; BELLOWS, 1983; RICHARDS et al., 1986; SELK et al., 1988). Prova disso é a existência de uma correlação negativa entre ECC ao parto e duração do anestro pós-parto (RICHARDS et al., 1986; WRIGHT et al., 1987, 1992).

Vacas de corte submetidas à severa baixa nutricional no último trimestre de gestação e no pós parto podem responder com ausência de folículos pequenos ( 5 mm de diâmetro) ou maiores (>8 mm, PERRY et al., 1991; JOLLY, 1992). Perry et 
al. (1991) observaram que o crescimento de folículos até $8 \mathrm{~mm}$ foi praticamente extinto em vacas de corte alimentadas com dietas de baixa energia antes e após o parto. A baixa ingestão de energia após o parto também resultou em uma taxa reduzida de aparecimento de pequenos folículos $(5-7.9 \mathrm{~mm})$, que persistiram no ovário por um período prolongado, possivelmente reflexo da ausência de funcionalidade do folículo dominante (PERRY et al., 1991).

Em vacas de leite, podemos verificar a existência de uma condição corporal ideal para cada fase da lactação e esta é uma ferramenta que otimiza a produção de leite, minimiza os problemas reprodutivos e maximiza retorno econômico (GEARHART et al., 1990). Algumas recomendações foram dadas para definir o ECC ideal para cada fase da lactação de vacas de leite (BRAUN et al., 1986; HEUWIESER; MANSFELD, 1992). A supracondição de vacas seca é um fator de risco para uma maior ocorrência de distúrbios metabólicos, infecciosos, digestivos e reprodutivos (MORROW, 1976; MORROW et al., 1979; FRONK et al., 1980; GANSWORTHY; TOPPS, 1982; GEARHART et al., 1990), além da menor produção de leite (MUSENFECHTEL et al., 2000). Por outro lado, o baixo ECC ao parto também reduz taxas de prenhez ao primeiro serviço $(E C C<2.5)$ e aumenta os dias em aberto (BCS $\leq 3,5$; LOPEZ-GATIUS et al., 2003). Uma maior perda da condição corporal no início da lactação também está relacionada com pior capacidade reprodutiva (PRYCE et al., 2001).

Em bovinos de corte, o aumento do ECC elevou a proporção de vacas que se apresentaram cíclicas antes da estação de monta (STEVENSON et al., 2003).

Portanto pode-se notar a importância da mantença das reservas corporais e da preocupação em desenvolver uma técnica adequada para que se possa mensura-lá. A seguir algumas destas técnicas serão abordadas.

\subsubsection{Peso Vivo}

A mensuração do peso vivo (PV) reflete mudanças em níveis de proteínas, bem como de gordura. No entanto, muitas desvantagens relativas a essa técnica são evidentes, uma vez que os percentuais de proteína, gordura e água, assim como a 
energia armazenada em kg de PV são altamente variáveis (REID; ROBB, 1971; STAUFENBIEL et al., 1993).

\subsubsection{Mensuração da Caixa Torácica}

A contenção e a manipulação necessárias para se determinar o peso vivo (PV) nem sempre estão disponíveis em fazendas comerciais. Portanto, equações para calcular PV através de outras medidas corporais foram desenvolvidas. Para este efeito, a mensuração da caixa torácica, largura da anca ou do comprimento do corpo podem ser utilizados. Heinrichs et al. (1992) demonstrou que todas estas medidas são adequadas para prever $\mathrm{PV}\left(R^{2}>0,95\right)$, porém mensuração da caixa torácica foi o método que apresentou a maior correlação com essa medida. A respeito do balanço energético, a mensuração da caixa torácica tem as mesmas desvantagens que o próprio PV.

\subsubsection{Perfil Hormonal}

Outro sistema para estimar o balanço energético é a análise do status metabólico, através da utilização de amostras de sangue e/ou leite, uma vez que diversos metabólitos, hormônios e vestígios encontrados nessas amostras foram relacionados ao balanço energético. Concentrações de glicose, colesterol, uréia, insulina, IGF -1 e tiroxina no plasma sanguíneo e concentrações de lactose e uréia no leite foram correlacionados positivamente com o balanço energético. Em contraste, as concentrações de AGNE, creatinina, albumina, BHBA, GH e atividades enzimáticas no sangue e de acetona, gordura, proteína, gordura e lactose no leite foram correlacionadas negativamente com o balanço energético (KUNZ et al., 1985; REIST et al., 2002). 


\subsubsection{Dobra Subcutânea}

A dobra cutânea é um parâmetro bastante utilizado na avaliação do estado nutricional em humanos. Este método tem sido também utilizado em gado de leite (BRUCKMAIER et al., 1998). O valor das dobras foi definido como a média das mensurações obtidas por um paquímetro na escápula, barbela, base do úbere, e base da cauda menos as dobras cutâneas na região do pescoço (quase sem gordura subcutânea neste sítio). Os investigadores concluíram que a dobra subcutânea comportou-se de forma semelhante aos ECC, podendo ser aliada a esse parâmetro na avaliação do estado nutricional.

\subsubsection{Escore de Condição Corporal}

O escore condição corporal é uma estimativa subjetiva das reservas energéticas metabolizáveis do tecido adiposo. Baseia-se na avaliação da aparência exterior do animal com relação às suas reservas de gordura corporal, as quais são diretamente influenciadas pelo seu balanço energético. Para vacas de corte, é comumente utilizada uma escala de 9 pontos (WAGNER et al., 1988). No entanto, as escalas de 5 pontos (MARLOWE et al., 1962) e de 5 a 15 pontos (SPELBRING et al., 1977) também têm sido descritas.

Diversos autores recomendam o acompanhamento do ECC, uma vez que ele se mostra como um reflexo da condição nutricional (SHORT et al., 1990; ARREGUIN et al., 1997) em vacas de corte (RAE et al., 1996) e leite (WILDMAN et al., 1982; EDMONSON et al., 1989). Em vacas de leite, esta técnica tem sido recomendada como método para elucidar a evolução do manejo nutricional (GILLUND et al., 2001).

O ECC é determinado por avaliações visuais e/ou táteis de locais definidos do corpo, sendo que elas podem variar tanto em locais a serem examinados, como no número de locais (WILDMAN et al., 1982; WAGNER et al., 1988; EDMONSON et al., 1989; HOUGHTON et al., 1990; FERGUSON; GALLIGAN; THOMSEN, 1994; LASSEN et al., 2003; ROCHE et al., 2004). A subjetividade, repetibilidade e validade 
do ECC foram investigadas em vários estudos (EDMONSON et al., 1989; FERGUSON; GALLIGAN; THOMSEN, 1994; DOMECQ et al., 1995). Edmonson et al. (1989) investigaram a repetibilidade e a precisão do ECC por eles desenvolvido e encontraram apenas pequenas variações entre os avaliadores, porém, a experiência prática pessoal não influenciou significativamente o resultado.

Em contraste, Ferguson e Galligan e Thomsen (1994) encontraram menor precisão nos resultados da pontuação de pessoas com pouca experiência. Nesse estudo, as pontuações avaliadas por pessoas experientes foram consistentes com a média ECC de todos os observadores em 58 a 67\% dos casos, enquanto que para uma pessoa com pouca experiência foi de apenas de $27 \%$. Ainda, a correlação entre os diferentes observadores variou de 0,76 a 0,86. A análise estatística revelou que a condição corporal pôde ser separada em incrementos 0,25 pontos entre 2,5 e 4,0, sendo que, para pontuações superiores a 4,0 e inferiores a 2,5 só puderam ser separadas diferenças de 0,5 unidades (FERGUSON; GALLIGAN; THOMSEN, 1994).

Domecq et al. (1995) validou ECC com medições de gordura subcutânea com o uso da ultra-sonografia, abordando a região lombar, a garupa e a inserção da calda. Os níveis de ECC foram significativamente associados às medições ultrassonográficas e os coeficientes de determinação para os modelos variaram de 0,36 a 0,65 , dependendo do local de mensuração. Os autores concluíram que o ECC é tão válido quanto as mensurações por ultra-sonografia para quantificar a quantidade de gordura subcutânea, em vacas leiteiras.

\subsubsection{Mensuração da Espessura da Gordura Subcutânea na Garupa (EGPU)}

Espessura da gordura subcutânea na garupa (EGPU), ou no P8, como é conhecido na Austrália, é a camada de gordura subcutânea localizada entre a pele, a fáscia profunda do glúteo médio e o bíceps femural. A mensuração desse paraâmetro pode ser precisamente realizada com auxílio da ultra-sonografia.

O potencial da utilização da ultra-sonografia para avaliação de características de carcaça em bovinos vivos, tem sido bastante estudado por vários pesquisadores 
(WILSON, 1992; KEMP et al., 2002, entre outros). O exame ultra-sonográfico é um método rápido, não-invasivo, e fácil de aprender. Para tal, utiliza-se um aparelho de ultra-sonografia (B-mode) com um transdutor linear e uma freqüência de 3,5 MHz. O equipamento transforma impulsos elétricos em ondas sonoras de alta freqüência através de cristais piezelétricos. A imagem é gerada pelas ondas sonoras que são refletidas (eco) pelos diversos tecidos, os quais possuem diferentes densidades (HOUGHTON; TURLINGTON, 1992), neste caso particular, entre tecido adiposo, fáscia, e músculo. Para realização dessa medição, o transdutor deve ser colocado na vertical e com leve pressão, pois a gordura é facilmente comprimida (BRETHOUR, 1992). As vacas devem estar em posição quadrupedal e relaxadas.

Após o congelamento da imagem na tela do aparelho, a camada de gordura subcutânea é medida com precisão de $0,1 \mathrm{~cm}$. A fáscia profunda é claramente visível, em quase todos os casos. A espessura da pele (de 5 a $6 \mathrm{~mm}$ ) é sempre incluída na medição ultra-sonográfica, de modo que, para se obter o valor da espessura de gordura subcutânea propriamente dita, faz-se necessário subtrair essa quantia. Assim sendo, um valor de $6 \mathrm{~mm}$ de EGPU caracteriza, consequentemente, uma quase completa ausência de gordura corporal.

Klawuhn (1992) e Staufenbiel (1992) realizaram a avaliação ultra-sonográfica de diversos pontos e encontraram no sacro o local mais adequado para se avaliar a EGPU. A região do sacro possuí a maior quantidade de tecido adiposo na região traseira e alta correlação $(r=0,90)$ entre gordura corporal e conteúdo da EGPU. Além disso, este ponto é de fácil localização e a sua espessura apresenta pouca mudança em um intervalo de vários centímetros.

Assim sendo, o melhor local definido para o exame está localizado na região do sacro, no terço superior da garupa, na linha entre o tubérculo isquiático e a tubérculo coxal. Este local corresponde ao espaço entre o fim da crista sacral e o final do sacro (ou seja, início da primeira vértebra coccígea)., onde a estratificação do tecido torna-se evidente. A fáscia profunda situa-se diretamente sobre o músculo glúteo e aparece como uma linha branca na imagem ultra-sonográfica; a gordura subcutânea está posicionada entre a pele e a fáscia profunda; na maioria das vacas, a fáscia superficial está presente no tecido adiposo e aparece como uma fina linha branca, separando a gordura subcutânea e a gordura interfascial (STAUFENBIEL, 1992). 
Silza et al. (2003) utilizando a EGPU, demonstrou que a mesma pode ser utilizada com a mesma confiabilidade que a espessura da gordura subcutânea na área de lombo (EGSU). Esse resultado indica a possibilidade de utilização dessa medida como uma alternativa à EGSU, já que a gordura subcutânea deposita-se primeiramente na região posterior em relação à região lombar. Outra vantagem seria a facilidade de realização desta medida, pois mesmo um operador com pouco treinamento conseguira realizá-la mais facilmente e rapidamente em comparação a EGSU.

A repetibilidade das medições ultra-sonográficas também tem sido investigada. Nesse caso, a correlação entre medições consecutivas foi de 0,975 com uma diferença média absoluta de 0,72 mm (BRETHOUR, 1992). 


\section{CAPÍTULO I}

\section{Validação do escore de}

\section{condição corporal na}

escala em vacas $\mathcal{N}$ elore 


\section{HIPÓTESE}

A hipótese do presente trabalho é que a avaliação de escore de condição corporal na escala de 1 a 5 , utilizando o método visual, é um bom preditor da espessura da gordura subcutânea em vacas Nelore (Bos indicus). 


\section{OBJETIVO}

- Determinar a relação entre as variáveis: peso vivo, avaliação visual do escore de condição corporal e espessura da gordura subcutânea mensurada por ultrasonografia. 


\section{MATERIAIS E MÉTODO}

\subsection{ANIMAIS E MANEJO}

Um total de 266 vacas Nelore em terço médio de gestação e idade média de 7,3 \pm 0,1 anos, foram avaliadas quanto ao escore de condição corporal (método visual) e a espessura da gordura subcutânea (por ultra-sonografia) e peso vivo. $O$ experimento foi efetuado em um único rebanho criado sob sistema pastoreio, com suplementação mineral e água ad libitum, no estado de Mato Grosso do Sul, Brasil. O período experimental foi de Maio de 2005 a Julho de 2006. Os procedimentos com os animais foram aprovados pela comissão de bioética para experimentação animal da Universidade de São Paulo-USP.

\subsection{AVALIAÇÃO DA CONDIÇÃO CORPORAL E DA ESPESSURA DA GORDURA SUBCUTÂNEA (EGPU) E DO PESO VIVO}

Todos os animais foram avaliados quanto à condição corporal (ECC), à EGPU e ao peso vivo, em cinco momentos distintos: M1) no momento da desmama dos bezerros (165,5 \pm 0,9 dias antes do parto); M2) próximo aos 245 dias de gestação (variando entre 225 e 270 dias de prenhez; M3) no início do programa de sincronização (42,0 \pm 0,5 dias pós-parto, variando de 29 a 74); M4) no dia da avaliação aos 82 dias (82,0 \pm 0,5 dias pós-parto) e M5) no dia da avaliação aos 112 dias (112,0 $\pm 0,5$ dias pós-parto; Figura 2). 


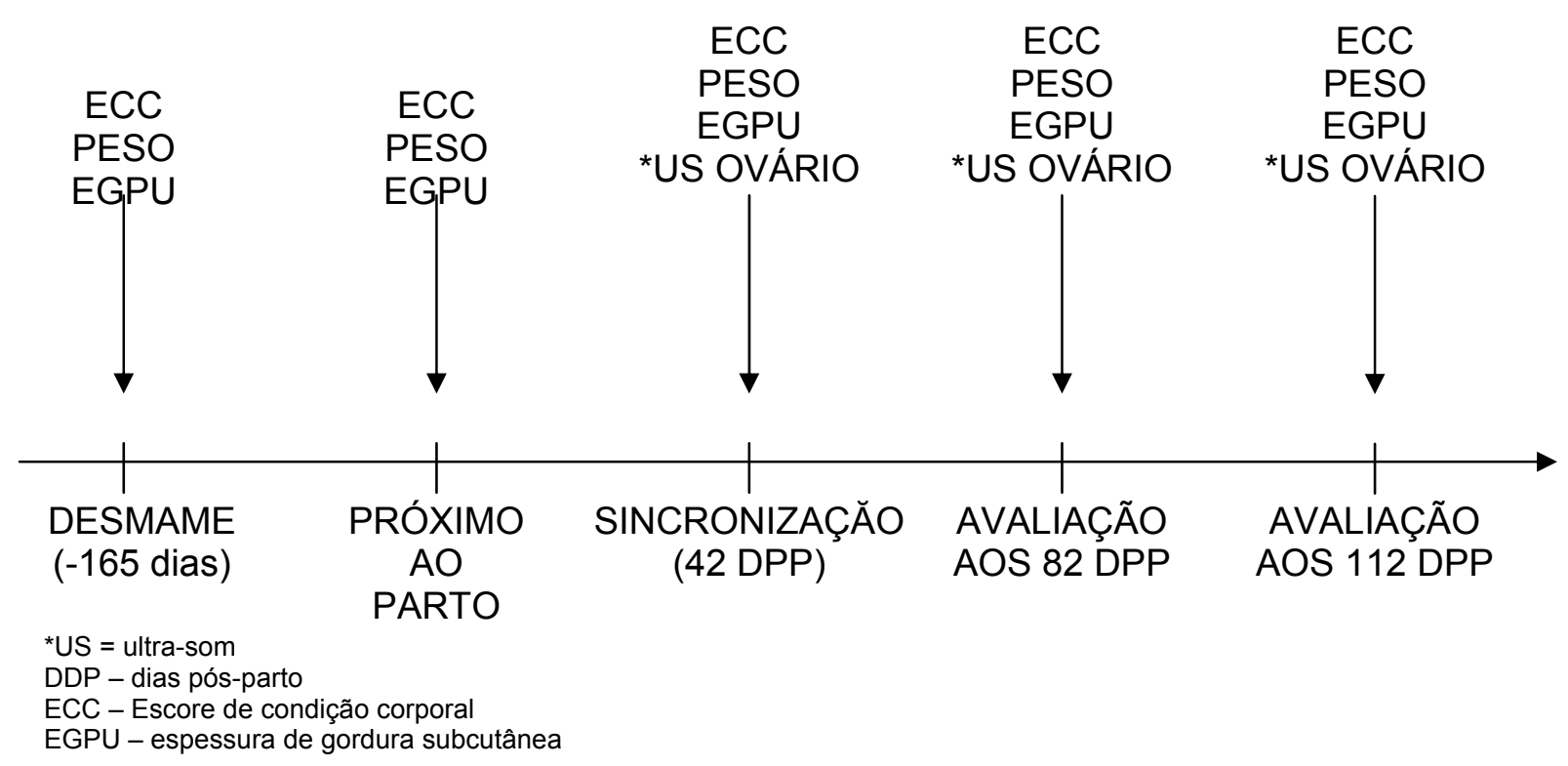

Figura 2 - Diagrama esquemático dos momentos de coleta de dados

A avaliação do escore de condição corporal e as medidas por ultra-sonografia foram obtidos independentemente, no mesmo animal e no mesmo momento, por um único avaliador devidamente treinado. O peso corporal foi aferido com auxílio de balança digital calibrada com peso padrão, acoplada a um tronco individual, por onde os animais passaram e foram pesados um a um. Não foi realizado nenhum tipo de jejum hídrico ou alimentar antes das pesagens.

Ao longo de todo o estudo, o ECC atribuído para cada vaca (em cada momento) foi realizado utilizando-se a técnica visual desenvolvida por Maciel (2006). Dessa forma, as vacas foram classificadas em escala variando de 1 (magra) a 5 (extremamente gorda), com incrementos de um quarto de ponto $(0,25)$.

Para a obtenção das imagens ultra-sonográficas para mensuração EGPU, foi utilizado um equipamento de ultra-som da marca Piemedical, modelo Scanner 200 VET, com transdutor de arranjo linear com freqüência de $3,5 \mathrm{MHz}$ e $178 \mathrm{~mm}$ de comprimento, sem guia acústica acoplada.

Após a imobilização do animal em um tronco de contenção, localizou-se por meio de palpação, o local anatômico para a tomada da imagem. Então, foi colocado óleo vegetal nessa região, a fim de se proporcionar melhor superfície de contato do transdutor com o corpo do animal. Para a avaliação da EGPU, o transdutor foi posicionado em linha reta entre o íleo e o ísquio (Figura 3), até a visualização da 
imagem correta para a realização da medida, ou seja, a borda superior do Biceps femuris (P8, Figura 4). As imagens obtidas foram congeladas e imediatamente analisadas, levando-se em consideração a medida entre o limite inferior da pele e a fáscia profunda. Dessa maneira, a medida da espessura da pele já foi devidamente descontada.

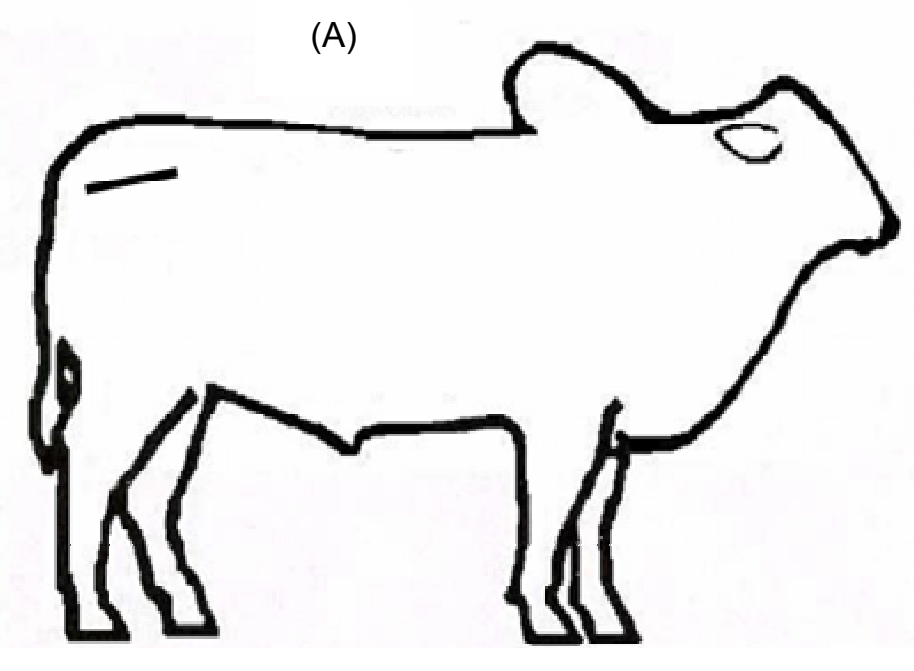

(B)

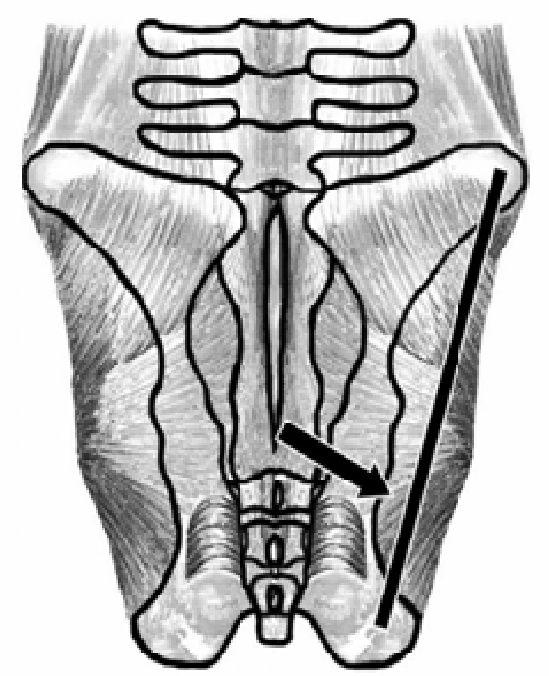

Figura 3 - Diagrama esquemático do local de mensuração da espessura da gordura subcutânea vista lateral (A) e vista superior (B; adaptado SCHRODER; STAUFENBIEL, 2006)

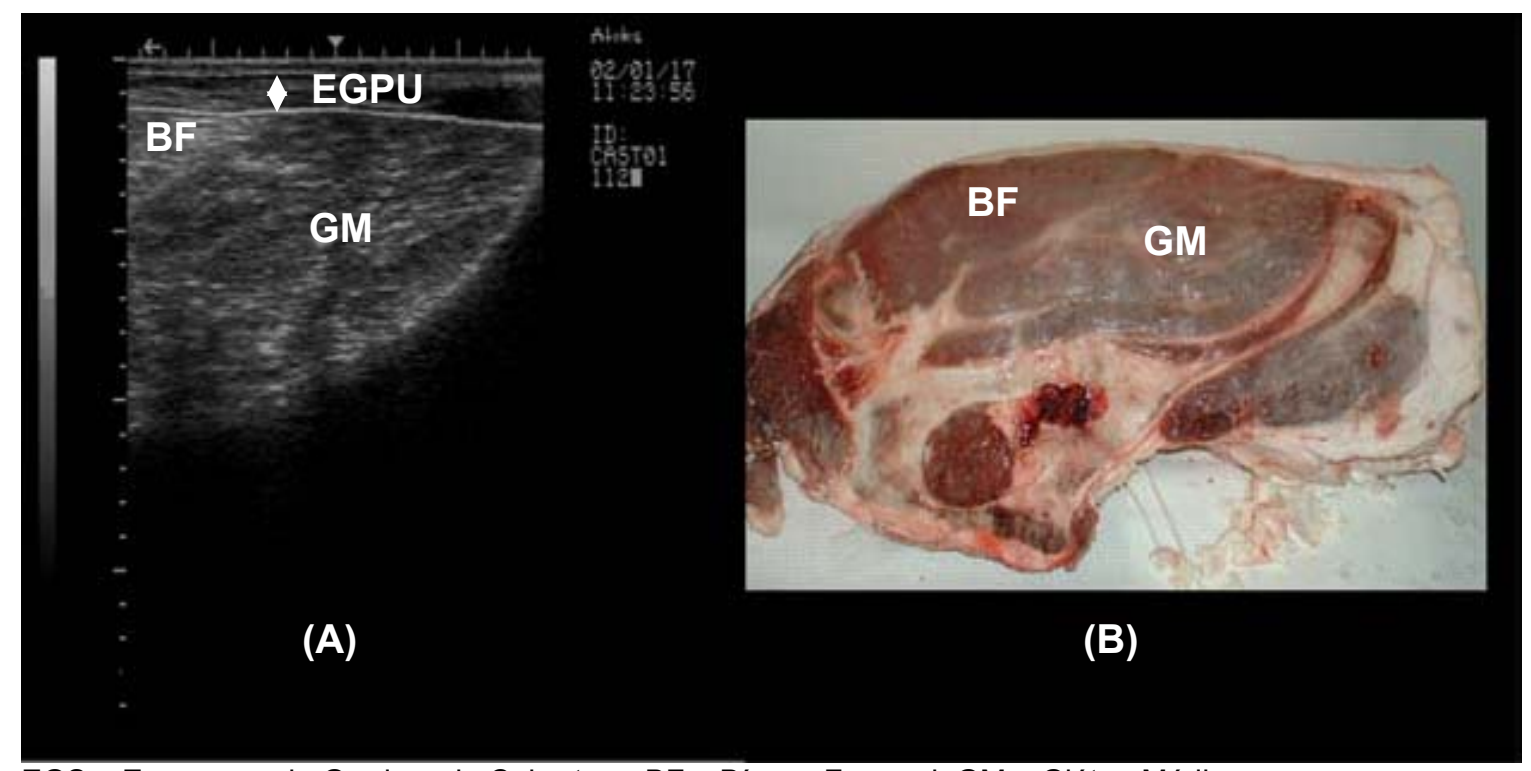

EGS - Espessura da Gordura de Cobertura; BF - Bíceps Femoral; GM - Glúteo Médio

Figura 4 - Imagem ultra-sonográfica do local de mensuração da espessura da gordura subcutânea (A) e corte longitudinal do Gluteus medius e Bíceps femoris (B; adaptado de SAINZ; ARAÚJO; 2002) 


\subsection{ANÁLISE ESTATÍSTICA}

As relações entre ECC e as mensurações de EGPU foram investigadas utilizando modelos de regressão. Para cada momento foi gerado um modelo diferente. Assim, o modelo 1 incluiu as mensurações no momento do desmame, o modelo 2 incluiu as mensurações próximas ao parto, o modelo 3 incluiu as mensurações feitas no momento da sincronização, o modelo 4 incluiu as mensurações da avaliação aos 82 dias pós-parto e o modelo 5 incluiu as mensurações da avaliação aos 112 dias pós-parto.

Para a análise de semelhança entre os cinco modelos foi utilizado o proc MIXED do SAS (Version 9,1 for Windows; SAS Inst., Cary, NC), sendo que os momentos foram comparados entre si através de contraste ortogonal, comparando cada elemento da reta $(\alpha, \beta, \gamma$ e $\delta$ ). A unidade experimental "vaca" foi objeto das medidas repetidas ao longo do tempo e a estrutura matricial do tipo $\mathrm{CSH}$ foi utilizada. A estrutura matricial CSH especifica a estrutura do composto de simetria heterogênea que possuí uma estrutura de equi-correlação, mas que permite diferentes variâncias.

Foi constatado que os momentos respeitam o comportamento do $3^{\circ} \mathrm{grau}$, podendo ser generalizados pela seguinte equação:

$$
Y_{i}=\alpha_{i}+\beta_{i} x+\gamma_{i} x^{2}+\delta_{i} x^{3}
$$

onde:

$Y_{i}$ - espessura da gordura subcutânea estimada;

$\alpha_{i}$ - intercept (ponto de intersecção);

$\beta_{\mathrm{i}}$ - elemento de primeiro grau;

$\gamma_{i}$ - elemento de segundo grau;

$\delta_{\mathrm{i}}$ - elemento de terceiro grau;

i - momento (desmame, parto, sincronização, avaliação aos 82 e 112 dias);

$\mathrm{x}$ - escore de condição corporal observado. 
Após a verificação de ocorrência de semelhança entre os cinco modelos, todos os dados foram agrupados e um novo modelo único foi então gerado. $O$ modelo geral de estimação da espessura da gordura subcutânea através do escore de condição corporal foi gerado utilizando o Guide Data Analysis do SAS. A fim de respeitar a normalidade dos resíduos e homogeneidade das variâncias, os dados de espessura da gordura subcutânea foram transformados para raíz quadrada.

As correlações entre variáveis foram analisadas com o proc CORR do SAS. Probabilidades de $\mathrm{P}<0,05$ foram consideradas como significantes. Todos os dados estão expressos como medias \pm erro padrão da média. 


\section{RESULTADOS}

Um total de 600 vacas foi analisado no presente estudo. Porém, foram efetivamente utilizados somente os animais que pariram entre o dia 15 de novembro de 2005 e 12 de janeiro de 2006 (período de 58 dias entre a primeira e a última parição; $n=297$ ). Dentre as 297 vacas pré-selecionadas, 24 não tiveram todos os dados de ECC, peso e/ou EGPU corretamente colhidos e, portanto, foram também removidas. Ainda, 7 animais foram classificados como outliers e também foram extraídos das análises. Assim, chegou-se às 266 vacas que foram consideradas aptas para integrarem o estudo.

Os valores médios, desvios padrão e as variações de ECC e EGPU por momento estão apresentados na tabela 1. O ECC apresentou variação de 2,00 a 4,50 , com média de $3,23 \pm 0,42$ pontos e o EGPU variou de 0,2 a $2,0 \mathrm{~cm}$, com média de $0,69 \pm 0,28 \mathrm{~cm}$. 
Tabela 1 - Número de observações, médias, erros padrão e valores mínimos e máximos do escore de condição corporal (ECC), da espessura da gordura subcutânea (EGPU, $\mathrm{cm}$ ) e do peso vivo ( $\mathrm{kg}$ ) de vacas Nelore (Bos indicus) avaliadas em diferentes momentos experimentais (desmame, parto, sincronização, avaliação aos 82 e aos 112 dias)

\begin{tabular}{lccccc}
\hline Variável & N & Média & Erro Padrão & Mínimo & Máximo \\
\hline ECC no Desmame & 266 & 3,19 & 0,02 & 2,50 & 4,25 \\
ECC no Parto & 266 & 3,46 & 0,02 & 2,50 & 4,50 \\
ECC na Sincronização & 266 & 3,21 & 0,03 & 2,25 & 4,50 \\
ECC aos 82 DPP & 266 & 3,10 & 0,02 & 2,50 & 4,50 \\
ECC aos 112 DPP & 266 & 3,17 & 0,02 & 2,00 & 4,00 \\
EGPU no Desmame & 266 & 0,68 & 0,02 & 0,3 & 1,7 \\
EGPU no Parto & 266 & 0,93 & 0,02 & 0,4 & 2,0 \\
EGPU na Sincronização & 266 & 0,65 & 0,01 & 0,2 & 1,7 \\
EGPU aos 82 DPP & 266 & 0,59 & 0,01 & 0,2 & 1,8 \\
EGPU aos 112 DPP & 266 & 0,61 & 0,01 & 0,2 & 1,6 \\
Peso no Desmame & 266 & 390,1 & 2,67 & 301 & 547 \\
Peso no Parto & 266 & 421,8 & 2,47 & 312 & 547 \\
Peso na Sincronização & 266 & 401,1 & 2,57 & 262 & 572 \\
Peso aos 82 DPP & 266 & 405,9 & 2,45 & 314 & 577 \\
Peso aos 112 DPP & 266 & 415,4 & 2,50 & 322 & 569 \\
\hline DPP - dias pós-par & 26,5 &
\end{tabular}

DPP - dias pós-parto; ECC - escore de condição corporal; EGPU - espessura da gordura subcutânea (garupa)

As correlações entre os escores de condição corporal, espessura da gordura subcutânea e o peso corporal foram também avaliados nos diversos momentos experimentais (Tabela 2). Nesse contexto, pôde-se verificar que, apesar do teste ser altamente significativo $(P<0,0001)$, uma baixa $(r=0,37)$ a média $(r=0,50)$ correlação foi encontrada entre peso/ECC e peso/EGPU, indicando a ocorrência de fraca relação entre estas variáveis. Ainda, modelos de regressão foram utilizados para verificar a relação entre o peso/ECC ou peso/EGPU. Os valores de coeficientes de regressão encontrados variaram entre 0,13 e 0,25, evidenciando novamente uma fraca ligação entre o peso corporal e estas variáveis. 
Porém, quando analisada a relação entre ECC e EGPU, dentro de cada momento, pôde ser verificada alta correlação ( $r=0,82$ a 0,93, Tabela 2) e alto coeficiente de regressão $\left(R^{2}=0,73\right.$ a 0,92 , Tabela 3 ) entre essas variáveis, evidenciando, desta maneira, a existência de uma estreita relação entre elas.

Tabela 2 - Coeficiente de correlação de Pearson ( $r$ ) entre os escores de condição corporal (ECC) e as espessuras da gordura subcutânea (EGPU; n=266) encontrados em vacas Nelore (Bos indicus) avaliadas em diferentes momentos experimentais (desmame, parto, sincronização, avaliações aos 82 e aos 112 dias pós-parto)

\begin{tabular}{cccccc}
\hline & $\begin{array}{c}\text { Desmame } \\
(-165 \mathrm{~d})\end{array}$ & Parto & $\begin{array}{c}\text { Sincronização } \\
(42 \text { DPP })\end{array}$ & $\begin{array}{c}\text { Avaliação } \\
\text { aos 82 DPP }\end{array}$ & $\begin{array}{c}\text { Avaliação } \\
\text { aos 112 DPP }\end{array}$ \\
\cline { 2 - 6 } & 0,82 & 0,93 & 0,93 & 0,93 & 0,88 \\
$\begin{array}{c}\text { Correlação entre } \\
\text { ECC e EGPU }\end{array}$ & $<0,0001$ & $<0,0001$ & $<0,0001$ & $<0,0001$ & $<0,0001$ \\
$\begin{array}{c}\text { Correlação entre } \\
\text { ECC e Peso }\end{array}$ & 0,50 & 0,37 & 0,47 & 0,41 & 0,42 \\
$\begin{array}{c}\text { Correlação entre } \\
\text { EGPU e Peso }\end{array}$ & 0,0001 & $<0,0001$ & $<0,0001$ & $<0,0001$ & $<0,0001$ \\
\hline
\end{tabular}


Tabela 3 - Número de animais $(\mathrm{N})$ e valores do coeficiente de regressão $\left(R^{2}\right)$, de.F e de $P$ (nível de significância) obtidos nos diferentes modelos testados para ECC e EGPU de vacas Nelore (Bos indicus) avaliadas em diferentes momentos experimentais (desmame, parto, sincronização, avaliação aos 82 e aos 112 dias pós-parto)

\begin{tabular}{|c|c|c|c|c|c|c|}
\hline & \multicolumn{6}{|c|}{ Momento } \\
\hline & $\begin{array}{l}\text { Desmame } \\
(-165 \mathrm{~d})\end{array}$ & Parto & $\begin{array}{l}\text { Sincronização } \\
\text { (42 DPP) }\end{array}$ & $\begin{array}{c}\text { Avaliação } \\
\text { aos } 82 \text { DPP }\end{array}$ & $\begin{array}{c}\text { Avaliação aos } \\
112 \text { DPP }\end{array}$ & Geral \\
\hline $\begin{array}{l}\mathrm{R}^{2} \\
\text { Adjustado }\end{array}$ & 0,73 & 0,89 & 0,90 & 0,92 & 0,82 & 0,84 \\
\hline$F$ & 240,7 & 1042 & 771,5 & 958,3 & 410,9 & 2247 \\
\hline$P$ & $<0,0001$ & $<0,0001$ & $<0,0001$ & $<0,0001$ & $<0,0001$ & $<0,0001$ \\
\hline $\mathrm{N}$ & 266 & 266 & 266 & 266 & 266 & 1330 \\
\hline
\end{tabular}

Os dados de freqüência de ocorrência de cada ECC e EGPU em cada momento estão apresentados nas tabelas 4 e 5 . 
Tabela 4 - Freqüência de ocorrência de cada escore de condição corporal em vacas Nelore (Bos indicus) avaliadas em diferentes momentos experimentais (desmame, parto, sincronização, avaliação aos 82 e aos 112 dias pós-parto)

\begin{tabular}{|c|c|c|c|c|c|c|c|c|c|c|}
\hline \multirow[b]{2}{*}{ ECC } & \multicolumn{2}{|c|}{ Desmame $(-150 \mathrm{~d})$} & \multicolumn{2}{|r|}{ Parto } & \multicolumn{2}{|c|}{ Sincronização (42 DPP) } & \multicolumn{2}{|c|}{ Avaliação aos 82 DPP } & \multicolumn{2}{|c|}{ Avaliação aos 112 DPP } \\
\hline & $\mathrm{N}$ & $\begin{array}{c}\text { Porcentagem } \\
(\%)\end{array}$ & $\mathrm{N}$ & $\begin{array}{c}\text { Porcentagem } \\
(\%)\end{array}$ & $\mathrm{N}$ & $\begin{array}{c}\text { Porcentagem } \\
(\%)\end{array}$ & $\mathrm{N}$ & $\begin{array}{c}\text { Porcentagem } \\
(\%)\end{array}$ & $\mathrm{N}$ & $\begin{array}{c}\text { Porcentagem } \\
(\%)\end{array}$ \\
\hline 2,00 & - & - & - & - & - & - & - & - & 2 & 0,8 \\
\hline 2,25 & - & - & - & - & 1 & 0,4 & - & - & 1 & 0,4 \\
\hline 2,50 & 13 & 4,9 & 2 & 0,8 & 23 & 8,7 & 27 & 10,2 & 18 & 6,8 \\
\hline 2,75 & 39 & 14,7 & 9 & 3,4 & 31 & 11,7 & 47 & 17,7 & 32 & 12,0 \\
\hline 3,00 & 79 & 29,7 & 58 & 21,8 & 75 & 28,2 & 93 & 35,0 & 89 & 33,5 \\
\hline 3,25 & 56 & 21,1 & 30 & 11,3 & 40 & 15,0 & 33 & 12,4 & 41 & 15,4 \\
\hline 3,50 & 46 & 17,3 & 84 & 31,6 & 43 & 16,2 & 33 & 12,4 & 40 & 15,0 \\
\hline 3,75 & 20 & 7,5 & 44 & 16,5 & 37 & 13,9 & 26 & 9,8 & 34 & 12,8 \\
\hline 4,00 & 11 & 4,1 & 28 & 10,5 & 11 & 4,1 & 4 & 1,5 & 9 & 3,4 \\
\hline 4,25 & 2 & 0,8 & 4 & 1,5 & 4 & 1,5 & 1 & 0,4 & - & - \\
\hline 4,50 & - & - & 7 & 2,6 & 1 & 0,4 & 2 & 0,8 & - & - \\
\hline Total & 266 & 100,0 & 266 & 100,0 & 266 & 100,0 & 266 & 100,0 & 266 & 100,0 \\
\hline
\end{tabular}

ECC - escore de condição corporal; DPP - dias pós-parto; $\mathrm{N}$ - número de amimais 
Tabela 5 - Freqüência de ocorrência de cada espessura da gordura subcutânea (EGPU) em vacas Nelore (Bos indicus) avaliadas em diferentes momentos experimentais (desmame, parto, sincronização, avaliação aos 82 e 112 dias)

\begin{tabular}{|c|c|c|c|c|c|c|c|c|c|c|}
\hline \multirow[b]{2}{*}{$\begin{array}{l}\text { EGPU } \\
(\mathrm{cm})\end{array}$} & \multicolumn{2}{|c|}{ Desmame $(-150 d)$} & \multicolumn{2}{|c|}{ Parto } & \multicolumn{2}{|c|}{ Sincronização (42 DPP) } & \multicolumn{2}{|c|}{ Avaliação aos 82 DPP } & \multicolumn{2}{|c|}{ Avaliação aos 112 DPP } \\
\hline & $\mathrm{N}$ & $\begin{array}{c}\text { Porcentagem } \\
(\%)\end{array}$ & $\mathrm{N}$ & $\begin{array}{c}\text { Porcentagem } \\
(\%)\end{array}$ & $\mathrm{N}$ & $\begin{array}{c}\text { Porcentagem } \\
(\%)\end{array}$ & $\mathrm{N}$ & $\begin{array}{c}\text { Porcentagem } \\
(\%)\end{array}$ & $\mathrm{N}$ & $\begin{array}{c}\text { Porcentagem } \\
(\%)\end{array}$ \\
\hline 0,2 & - & - & - & - & 4 & 1,5 & 5 & 1,9 & 1 & 0,4 \\
\hline 0,3 & 4 & 1,5 & - & - & 19 & 7,1 & 22 & 8,3 & 21 & 7,9 \\
\hline 0,4 & 31 & 11,7 & 5 & 1,9 & 37 & 13,9 & 42 & 15,8 & 39 & 14,7 \\
\hline 0,5 & 47 & 17,7 & 16 & 6,0 & 57 & 21,4 & 68 & 25,6 & 57 & 21,4 \\
\hline 0,6 & 55 & 20,7 & 17 & 6,4 & 33 & 12,4 & 49 & 18,4 & 56 & 21,1 \\
\hline 0,7 & 49 & 18,4 & 35 & 13,2 & 31 & 11,7 & 24 & 9,0 & 29 & 10,9 \\
\hline 0,8 & 34 & 12,8 & 49 & 18,4 & 37 & 13,9 & 33 & 12,4 & 38 & 14,3 \\
\hline 0,9 & 17 & 6,4 & 39 & 14,7 & 13 & 4,9 & 7 & 2,6 & 8 & 3,0 \\
\hline 1,0 & 8 & 3,0 & 24 & 9,0 & 14 & 5,3 & 6 & 2,3 & 7 & 2,6 \\
\hline 1,1 & 7 & 2,6 & 39 & 14,7 & 12 & 4,5 & 5 & 1,9 & 3 & 1,1 \\
\hline 1,2 & 5 & 1,9 & 9 & 3,4 & 1 & 0,4 & 1 & 0,4 & 1 & 0,4 \\
\hline 1,3 & 4 & 1,5 & 8 & 3,0 & - & - & - & - & 3 & 1,1 \\
\hline 1,4 & 3 & 1,1 & 10 & 3,8 & 2 & 0,8 & 1 & 0,4 & - & - \\
\hline 1,5 & 1 & 0,4 & 6 & 2,3 & 3 & 1,1 & 1 & 0,4 & 2 & 0,8 \\
\hline 1,6 & 1 & 0,4 & - & - & 2 & 0,8 & - & - & 1 & 0,4 \\
\hline 1,7 & - & - & 5 & 1,9 & 1 & 0,4 & 1 & 0,4 & - & - \\
\hline 1,8 & - & - & 1 & 0,4 & - & - & 1 & 0,4 & - & - \\
\hline 1,9 & - & - & 2 & 0,8 & - & - & - & - & - & - \\
\hline 2,0 & - & - & 1 & 0,4 & - & - & - & - & - & - \\
\hline Total & 266 & 100,0 & 266 & 100,0 & 266 & 100,0 & 266 & 100,0 & 266 & 100,0 \\
\hline
\end{tabular}

ECC - escore de condição corporal; DPP - dias pós-parto; N - número de amimais 
Como não foi verificada diferença estatística entre cada momento de mensuração de ECC e EGPU, os dados foram agrupados e geraram o modelo geral apresentado abaixo:

$$
\sqrt{E G P U}=-1,0313+1,201 * E C C-0.3153 * E C C^{2}+0.0371 * E C C^{3}
$$

onde:

$$
\begin{aligned}
& \sqrt{E G P U} \text { - raiz quadrada da espessura da gordura subcutânea predita; } \\
& \text { ECC - escore de condição corporal observado }
\end{aligned}
$$

O gráfico de dispersão do escore de condição corporal pele raiz quadrada da espessura da gordura subcutânea está apresentado na figura 5.

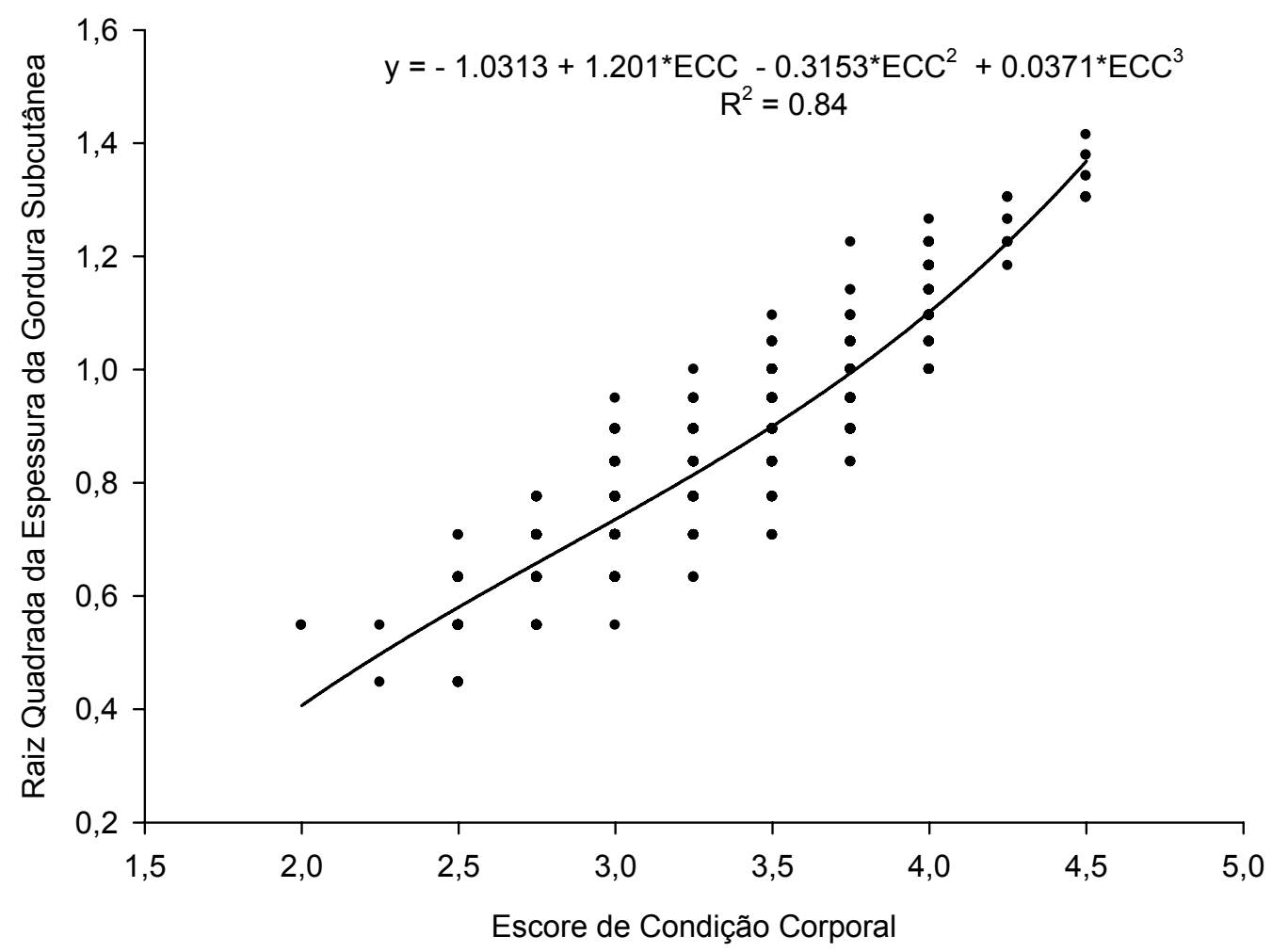

Figura 5 - Gráfico de dispersão do escore de condição corporal pela raíz quadrada da espessura da gordura subcutânea em vacas Nelore (Bos indicus) avaliadas em diferentes momentos experimentais (desmame, parto, sincronização, avaliação aos 82 e 112 dias pós-parto) 
As mensurações de EGPU dentro dos diferentes momentos foram associadas significantemente com o ECC ( $P<0,0001)$. Assim como no modelo geral.

Entretanto nas as análises entre ECC e peso e entre EGPU e peso foram detectadas diferenças entre os momentos, e, por isso os dados não puderam ser agrupados para gerar um modelo geral. Como no momento da sincronização a equação de regressão não apresentou necessidade de transformação e teve comportamento linear entre as variáveis, analisou-se as mudanças do peso vivo para cada unidade de mudança na condição corporal nesse momento (sincronização). Assim, cada aumento de uma unidade de ECC equivaleu a adição de $45 \mathrm{~kg}$ de peso vivo no momento da sincronização. 


\section{DISCUSSÃO}

Neste trabalho o uso da P8 foi escolhido devido a diversas razões. Primeiro, porque esta é a área inspecionada para a realização do ECC, mas também por ser uma região de fácil acesso em troncos de contenção utilizados em fazendas de corte no Brasil. Dessa forma, a avaliação ultra-sonográfica da EGPU pode ser realizada tanto pela parte lateral do tronco, quanto pela parte de trás, utilizando-se a mesma estrutura demandada para a realização da IA, colocação de dispositivos intravaginais, para a aplicação dos hormônios referentes ao protocolo de sincronização da onda folicular, dentre outros procedimentos.

Silva et al. (2003) também trabalharam com mensuração da espessura da gordura subcutânea da garupa e demonstraram que a mesma poderia ser utilizada com a mesma confiabilidade que a EGS aferida entre a $12^{\mathrm{a}}$ e $13^{\mathrm{a}}$ costela (EGSU). Esse resultado indica a possibilidade de utilização da EGPU como alternativa à EGSU, o que seria bastante interessante, uma vez que a gordura subcutânea deposita-se primeiramente na região posterior em relação à região lombar. Outra vantagem da EGPU seria a facilidade de realização desta medida, tanto pela região em que é feita, quanto pelo fato de mesmo um operador com pouco treinamento ser capaz de realizá-la com maior precisão, agilidade e com repetibilidade em comparação a EGSU (STOUFFER; CROSS, 1985). Esses dados embasam a escolha por esse local de medida para o presente experimento.

Mais além, Domeq et al. (1995) sugerem, em seu estudo, que um único local de mensuração da espessura da gordura subcutânea pode ser o mais indicado. Esses autores verificaram que, ao combinar duas áreas de mensuração no mesmo modelo matemático, este não foi eficaz em aumentar o coeficiente de regressão $\left(R^{2}\right)$, quando comparado com apenas um dos locais. Além disso, verificaram maior valor numérico de $R^{2}$ para a região da $P 8\left(R^{2}=0,65\right)$ em comparação a região lombar $\left(R^{2}=0,36\right)$ ou a combinação das duas $\left(R^{2}=0,57\right)$. Mais uma vez, dados de trabalhos previamente realizados evidenciam a eficiência da região $\mathrm{P} 8$ na avaliação da EGPU e dão suporte à decisão pelo uso dessa região no atual estudo. 
A repetibilidade das medições ultra-sonográficas também tem sido alvo de investigações. Nesse caso, a correlação entre medições consecutivas observada foi de 0,975, com uma diferença média absoluta de 0,72 mm (BRETHOUR, 1992).

Diversos outros trabalhos mostram boas correlações entre as medidas realizadas por ultra-sonografia pré-abate e as respectivas medidas na carcaça (ROUSE et al., 1992; SILVA et al.; 2001; SILVA et al., 2003, entre outros). Nesses estudos, os coeficientes de correlação variaram entre 0,72 e 0,92 (BRETHOUR, 1992; PERKINS et al., 1992; ROBINSON et al., 1992; GREINER et al., 2003). Entretanto, é importante ressaltar que as correlações entre as medidas ultrasonográficas e as aferidas diretamente na carcaça podem ser influenciadas por limitações tecnológicas (aparelhos), experiência do técnico, nível de gordura e músculo, sexo e idade do animal e deslocamento dos músculos em relação ao esqueleto (PERKINS, 1992).

Ainda, avaliações de carcaça geralmente são realizadas entre a $12^{\text {a }}$ e $13^{\text {a }}$ costelas e, como mencionado anteriormente, esse local não é alvo de avaliação quanto se pontua o ECC. Segundo Domecq et al. (1995), para fazer com que ambos os métodos sejam comparáveis, a mensuração da espessura da gordura subcutânea deve ser realizada na região da garupa. De fato, essa é a razão pela qual, em contraste com o gado de corte, a P8 é utilizada para a mensuração da espessura da gordura subcutânea em rebanhos leiteiros (STAUFENBIEL, 1992).

Como os objetivos do presente trabalho eram justamente determinar a relação entre a avaliação visual do ECC e a EGS mensurada por ultra-sonografia e determinar a relação entre o peso vivo, a avaliação visual do ECC e a EGS mensurada por ultra-sonografia, fica evidente o motivo da escolha do uso da P8.

Conforme esperado, foi possível notar, no atual estudo, alta correlação entre o ECC e o EGPU (variando de 0,82 a 0,93). Este dado está de acordo com resultados encontrados na literatura, pois alguns estudos têm demonstrado valores variando entre 0,90 e 0,95 (WITTEK; FÜRLL, 2002; SCHRODER; STAUFENBIEL, 2006). Entretanto, Maciel (2006) encontrou valor inferior $(r=0,49)$ para os animais da raça Nelore. Em sua discussão, a autora supõe que este resultado pode ter ocorrido devido ao fato das vacas Nelore terem apresentado grande amplitude de valores do ECC. Porém, no presente estudo este fato não foi constatado, mesmo com a alta amplitude de valores (de 2,00 a 4,50). 
Os resultados apresentados na tabela 3 dessa dissertação demonstram que o ECC sempre foi eficiente em predizer a EGPU, tanto nos distintos momentos isoladamente, como quando os dados foram agrupados, demonstrando que o ECC pode ser utilizado para predizer a EGS em qualquer momento e ainda, com uma única fórmula. Este dado corrobora com os achados de Domeq et al. (1995), os quais indicaram que ECC é uma medida válida para prever a gordura subcutânea ao longo do tempo.

Ao analisar o comportamento da reta de regressão entre o EGPU e o ECC foi comprovada a relação de terceiro grau entre estas variáveis. Este fato evidência que os pontos extremos da reta têm relação de crescimento diferente dos pontos intermediários da reta. Este dado contraria os resultados de Maciel (2006), nos quais foi evidenciada a ocorrência de relação linear. Ainda, neste mesmo trabalho, os dados de espessura da gordura de cobertura não foram transformados e o coeficiente de regressão não foi apresentado, dificultando desta forma a comparação entre os trabalhos.

Uma possível explicação para a diferença entre o comportamento das retas encontradas nesses trabalhos (atual e MACIEL, 2006) pode decorrer do fato do presente trabalho utilizar dados provenientes de diferentes momentos e Maciel ter utilizado um único momento. Outra possível justificativa para essa divergência de resultados seria a diferente idade ou ainda, a categoria de criação dos animais, pois vacas de cria podem apresentar diferenças na quantidade de gordura subcutânea em comparação a vacas em terminação para abate, uma vez que no trabalho de Maciel (2006) não está especificada a categoria e a idade dos animais experimentais. 


\section{CONCLUSÃO}

A hipótese inicial do presente estudo foi comprovada, uma vez que o escore de condição corporal na escala de 1 a 5 , utilizando o método visual foi capaz de predizer a espessura da gordura subcutânea de vacas Nelores em diferentes momentos do ciclo de criação. Ainda, foi demonstrado que o escore de condição corporal apresentou alta correlação e relação com a espessura da godura subcutânea. Porém, tanto o escore de condição, quanto a espessura da gordura subcutânea apresentam baixa correlação e baixíssima relação com o peso.

Adicionalmente, foi possível demonstrar que, no momento da sincronização, cada aumento de uma unidade de ECC equivaleu a implementação de $45 \mathrm{~kg}$ de peso vivo. Porém, mais estudos são necessários para confirmar os dados deste estudo. 


\section{CAPÍTULO II}

\section{Efeito do Escore de}

condição Corporal, da

Espessura da Gordura

Subcutânea e do Peso na

Eficiência Reprodutiva de

$$
\text { vacas } \mathcal{N e l o r e}
$$




\section{HIPÓTESE}

As hipóteses do presente trabalho são que animais com maiores escore de condição corporal e gordura subcutânea, assim como os que apresentam maior ganho destas medidas entre o desmame e o parto e menor perda entre o parto e a sincronização apresentam melhor eficiência reprodutiva. $O$ peso e suas variações não são bons preditores da eficiência reprodutiva. 


\section{OBJETIVOS}

- Determinar o impacto do escore de condição corporal, da espessura da gordura subcutânea e do peso em diferentes momentos do sistema de criação na eficiência reprodutiva de vacas Nelore (Bos indicus) submetidas à IATF e repasse com o touro.

- Determinar o impacto da mudança de escore de condição corporal, de espessura da gordura subcutânea e do peso em entre diferentes momentos do sistema de criação na eficiência reprodutiva de vacas Nelore (Bos indicus) submetidas á IATF e e repasse com o touro.

- Determinar o(s) momento(s) de avaliação que possuem maior impacto na eficiência reprodutiva de vacas Nelore (Bos indicus) submetidas à IATF e repasse com o touro. 


\section{MATERIAIS E MÉTODOS}

\subsection{ANIMAIS E MANEJO}

As unidades experimentais utilizadas nesse trabalho foram vacas Nelore (Bos indicus) lactantes, apresentando média de condição corporal de $2,9 \pm 0,01$. Apenas os animais considerados aptos para o estudo do capítulo $1(n=266)$ foram utilizados nessa fase.

O experimento foi efetuado em um único rebanho, criado sob sistema de pastoreio, com suplementação mineral e água ad libitum, no estado de Mato Grosso do Sul, Brasil. O período experimental foi de Maio de 2005 a Julho de 2006. Todos os procedimentos com os animais foram aprovados pela comissão de ética para experimentação animal da Universidade de São Paulo-USP.

\subsection{HORMÔNIOS UTILIZADOS}

Os hormônios utilizados no presente experimento foram: implante auricular de Norgestomet (Crestar contendo $3 \mathrm{mg}$ de Norgestomet; Intervet). Benzoato de estradiol (BE-Estrogin; Pharmavet). Prostaglandina F2 $\alpha$ (Preloban; Intervet). Gonadotrofina Coriônica Equina (Folligon; Intervet). Todos os tratamentos hormonais exceto o implante auricular foram realizados por via intramuscular.

\subsection{PROTOCOLO HORMONAL UTILIZADO}

Durante o presente experimento, os animais formaram inseminados em duas etapas distintas. A primeira em janeiro (156 animais) e a segunda em fevereiro (110 
animais). Todos os animais receberam um implante auricular de Norgestomet, previamente utilizado por 9 dias, associado à aplicação de 2,0 mg de benzoato de estradiol intramuscular (IM) em dia aleatório do ciclo estral (D42, manhã). Oito dias após (D50), foi realizada a remoção do implante, juntamente com a administração de 400 UI de eCG e de $150 \mu \mathrm{g}$ de d-cloprostenol, IM. No dia seguinte (D51), foi administrado $1,0 \mathrm{mg}$ de benzoato de estradiol e os animais foram submetidos à inseminação artificial em tempo fixo (IATF) 56 horas após a retirada do implante (D52, tarde). A seqüência do tratamento hormonal está representada na figura 6.

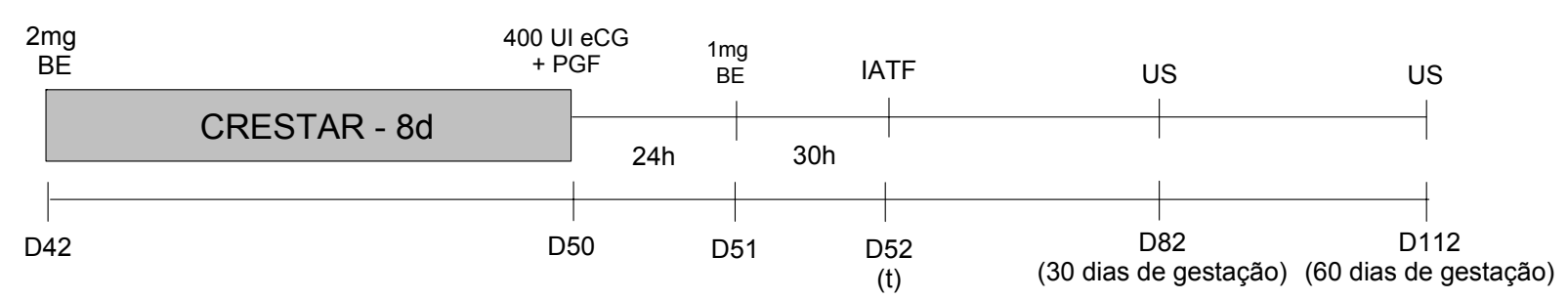

BE - benzoato se estradiol; IATF - inseminação artificial em tempo fixo; eCG - gonadotrofina coriônica eqüina; US - ultra-sonografia; PGF - prostaglandina; D - dia

Figura 6 - Representação esquemática do tratamento hormonal

O sêmen de 2 touros foi utilizado, sendo sua distribuição balanceada homogeneamente entre todos os animais. Após 10 dias da inseminação (D62), houve a introdução de touros para a cobertura natural dos animais não gestantes que retornassem ao estro. O diagnóstico de gestação foi realizado por exame ultrasonográfico, em média, aos 30 e 60 dias após a IATF (82 e 112 dias pós-parto).

\subsection{AVALIAÇÃO DO PESO, DA CONDIÇÃO CORPORAL E DA ESPESSURA DA GORDURA SUBCUTÂNNEA (EGPU)}

Todos animais foram avaliados quanto ao peso, condição corporal e EGPU da mesma forma como está descrito no capítulo 1. 


\subsection{AVALIAÇÃO DA ATIVIDADE OVARIANA PÓS-PARTO, DA TAXA DE CONCEPÇÃO À IATF, DA EFICIÊNCIA REPRODUTIVA DURANTE A ESTAÇÃO DE MONTA E DA PERDA GESTACIONAL}

A atividade ovariana pós-parto (ciclicidade) foi determinada pela porcentagem de presença de CL no início do programa de sincronização da ovulação (42 dias pós-parto), de acordo com Baruselli et al. (2003). Para tal, as fêmeas foram submetidas a exame ultra-sonográfico (Aloka SSD500, Japão) visando a determinação da presença ou ausência de corpo lúteo $(C L)$ nesse momento. $A$ taxa de ciclicidade foi definida como o número de animais apresentando CL pelo total de animais avaliados.

A eficiência reprodutiva foi avaliada pela taxa de concepção à IATF aos 82 e aos 112 dias pós-parto e pela taxa de prenhez acumulada, até 82 dias pós-parto (diagnosticada 60 dias após a IATF). Os animais não gestantes foram reavaliados de acordo com o grau de ciclicidade, conforme metodologia anteriormente descrita.

A perda gestacional foi determinada de maneira retrospectiva, através da diferença entre o número de animais gestantes ao primeiro exame ultra-sonográfico (82 dias pós-parto) e os não gestantes ao segundo exame (112 dias pós-parto). Não foi possível mensurar a taxa de mortalidade embrionária após a monta natural.

\subsection{ANÁLISE ESTATÍSTICA}

As variáveis resposta como ciclicidade (presença de CL), concepção à IATF aos 30 dias e aos 60 dias, prenhez à IATF + touro aos 60 dias e perda embrionária aos 60 dias obtidas no experimento descrito, são variáveis binárias, isto é, variáveis cujos valores observados podem ser representados por 0 ou 1 . Em geral, assume-se que variáveis desse tipo têm distribuição de Bernoulli, que é um caso particular de modelos lineares generalizados (DEMÉTRIO, 2001). Se for suposto que $Y_{i}$, 
$i=1,2, \ldots, n$, representa uma das variáveis medidas e que $Y_{i} \sim \operatorname{Bernouille}\left(\pi_{i}\right)$, sendo $\pi_{i}$ a probabilidade de sucesso (probabilidade de prenhez ou de morte embrionária), a função de probabilidade de ${ }^{i}$ seria calculada por:

$$
P\left(Y_{i}=y_{i}\right)=\pi_{i}^{y_{i}}\left(1-\pi_{i}\right)^{1-y_{i}}, \quad y_{i}=0,1 .
$$

O modelo linear generalizado permite modelar as probabilidades de sucesso $\pi_{i}$ em termos de variáveis explanatórias $\boldsymbol{x}_{i}$ (efeitos de tratamentos e covariáveis) através de $\eta_{i}=g\left(\pi_{i}\right)=\boldsymbol{x}_{i}{ }^{\prime} \boldsymbol{\beta}$, em que $g$ é uma função de ligação adequada e $\boldsymbol{\beta}$ é o vetor de parâmetros. A função de ligação mais comum para dados binários é logit, isto é, $g\left(\pi_{i}\right)=\ln \left[\pi_{i} /\left(1-\pi_{i}\right)\right]$, mas outras escolhas comuns são probito e complemento log-log. Estimados os parâmetros, pode-se estimar a probabilidade de sucesso através de $\hat{\pi}_{i}=\frac{\exp \left(\hat{\eta}_{i}\right)}{1+\exp \left(\hat{\eta}_{i}\right)}$ (no caso da função logit) quando plotado como função de uma das covariáveis origina uma curva sigmóide (ou um segmento da sigmóide).

Neste trabalho, foi considerado o modelo logístico (ligação logit) e, como covariáveis, foram consideradas: peso, espessura da gordura subcutânea, escore de condição corporal (nos diferentes momentos e também incluídas as diferenças entre cada momento), presença de CL no início da sincronização, idade da vaca, quinzena de nascimento, raça do touro utilizado na estação de monta anterior, data do parto do bezerro ao pé no momento do desmame, características do bezerro ao pé no momento do desmame (raça, sexo, peso aos 120 e 240 dias), data do parto atual, sexo do bezerro atual, data da concepção do bezerro atual, raça do touro, intervalo entre partos médio e do último, idade estimada do feto no momento do desmame, idade real do feto no momento do desmame em meses e em dias e as suas interações. Para as covariáveis quantitativas foram considerados efeitos lineares e quadráticos. Entretanto, verificou-se a existência de correlação alta entre as covariáveis peso, gordura e condição corporal, o que indica que se deve usar no modelo somente uma dentre as correlacionadas. O uso de mais de uma delas no modelo pode trazer problemas de multicolinearidade e não convergência no processo de ajuste. A seleção das covariáveis foi feita através da comparação da deviance (uma generalização da soma de quadrados) referente à covariável testada 
com o valor de $\chi_{v, p}^{2}$ com $v$ graus de liberdade e a um nível de significância de 100p\%. Baseia-se na inclusão e exclusão de covariáveis e interações.

Os dados binomiais foram analisados com o proc GLIMMIX do SAS (Versão 9,1 para Windows; SAS Inst., Cary, NC), os modelos de regressão linear foram gerados através do Guide Data Analysis do SAS e as correlações entre variáveis foram analisadas com o proc CORR do SAS. Probabilidades de $\mathrm{P}<0,05$ foram consideradas como significantes, e probabilidades entre 0,05 e 0,10 foram discutidas como tendências. Todos os dados estão expressos como médias \pm erro padrão da média. 


\section{RESULTADOS}

\subsection{RESULTADOS GERAIS}

Os animais mantidos no experimento apresentaram idade média de 7,33 \pm 0,09 anos (variando de 3 a 9 anos) no momento do início do experimento (desmame), intervalo entre partos de 416,8 $\pm 3,25$ dias (variando de 338 a 716 dias), intervalo entre o desmame e o parto de 165,5 \pm 0,9 dias (variando de 127 a 195 dias) e dias pós-parto ao inicio da sincronização de 42,0 \pm 0,5 dias (variando entre 29 a 74 dias; Tabela 6).

Os valores médios, desvios padrão e as variações de ECC e EGPU, por momento de avaliação estão apresentados na tabela 7. O ECC variou de 2,00 a 4,50, com média de 3,23 $\pm 0,42$, o EGPU variou de 0,2 a 2,0 cm, com média de 0,69 $\pm 0,28 \mathrm{~cm}$ e o peso variou de 262 a $577 \mathrm{~kg}$, com média de $406.9 \pm 1.2 \mathrm{~kg}$.

Os dados gerais relacionados à taxa de ciclidade, taxa de concepção à IATF aos 30 e 60 dias de gestação, taxa de prenhez acumulada aos 82 dias pós-parto e taxa de perda gestacional entre 30 e 60 dias de gestação estão apresentados na tabela 8.

Tabela 6 - Número de observações, médias, desvios padrão e valores mínimos e máximos da idade (ao desmame), intervalo entre partos, intervalo entre o desmame e o parto e dias pós-parto das vacas Nelore (Bos indicus) mantidas no experimento

\begin{tabular}{lccccc}
\hline Variável & $\mathrm{N}$ & Média & Erro Padrão & Mínimo & Máximo \\
\hline Idade (anos) & 266 & 7,33 & 0,09 & 3 & 9 \\
Intervalo entre partos (dias) & 266 & 416,8 & 3,25 & 338 & 716 \\
Intervalo desmame - parto (dias) & 266 & 165,5 & 0,90 & 127 & 195 \\
Intervalo parto-sincronização (dias) & 266 & 42,0 & 0,45 & 29 & 74 \\
\hline
\end{tabular}


Tabela 7 - Número de observações, médias, erros padrão e valores mínimos e máximos do escore de condição corporal (ECC), da espessura da gordura subcutânea (EGPU; $\mathrm{cm}$ ) e do peso vivo ( $\mathrm{kg}$ ) de vacas Nelore (Bos indicus) avaliadas em diferentes momentos experimentais (desmame, parto, sincronização, avaliação aos 82 e aos 112 dias pós-parto)

\begin{tabular}{lccccc}
\hline Variável & N & Média & Erro Padrão & Mínimo & Máximo \\
\hline ECC no Desmame & 266 & 3,19 & 0,02 & 2,50 & 4,25 \\
ECC no Parto & 266 & 3,46 & 0,02 & 2,50 & 4,50 \\
ECC na Sincronização & 266 & 3,21 & 0,03 & 2,25 & 4,50 \\
ECC aos 82 DPP & 266 & 3,10 & 0,02 & 2,50 & 4,50 \\
ECC aos 112 DPP & 266 & 3,17 & 0,02 & 2,00 & 4,00 \\
EGPU no Desmame & 266 & 0,68 & 0,02 & 0,3 & 1,7 \\
EGPU no Parto & 266 & 0,93 & 0,02 & 0,4 & 2,0 \\
EGPU na Sincronização & 266 & 0,65 & 0,01 & 0,2 & 1,7 \\
EGPU aos 82 DPP & 266 & 0,59 & 0,01 & 0,2 & 1,8 \\
EGPU aos 112 DPP & 266 & 0,61 & 0,01 & 0,2 & 1,6 \\
Peso no Desmame & 266 & 390,1 & 2,67 & 301 & 547 \\
Peso no Parto & 266 & 421,8 & 2,47 & 312 & 547 \\
Peso na Sincronização & 266 & 401,1 & 2,57 & 262 & 572 \\
Peso aos 82 DPP & 266 & 405,9 & 2,45 & 314 & 577 \\
Peso no aos 112 DPP & 266 & 415,4 & 2,50 & 322 & 569 \\
\hline DPP - dias pós-parto; ECC - escore de condição corporal; EGPU - espessura da gordura subcutânea (garupa)
\end{tabular}

Tabela 8 - Taxa de ciclidade, taxa de concepção à IATF aos 30 e 60 dias de gestação, taxa de prenhez acumulada aos 82 dias pós-parto e taxa de perda de gestação entre 30 e 60 dias de gestação de vacas Nelore (Bos indicus)

\begin{tabular}{lcc}
\hline Variável & N & Média \\
\hline Taxa de Ciclidade & 266 & $38,7 \%(103 / 266)$ \\
Taxa de concepção à IATF aos 30 dias de gestação & 266 & $60,5 \%(161 / 266)$ \\
Taxa de concepção à IATF aos 60 dias de gestação & 266 & $57,5 \%(153 / 266)$ \\
Taxa de Prenhez acumulada (IATF + Touro) aos 82 dias pós-parto & 266 & $69,9 \%(186 / 266)$ \\
Taxa de Perda de gestação entre 30 e 60 dias de gestação & 161 & $5,0 \%(8 / 161)$ \\
\hline
\end{tabular}




\subsection{EFICIÊNCIA REPRODUTIVA}

O efeito das variáveis analisadas sobre a taxa de ciclicidade, taxa de concepção à IATF aos 30 dias de gestação, taxa de concepção à IATF aos 60 dias de gestação, a taxa de prenhez acumulada (IATF + touro) aos 82 dias pós-parto e perda gestacional entre 30 e 60 dias de gestação estão apresentadas na tabela 9. 
Tabela 9 - Valores de $P$ de para o efeito de cada variável analisada sobre as taxas de ciclicidade, concepção à IATF aos 82 e 112 dias pós-parto (equivalente a $30 \mathrm{e}$ 60 dias de gestação, respectivamente), prenhez acumulada aos 82 dias pósparto e perda de gestacional entre 30 e 60 dias de gestação de vacas Nelore (Bos indicus)

\begin{tabular}{|c|c|c|c|c|c|}
\hline Variável & $C L$ & $\begin{array}{c}\text { Diag } \\
72 \\
\text { DPP }\end{array}$ & $\begin{array}{c}\text { Diag } \\
102 \\
\text { DPP }\end{array}$ & $\begin{array}{c}\text { Prenhez } \\
\text { Acumulada }\end{array}$ & Perda \\
\hline ECC no Desmame & 0,08 & 0,25 & 0,14 & 0,01 & 0,26 \\
\hline ECC no Parto & 0,35 & 0,07 & 0,02 & 0,0007 & 0,05 \\
\hline ECC na Sincronização & 0,04 & 0,85 & 0,50 & 0,18 & 0,16 \\
\hline ECC aos 82 DPP & - & 0,81 & 0,34 & 0,12 & 0,05 \\
\hline ECC aos 112 DPP & - & - & 0,07 & 0,05 & 0,02 \\
\hline Diferença de ECC Desmame-Parto & 0,43 & 0,42 & 0,26 & 0,24 & 0,30 \\
\hline Diferença de ECC Parto-Sincronização & 0,16 & 0,10 & 0,09 & 0,03 & 0,64 \\
\hline Diferença de ECC Sincronização-82 DPP & - & 0,96 & 0,74 & 0,85 & 0,42 \\
\hline Diferença de ECC 82-112 DPP & - & - & 0,19 & 0,58 & 0,58 \\
\hline EGPU no Desmame & 0,11 & 0,62 & 0,68 & 0,03 & 0,87 \\
\hline EGPU no Parto & 0,21 & 0,16 & 0,07 & 0,003 & 0,13 \\
\hline EGPU na Sincronização & 0,06 & 0,31 & 0,11 & 0,10 & 0,07 \\
\hline EGPU aos 82 DPP & - & 0,40 & 0,17 & 0,09 & 0,10 \\
\hline EGPU aos 112 DPP & - & - & 0,06 & 0,07 & 0,13 \\
\hline Diferença de EGPU Desmame-Parto & 0,97 & 0,20 & 0,06 & 0,10 & 0,046 \\
\hline Diferença de EGPU Parto-Sincronização & 0,53 & 0,55 & 0,63 & 0,06 & 0,82 \\
\hline Diferença de EGPU Sincronização-82 DPP & - & 0,59 & 0,43 & 0,75 & 0,41 \\
\hline Diferença de EGPU 82-112 DPP & - & - & 0,39 & 0,90 & 0,82 \\
\hline Peso no Desmame & 0,19 & 0,19 & 0,26 & 0,01 & 0,71 \\
\hline Peso no Parto & 0,44 & 0,49 & 0,73 & 0,34 & 0,37 \\
\hline Peso na Sincronização & 0,68 & 0,27 & 0,25 & 0,11 & 0,76 \\
\hline Peso aos 82 DPP & - & 0,12 & 0,17 & 0,11 & 0,84 \\
\hline Peso aos 112 DPP & - & - & 0,40 & 0,20 & 0,73 \\
\hline Diferença de Peso Desmame-Parto & 0,33 & 0,25 & 0,17 & 0,006 & 0,38 \\
\hline Diferença de Peso Parto-Sincronização & 0,64 & 0,53 & 0,25 & 0,32 & 0,09 \\
\hline Diferença de Peso Sincronização-82 DPP & - & 0,33 & 0,64 & 0,83 & 0,26 \\
\hline Diferença de Peso 82-112 DPP & - & - & 0,27 & 0,54 & 0,30 \\
\hline Idade da vaca & 0,29 & 0,62 & 0,95 & 0,58 & 0,13 \\
\hline Raça do Touro Anterior & 0,07 & 0,10 & 0,20 & 0,53 & 0,31 \\
\hline Data do Parto da EM anterior & 0,25 & 0,48 & 0,22 & 0,17 & 0,10 \\
\hline Sexo do bezerro da EM anterior & 0,70 & 0,13 & 0,29 & 0,35 & 0,29 \\
\hline Peso aos 120 dias do Bezerro da EM anterior & 0,64 & 0,44 & 0,44 & 0,21 & - \\
\hline Peso aos 240 dias do Bezerro da EM anterior & 0,90 & 0,75 & 0,89 & 0,71 & 0,22 \\
\hline Data do Parto & $<0,0001$ & 0,96 & 0,61 & 0,22 & 0,11 \\
\hline Sexo do Bezerro & 0,53 & 0,38 & 0,39 & 0,06 & 0,90 \\
\hline Raça do Touro & 0,57 & 0,77 & 0,35 & 0,11 & 0,09 \\
\hline
\end{tabular}

CL - Corpo Lúteo; ECC - escore de Condição Corporal, EGPU - Espessura da Gordura Subcutânea; Sistema de Cobertura - IA ou Monta Natural; EM - estação de Monta; DPP - dias pós-parto. 


\subsubsection{Taxa de Ciclicidade}

Os dados de ECC no momento do desmame ( $P=0,08)$, EGPU no momento da sincronização $(P=0,06)$ e raça do touro utilizado na estação de monta anterior $(P=0,07)$ tenderam a apresentar efeito sobre a taxa de ciclicidade. Ainda, o ECC no momento de sincronização $(P=0,04$; Figura 7$)$ e a data do parto $(P<0,0001$; Figura 8) apresentaram efeito significativo sobre essa taxa.

A probabilidade de ciclicidade no início do protocolo de sincronização em função do escore de condição corporal no momento da sincronização pode ser estimada através da equação:

$$
\text { Probabilidade de ciclicidade }=\frac{\exp (-2,4624+0,6211 \cdot \text { ECCSinc })}{1+\exp (-2,4624+0,6211 \cdot \text { ECCSinc })}
$$

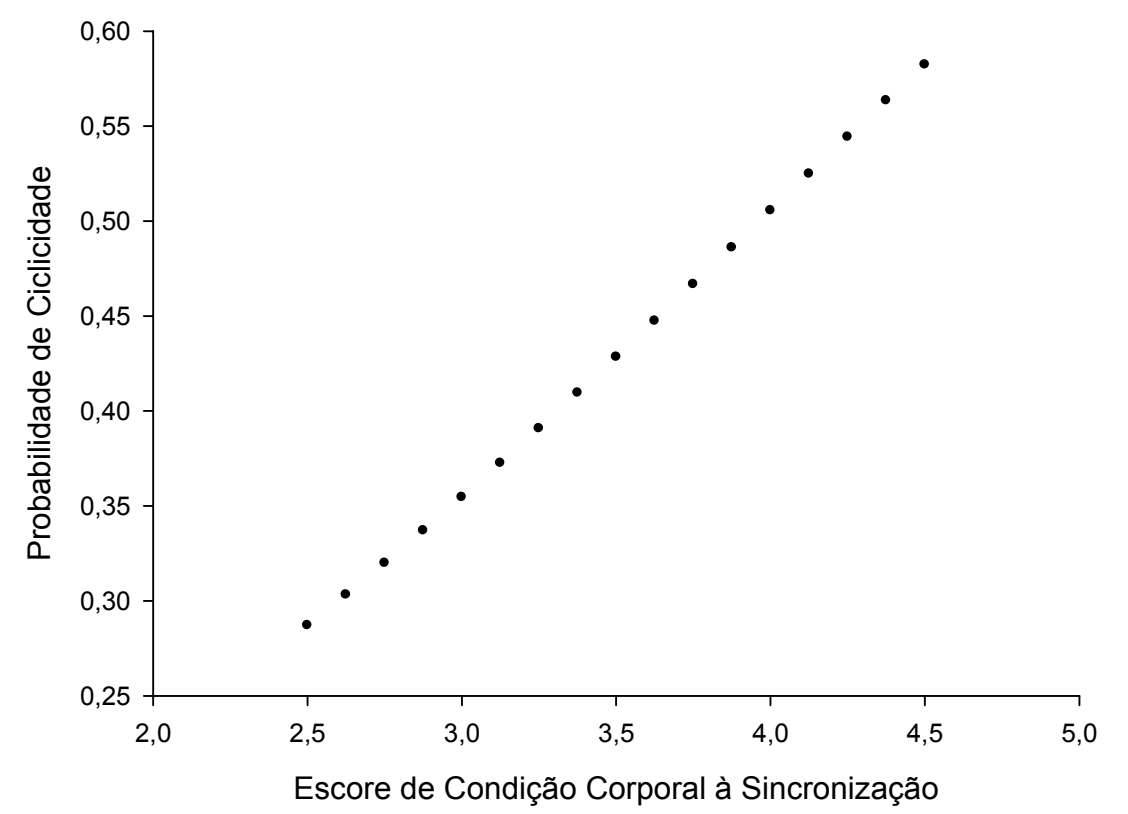

Figura 7 - Representação gráfica da probabilidade de ciclicidade no início do protocolo de sincronização em função do escore de condição corporal no momento da sincronização $(P=0,04)$ em vacas Nelore (Bos indicus) 
A probabilidade de ciclicidade no início do protocolo de sincronização em função da data do parto pode ser estimada através da equação:

Probabilidade de ciclicidade $=\frac{\exp (0,98797-0,1090 \cdot \text { DatadoParto })}{1+\exp (0,98797-0,1090 \cdot \text { DatadoParto })}$

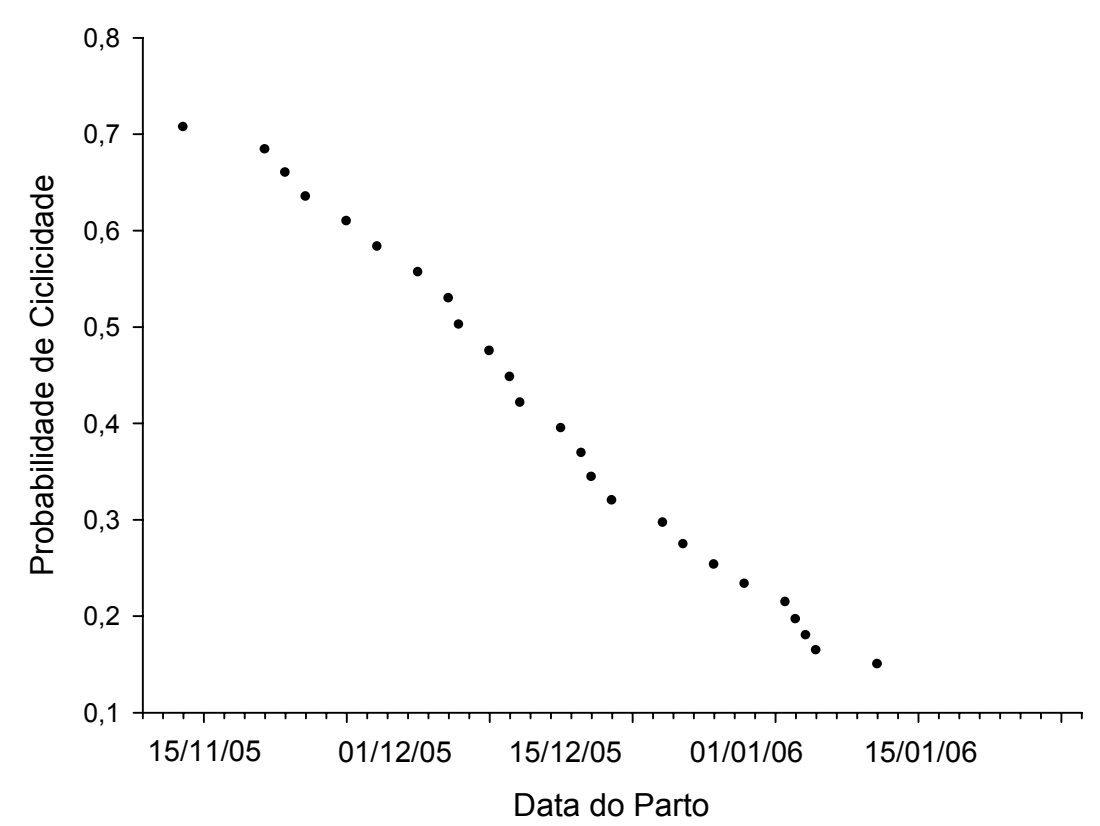

Figura 8 - Representação gráfica da probabilidade de ciclicidade no início do protocolo de sincronização em função da data do parto $(P=0,0001)$ em vacas Nelore (Bos indicus)

Ainda, foi realizada a divisão dos animais em grupos experimentais de acordo com o ECC $(\leq 3,0$ ou $>3,0)$ ou EGPU $(\leq 0,6$ ou $>0,6 \mathrm{~cm})$. As taxas de ciclicidade para ECC $(\leq 3,0$ vs. $>3,0)$ e para EGPU $(\leq 0,6$ ou $>0,6 \mathrm{~cm})$ foram respectivamente: $33,8 \%$ $(44 / 130)^{\text {b }}$ vs. $43,4 \%\left(59 / 136^{a}, P=0,002\right)$ e $36,0 \%(54 / 150)^{b}$ vs. $42,2 \%\left(49 / 116^{a}, P=\right.$ 0,009).

Foram analisadas as diferenças de ECC no momento da sincronização segundo o status ovariano e a etapa de sincronização (primeira vs segunda; Tabela 10). Também, foram verificados os efeitos principais, pois não ocorreu interação entre etapa e ECC no início da sincronização ( $P=0,22$, Tabela 11). 
Tabela 10 - Escore de condição corporal no momento da sincronização de acordo com a etapa de sincronização (primeira vs segunda) e o status ovariano de vacas Nelore (Bos indicus)

\begin{tabular}{cccc}
\hline \multirow{2}{*}{ Status Ovariano } & \multicolumn{2}{c}{ Etapa de Sincronização } & \multirow{2}{*}{$\mathrm{P}^{*}$} \\
\cline { 2 - 3 } & Primeira & Segunda & \\
\hline Anestro & $3,06 \pm 0,05$ & $3,26 \pm 0,05$ & 0,02 \\
Ciclando & $3,22 \pm 0,05$ & $3,56 \pm 0,10$ & 0,01 \\
$\mathrm{P}^{* *}$ & 0,02 & 0,003 & \\
\hline
\end{tabular}

* Valor de $\mathrm{P}$ para comparação entre primeira e segunda etapa.

** Valor de P para comparação entre vacas ciclando ou em anestro.

Tabela 11 - Escore de condição corporal no início da sincronização de acordo com a etapa de sincronização (primeira vs segunda) e o status ovariano (efeito principal)

\begin{tabular}{cccc}
\hline \multicolumn{4}{c}{ Efeito Principal } \\
\hline Status Ovariano & Etapa de Sincronização & $\mathrm{N}$ & ECC na Sincronização \\
\hline Anestro & 163 & $3.17 \pm 0.03^{\mathrm{a}}$ \\
Ciclando & 103 & $3.28 \pm 0.04^{\mathrm{b}}$ \\
& Primeira & 156 & $3,14 \pm 0,03^{\mathrm{c}}$ \\
& Segunda & 110 & $3,21 \pm 0,04^{\mathrm{d}}$ \\
\hline
\end{tabular}

$a \neq b, P=0,0002 ; c \neq d, P=<0,0001$

\subsubsection{Taxa de concepção à IATF (30 dias de gestação)}

Os dados de ECC próximo ao parto $(P=0,07)$ e a diferença de ECC entre o parto e a sincronização $(P=0,10)$ tenderam apresentar efeito sobre a taxa de concepção à IATF aos 30 dias de gestação (82 dias pós-parto).

\subsubsection{Taxa de concepção á IATF (60 dias de gestação)}

O ECC aos 112 dias pós-parto $(P=0,07)$; a diferença de ECC entre o parto e a sincronização ( $P=0,09)$, a EGPU próxima ao parto $(P=0,07)$; a EGPU aos 112 dias pós-parto $(P=0,06)$ e a diferença de EGPU entre o desmame e o parto $(P=0,06)$ 
tenderam a apresentar efeito sobre a taxa de concepção à IATF aos 60 dias de gestação (112 dias pós-parto).

O ECC próximo ao parto ( $P=0,02$; Figura 9) apresentou efeito significativo na taxa de concepção à IATF aos 60 dias de gestação.

A probabilidade de concepção à IATF aos 60 dias de gestação em função do ECC no próximo ao parto pode ser estimada através da equação:

Probabilidade de concepção $=\frac{\exp (-2,3345+0,7641 \cdot \text { ECCParto })}{1+\exp (-2,3345+0,7641 \cdot \text { ECCParto })}$

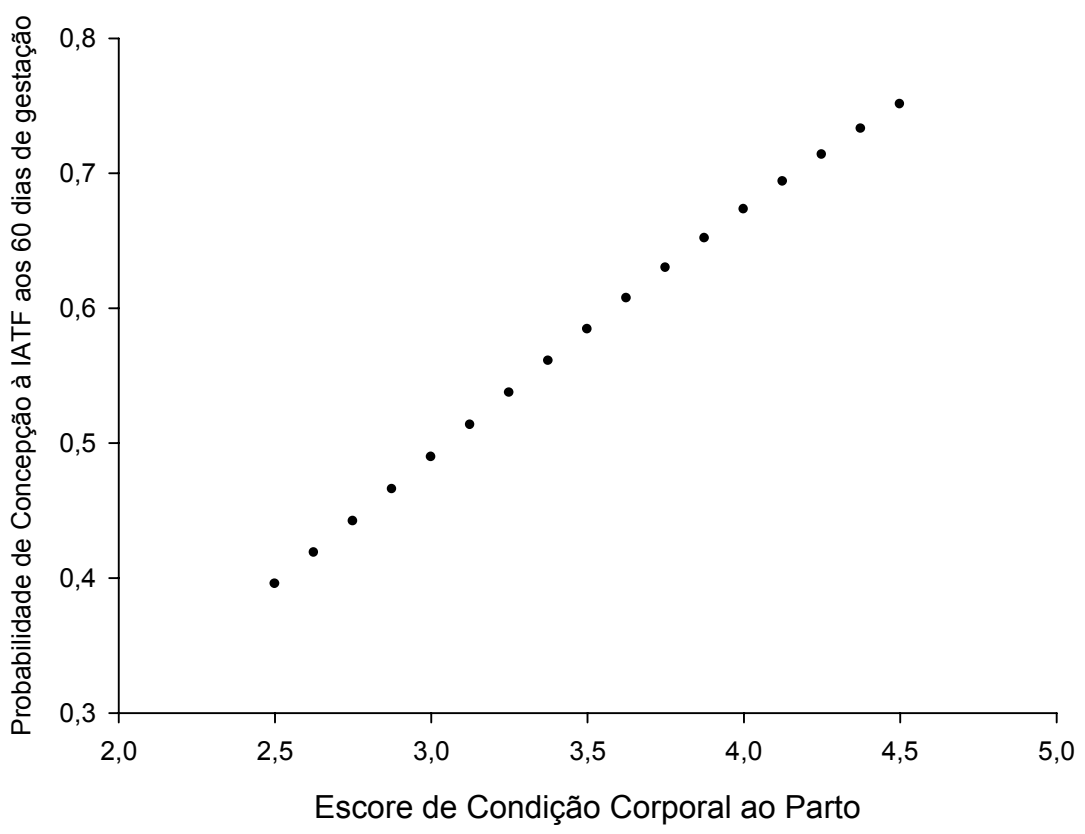

Figura 9 - Representação gráfica da probabilidade de concepção à IATF aos 60 dias de gestação (112 dias pós-parto) em função do escore de condição corporal próximo ao parto $(P=0,02)$ em vacas Nelore (Bos indicus) 


\subsubsection{Taxa de Prenhez Acumulada (até 82 dias pós-parto; IATF com repasse de touro)}

Os dados de EGPU no momento da sincronização $(P=0,10)$, de EGPU aos 82 dias pós-parto $(P=0,09)$, de EGPU aos 112 dias pós-parto $(P=0,07)$, de diferença da EGPU entre o desmame e o parto $(P=0,10)$, de diferença da EGPU entre o parto e a sincronização $(P=0,06)$ e de sexo do bezerro atual $(P=0,06$; Figura 10$)$ tenderam a apresentar efeito sobre a taxa de prenhez acumulada aos 102 dias pósparto.

Os dados do ECC no desmame ( $P=0,01$; Figura 11), do ECC próximo ao parto $(P=0,0007$; Figura 12), do ECC aos 112 dias pós-parto $(P=0,048$; Figura 13), de diferença do ECC entre o parto e a sincronização ( $P=0,03$; Figura 14), da EGPU no desmame $(P=0,03$; Figura 15$)$, da EGPU no parto ( $P=0,003$; Figura 16$)$, do peso no desmame $(P=0,01$; Figura 17) e de diferença do peso entre o desmame e o parto $(P=0,006$; Figura 18$)$ apresentaram efeito significativo na taxa de prenhez acumulada aos 82 dias pós-parto. 
A probabilidade de prenhez acumulada aos 82 dias pós-parto em função do sexo do bezerro pode ser estimada através da equação:

Probabilidade de prenhez $=\frac{\exp (1,1087-0,5045 . \text { SexoBezerro })}{1+\exp (1,1087-0,5045 . \text { SexoBezerro })}$

para macho $=0$ e fêmea $=1$

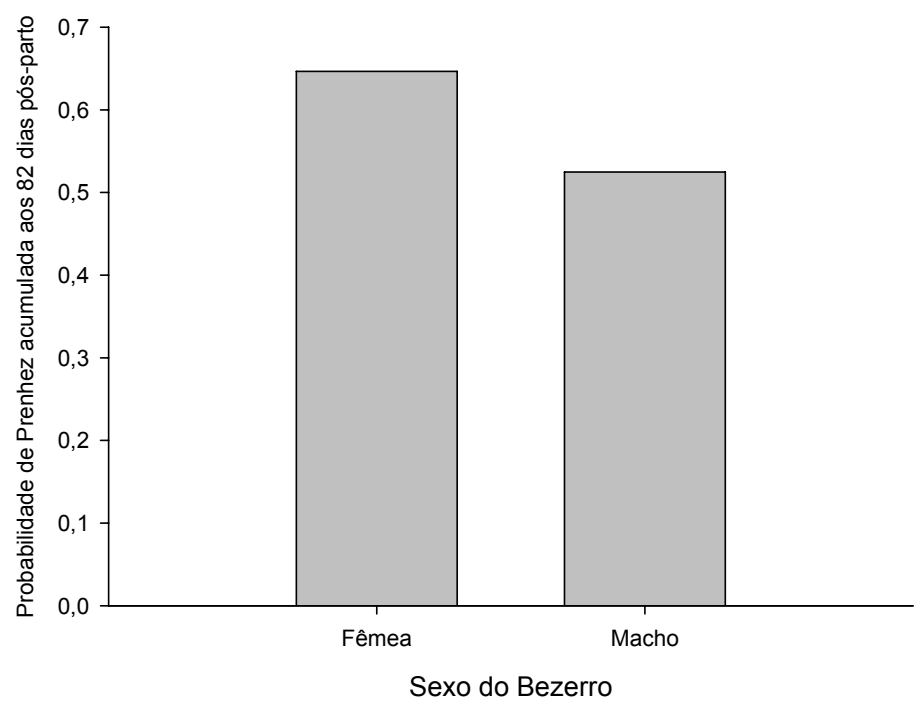

Figura 10 - Representação gráfica da probabilidade de prenhez acumulada aos 82 dias pósparto em função do sexo do bezzero $(P=0,06)$ de vacas Nelore (Bos indicus) 
A probabilidade de prenhez acumulada aos 82 dias pós-parto em função do ECC no desmame pode ser estimada através da equação:

$$
\text { Probabilidade de prenhez }=\frac{\exp (-2,2959+0,9944 \cdot E C \text { CDesm })}{1+\exp (-2,2959+0,9944 \cdot E C \text { CDesm })}
$$

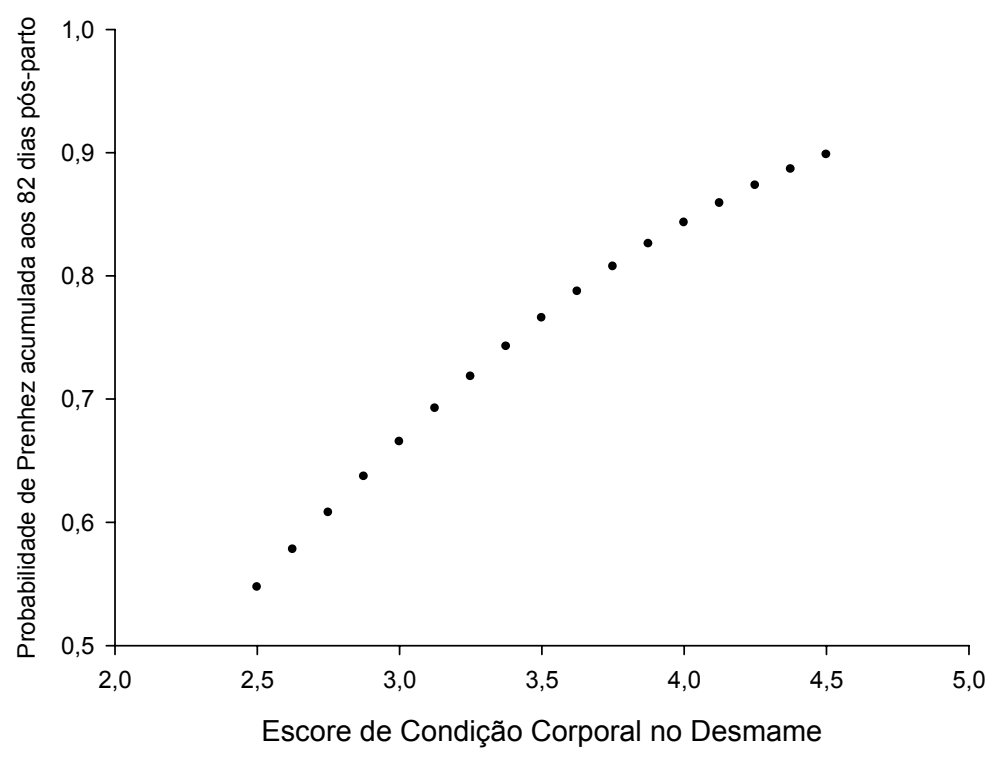

Figura 11 - Representação gráfica da probabilidade de prenhez acumulada aos 82 dias pósparto em função do escore de condição corporal no desmame $(P=0,01)$ em vacas Nelore (Bos indicus) 
A probabilidade de prenhez acumulada aos 82 dias pós-parto em função do ECC próximo ao parto pode ser estimada através das equação:

$$
\text { Probabilidade de prenhez }=\frac{\exp (-3,4806+1,2635 . \text { ECCParto })}{1+\exp (-3,4806+1,2635 . \text { ECCParto })}
$$

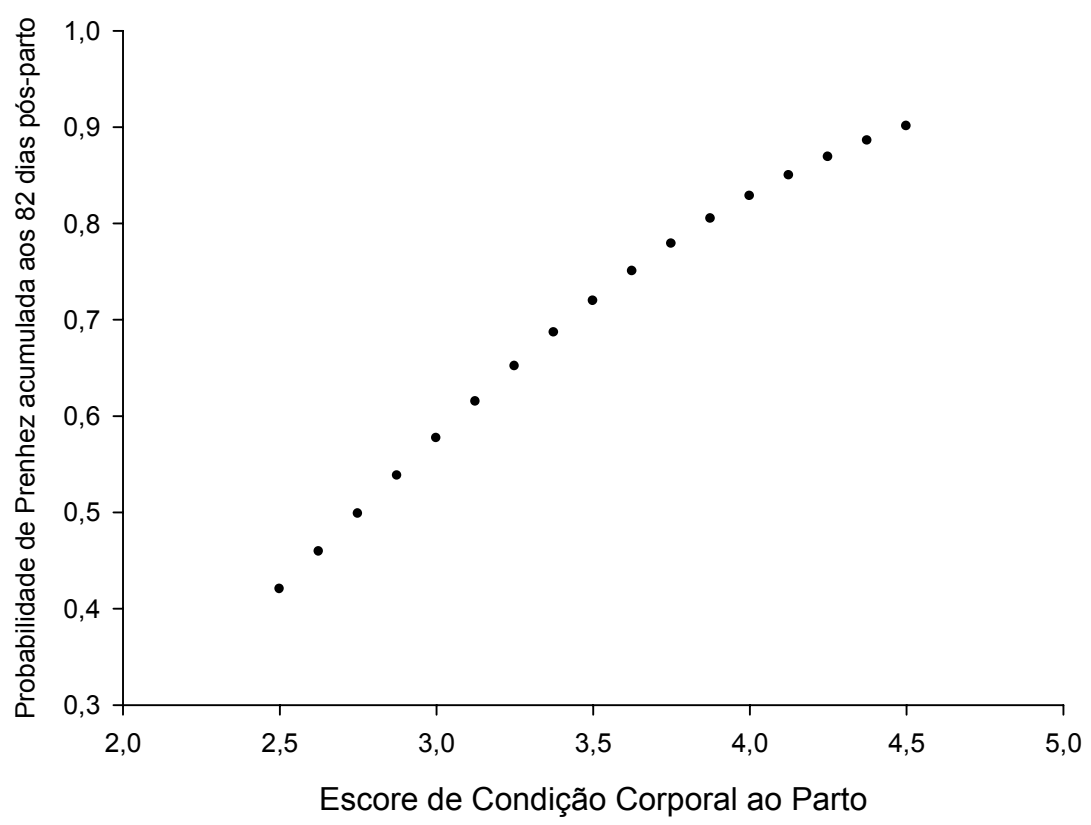

Figura 12 - Representação gráfica da probabilidade de prenhez acumulada aos 82 dias pósparto em função do escore de condição corporal ao parto $(P=0,0007)$ em vacas Nelore (Bos indicus) 
A probabilidade de prenhez acumulada aos 82 dias pós-parto em função do ECC aos 112 dias pós-parto pode ser estimada através da equação:

$$
\text { Probabilidade de prenhez }=\frac{\exp (-1,2474+0,6642 \cdot E C C D i a g 102 d)}{1+\exp (-1,2474+0,6642 \cdot E C \text { CDiag } 102 d)}
$$

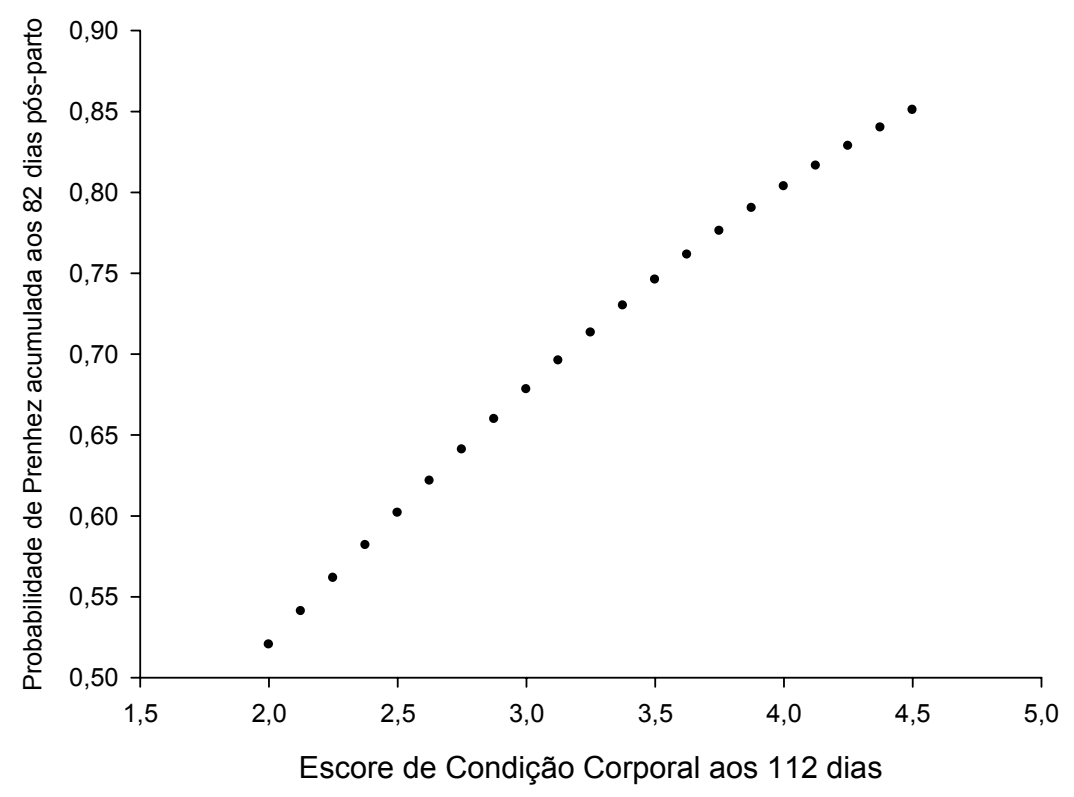

Figura 13 - Representação gráfica da probabilidade de prenhez acumulada aos 82 dias pósparto em função do escore de condição corporal aos 112 dias pós-parto ( $P=$ 0,048 ) em vacas Nelore (Bos indicus) 
A probabilidade de prenhez acumulada aos 82 dias pós-parto em função da diferença de ECC entre o parto e a sincronização pode ser estimada através da equação:

$$
\text { Probabilidade de prenhez }=\frac{\exp (0,6703-0,7657 . \text { ECCParto }- \text { Sinc })}{1+\exp (0,6703-0,7657 \cdot \text { ECCParto }- \text { Sinc })}
$$

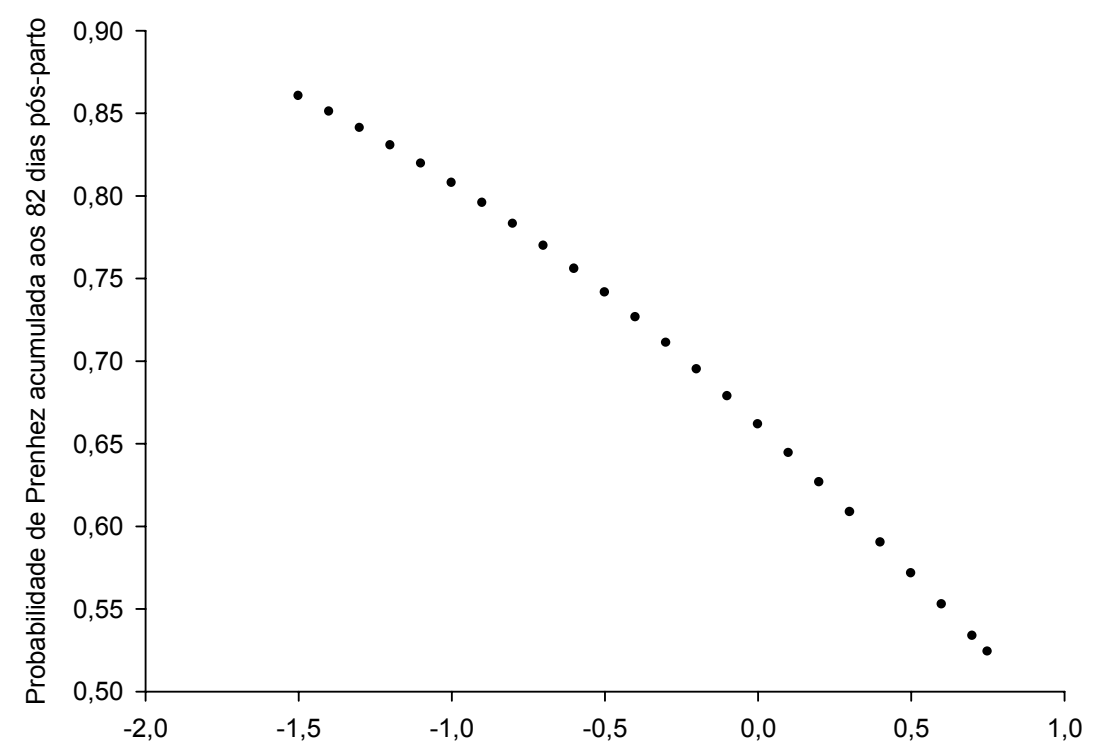

Diferença de Escore de Condição Corporal entre o Parto e a Sincronização

Figura 14 - Representação gráfica da probabilidade de prenhez acumulada aos 82 dias pósparto em função da diferença de escore de condição corporal entre o parto e a sincronização $(P=0,03)$ em vacas Nelore (Bos indicus)

Entretanto, não foi encontrado efeito da diferença do ECC entre o parto e a sincronização, quando apenas os animais com médio e alto ECC ao parto $(\geq 3,00)$ foram analisados $(P=0,63)$. Apesar disso o comportamento da reta de probabilidade continuou sendo o mesmo.

Este mesmo comportamento foi observado para a diferença de EGPU entre o parto e a sincronização, com a ressalva que para EGPU os dados apresentaram apenas tendência $(P=0,06)$. 
A probabilidade de prenhez acumulada aos 82 dias pós-parto em função do EGPU no desmame pode ser estimada através da equação:

$$
\text { Probabilidade de prenhez }=\frac{\exp (-0,0823+1,3913 \cdot \text { EGPUDesm })}{1+\exp (-0,0823+1,3913 \cdot \text { EGPUDesm })}
$$

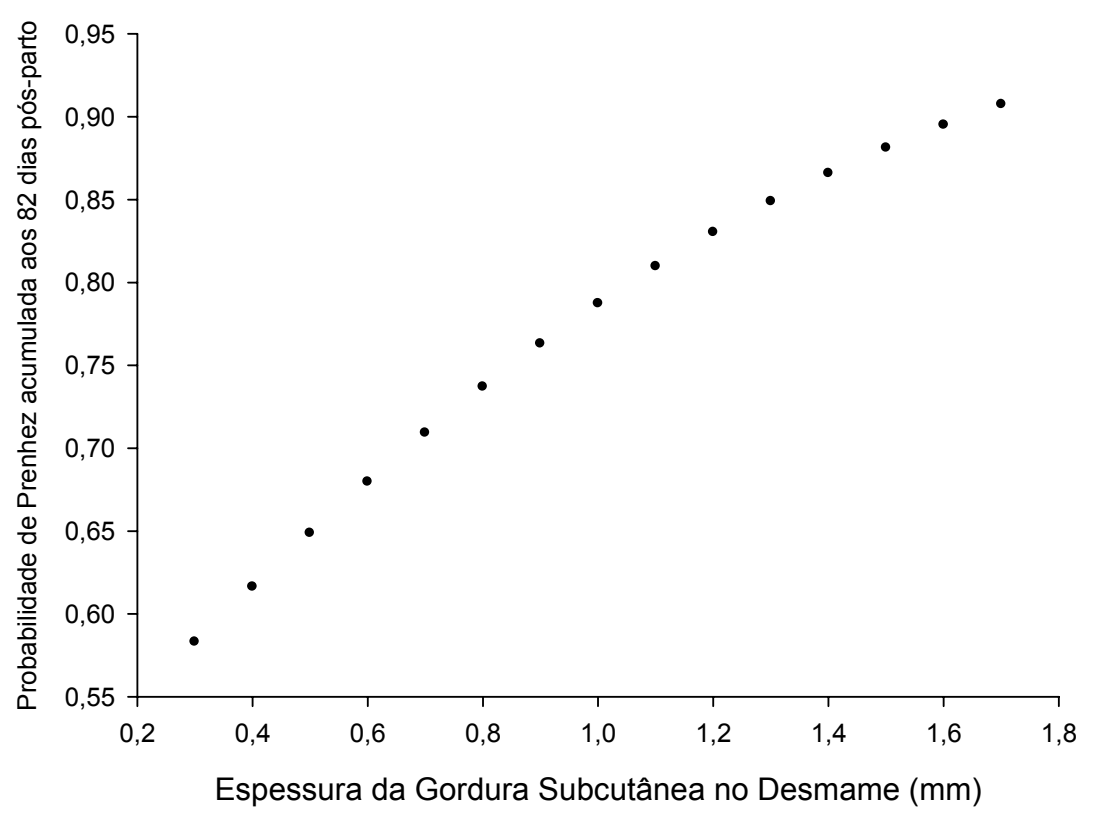

Figura 15 - Representação gráfica da probabilidade de prenhez acumulada aos 82 dias pósparto em função da espessura da gordura subcutânea no desmame $(P=0,03)$ em vacas Nelore (Bos indicus) 
A probabilidade de prenhez acumulada aos 82 dias pós-parto em função do EGPU no parto pode ser estimada através da equação:

$$
\text { Probabilidade de prenhez }=\frac{\exp (-0,5665+1,5701 . \text { EGPUParto })}{1+\exp (-0,5665+1,5701 . \text { EGPUParto })}
$$

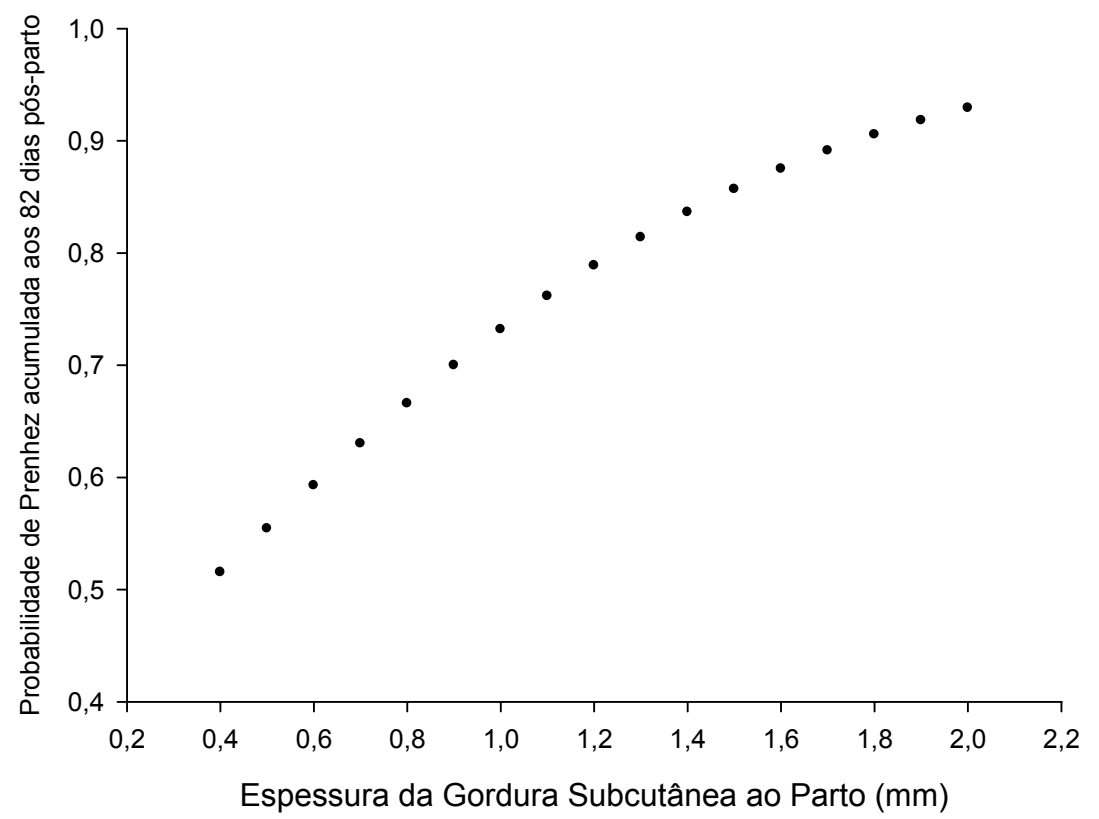

Figura 16 - Representação gráfica da probabilidade de prenhez acumulada aos 82 dias pósparto em função da espessura da gordura subcutânea ao parto $(P=0,003)$ em vacas Nelore (Bos indicus) 
A probabilidade de prenhez acumulada aos 82 dias pós-parto em função do peso da vaca no desmame pode ser estimada através da equação:

$$
\text { Probabilidade de prenhez }=\frac{\exp (-2,5460+0,0088 . \text { PesoDesm })}{1+\exp (-2,5460+0,0088 . \text { PesoDesm })}
$$

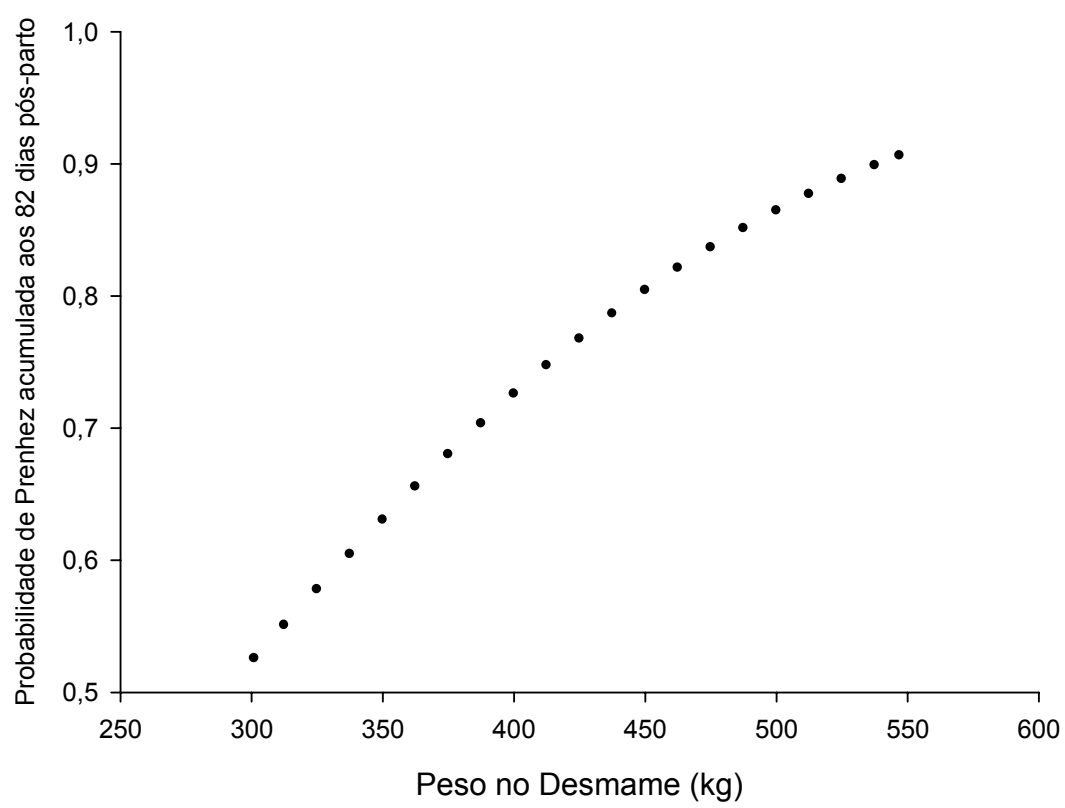

Figura 17 - Representação gráfica da probabilidade de prenhez acumulada aos 82 dias pósparto em função do peso da vaca no desmame $(P=0,01)$ em vacas Nelore (Bos indicus) 
A probabilidade de prenhez acumulada aos 82 dias pós-parto em função da diferença de peso entre o desmame e o parto pode ser estimada através da equação:

$$
\text { Probabilidade de prenhez }=\frac{\exp (1,4322-0,0175 . \text { PesoDesm }- \text { Parto })}{1+\exp (1,4322-0,0175 . \text { PesoDesm }- \text { Parto })}
$$

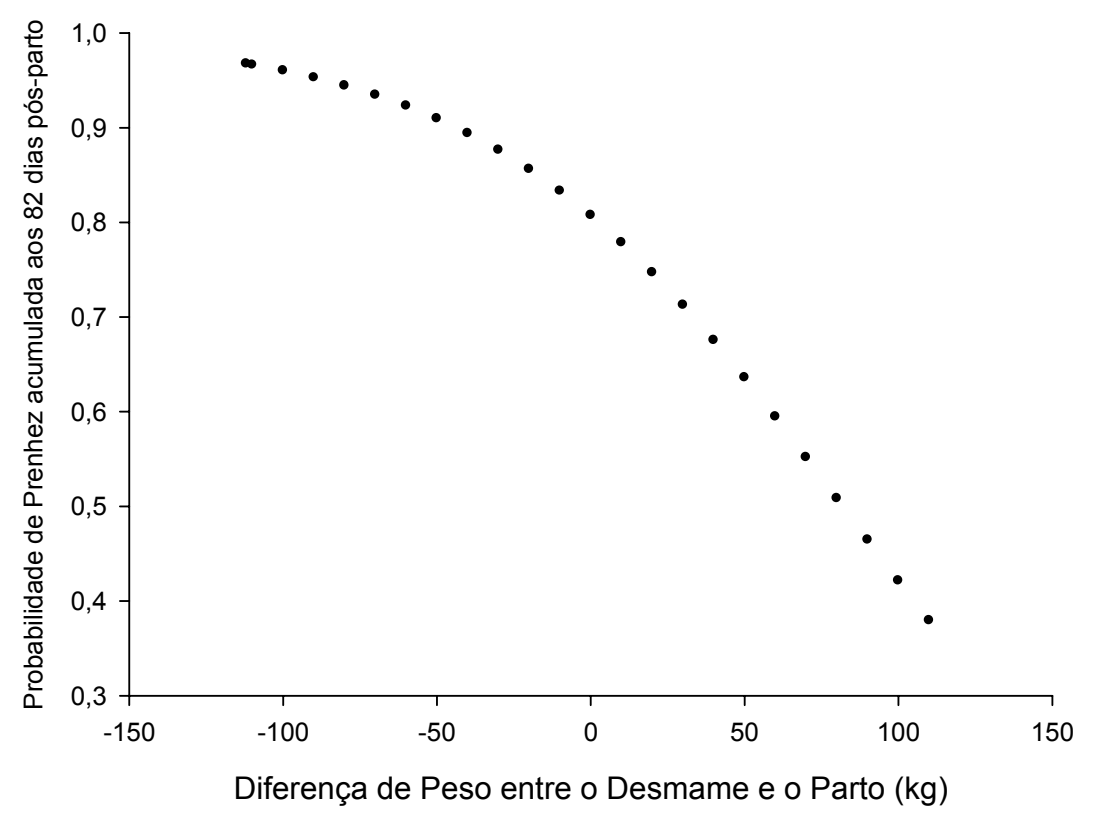

Figura 18 - Representação gráfica da probabilidade de prenhez acumulada aos 82 dias pósparto em função da diferença de peso entre o desmame e o parto $(P=0,006)$ em vacas Nelore (Bos indicus) 


\subsubsection{Perda Gestacional à IATF}

Os dados do ECC próximo ao parto $(P=0,05)$, da EGPU na sincronização ( $P=$ $0,07)$, de diferença do peso entre o parto e a sincronização $(P=0,09)$ e da raça do touro $(P=0.09)$ tenderam apresentar efeito sobre a taxa de perda de gestação (entre 82 e 112 dias pós-parto).

Os dados do ECC aos 82 dias pós-parto ( $P=0,046$; Figura 19), do ECC aos 112 dias pós-parto ( $P=0,02 ;$ Figura 20) e de diferença da EGPU entre o desmame e o parto $(P=0,046$; Figura 21$)$ apresentaram efeito significativo sobre a perda de gestação.

A probabilidade de perda de gestação à IATF em função do ECC aos 82 dias pós-parto pode ser estimada através da equação:

$$
\text { Probabilidade de perda }=\frac{\exp (4,3271-2,4675 \cdot \text { ECCDiag } 82 \text { dias })}{1+\exp (4,3271-2,4675 \cdot \text { ECCDiag } 82 \text { dias })}
$$

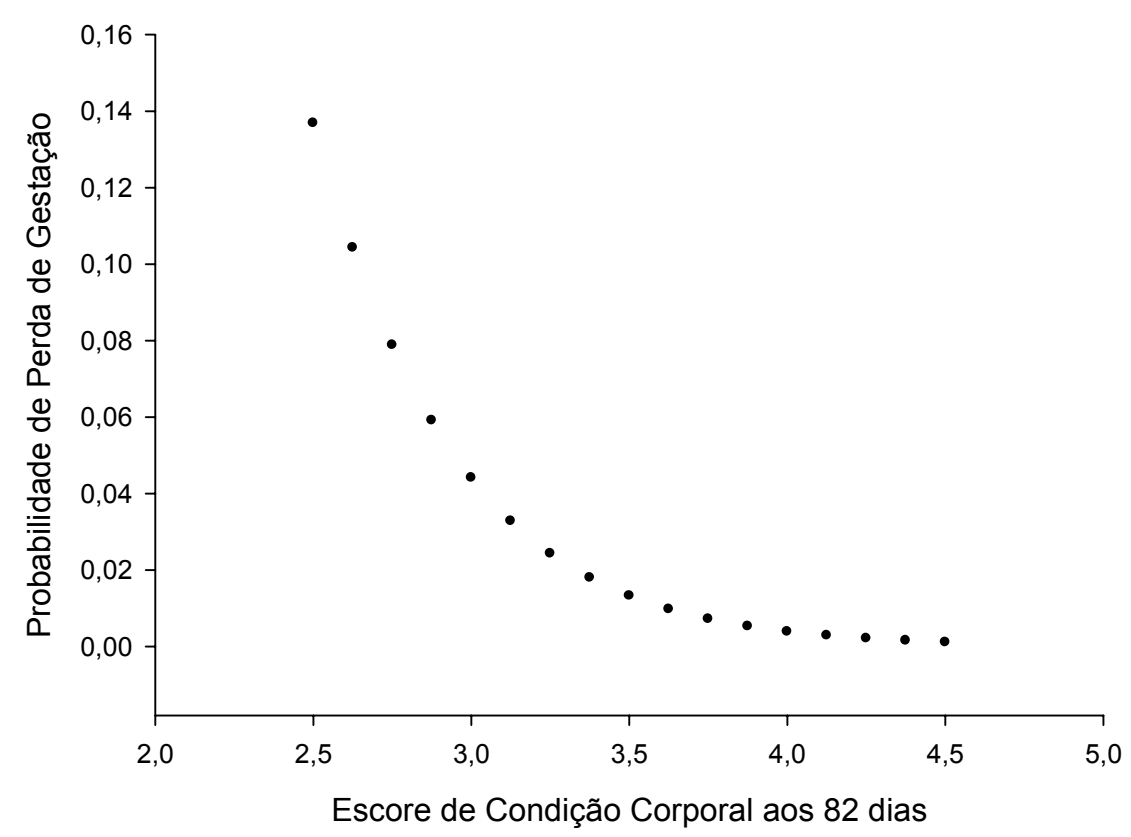

Figura 19 - Representação gráfica da probabilidade de perda de gestação à IATF (entre 30 e 60 dias de gestação) em função do escore de condição corporal aos 82 dias $(P=$ 0,046 ) em vacas Nelore (Bos indicus) 
A probabilidade de perda de gestação à IATF em função do ECC aos 112 dias pode ser estimada através da equação:

$$
\text { Probabilidade de perda }=\frac{\exp (3,7694-2,2214 \cdot E C C D i a g 102 \text { dias })}{1+\exp (3,7694-2,2214 \cdot E C \text { CDiag102dias })}
$$

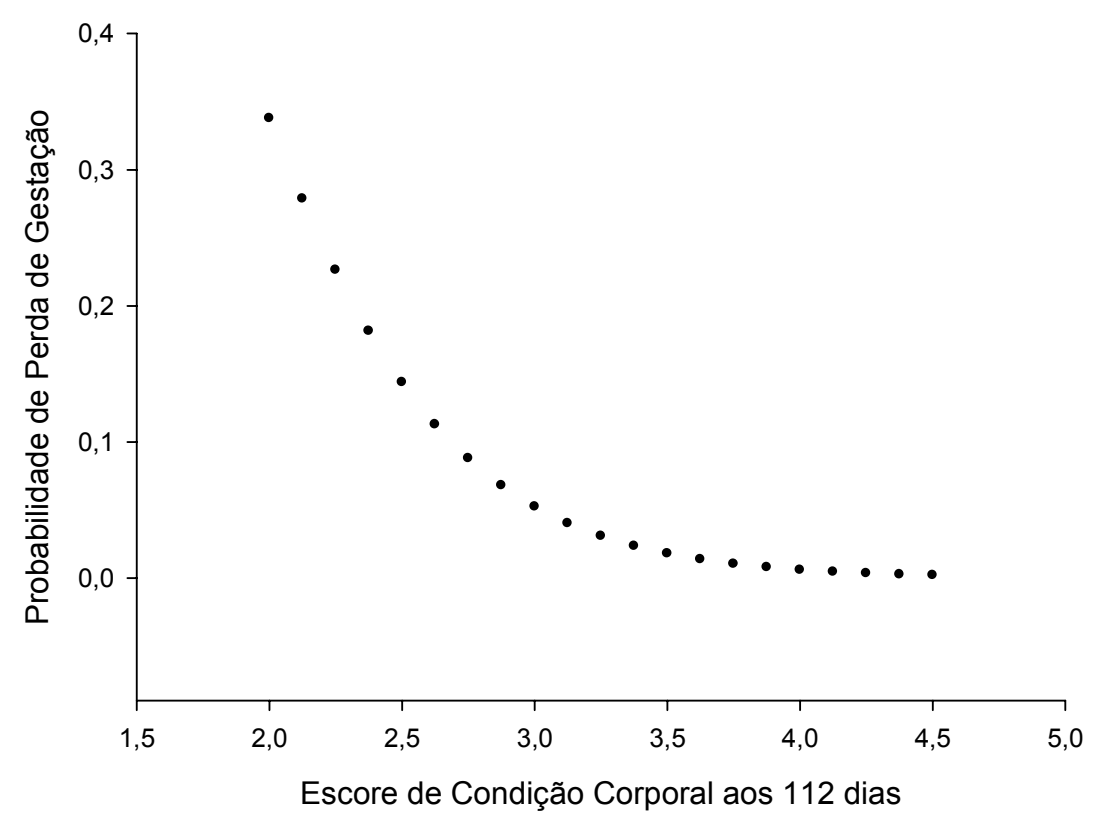

Figura 20 - Representação gráfica da probabilidade de perda de gestação à IATF (entre 30 e 60 dias de gestação) em função do escore de condição corporal aos 112 dias pós-parto ( $P=0,02)$ em vacas Nelore (Bos indicus) 
A probabilidade de perda de gestação à IATF em função da diferença de EGPU entre a desmame e o parto pode ser estimada através da equação:

$$
\text { Probabilidade de perda }=\frac{\exp (-2,3798-3,2551 . E G P U D e s m-\text { Parto })}{1+\exp (-2,3798-3,2551 . E G P U D e s m-\text { Parto })}
$$

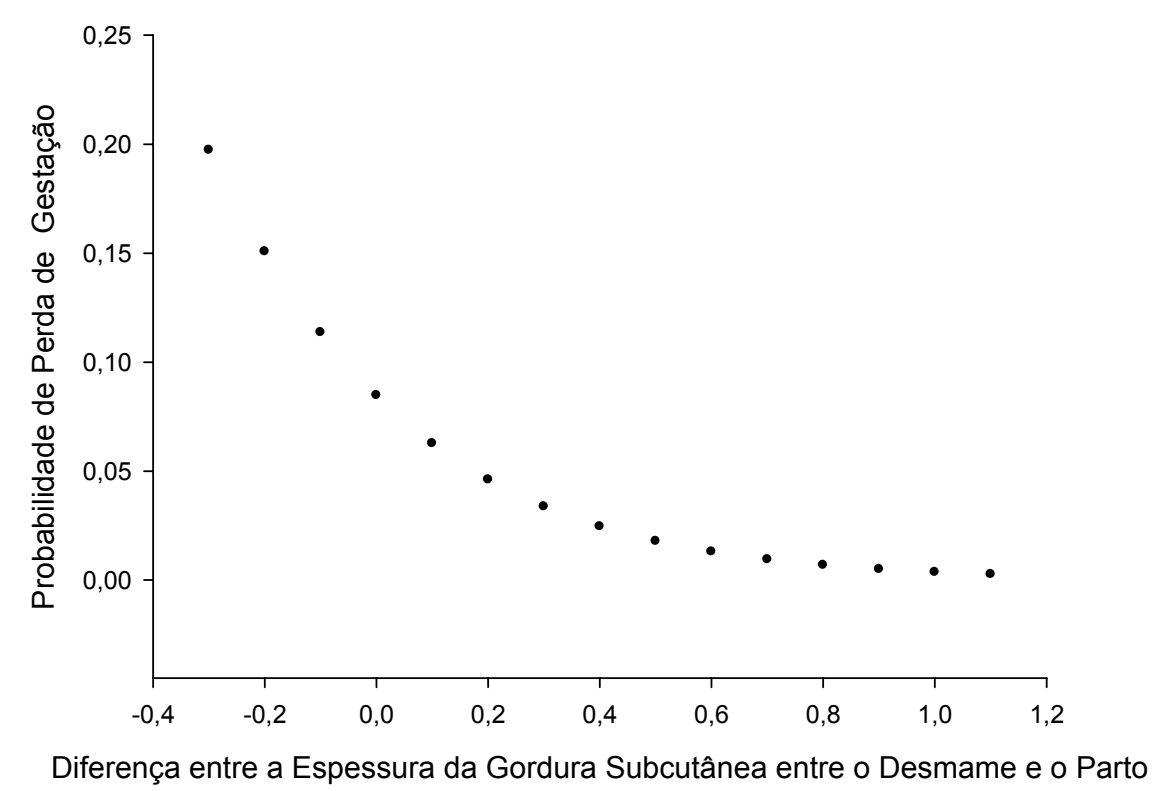

Figura 21 - Representação gráfica da probabilidade de perda de gestação à IATF (entre 30 e 60 de gestação) em função da diferença de espessura da gordura subcutânea entre o desmame e o parto $(P=0,046)$ em vacas Nelore (Bos indicus)

Ainda, foram analisados os dados de diferença de ECC, EGPU e peso, respectivamente, entre o parto e o diagnóstico realizado aos 82 dias $(0,90 ; 0,78$; $0,36)$, entre o parto e o diagnóstico realizado aos 112 dias $(0,61 ; 0,70 ; 0,08)$ e entre a sincronização e o diagnóstico realizado aos 112 dias $(0,18 ; 0,32 ; 0,96)$. Entretanto, não foi detectado diferença entre os animais que perderam a gestação e os que mantiveram. Também não foi detectada diferença de perda de prenhez entre as diferentes classes de ECC, EGPU e peso. 
Os animais foram divididos em diferentes classes de acordo com o escore de condição corporal em três momentos (Figura 22):

1. No desmame.

2. Próximo ao parto.

3. Na sincronização.

$\mathrm{Na}$ análise de regressão linear para verificação do efeito das classes de escore de condição nos três momentos (no desmame, próximo ao parto e na sincronização; Figura 23) sobre a taxa de prenhez acumulada aos 82 dias pós-parto, pôde-se verificar que tanto a classe de escore no momento do desmame, quanto próximo ao parto apresentaram efeito significativo no modelo de regressão $(P=$ 0,006 e 0,0007 , respectivamente), fato não observado no momento da sincronização $(P=0,23)$.

Outro ponto analisado foi à diferença de escore de condição corporal entre o desmame e o parto (Tabela 12), assim como entre o parto e a sincronização (Tabela 13). Fixando o parto como ponto de divisão de classe de condição corporal, notamos que os animais com menor escore de condição praticamente não apresentaram ganho de condição corporal entre o desmame e o parto $(0,01 \pm 0,04)$ e tiveram menor perda de escore entre o parto e a sincronização $(0,03 \pm 0,04)$. 

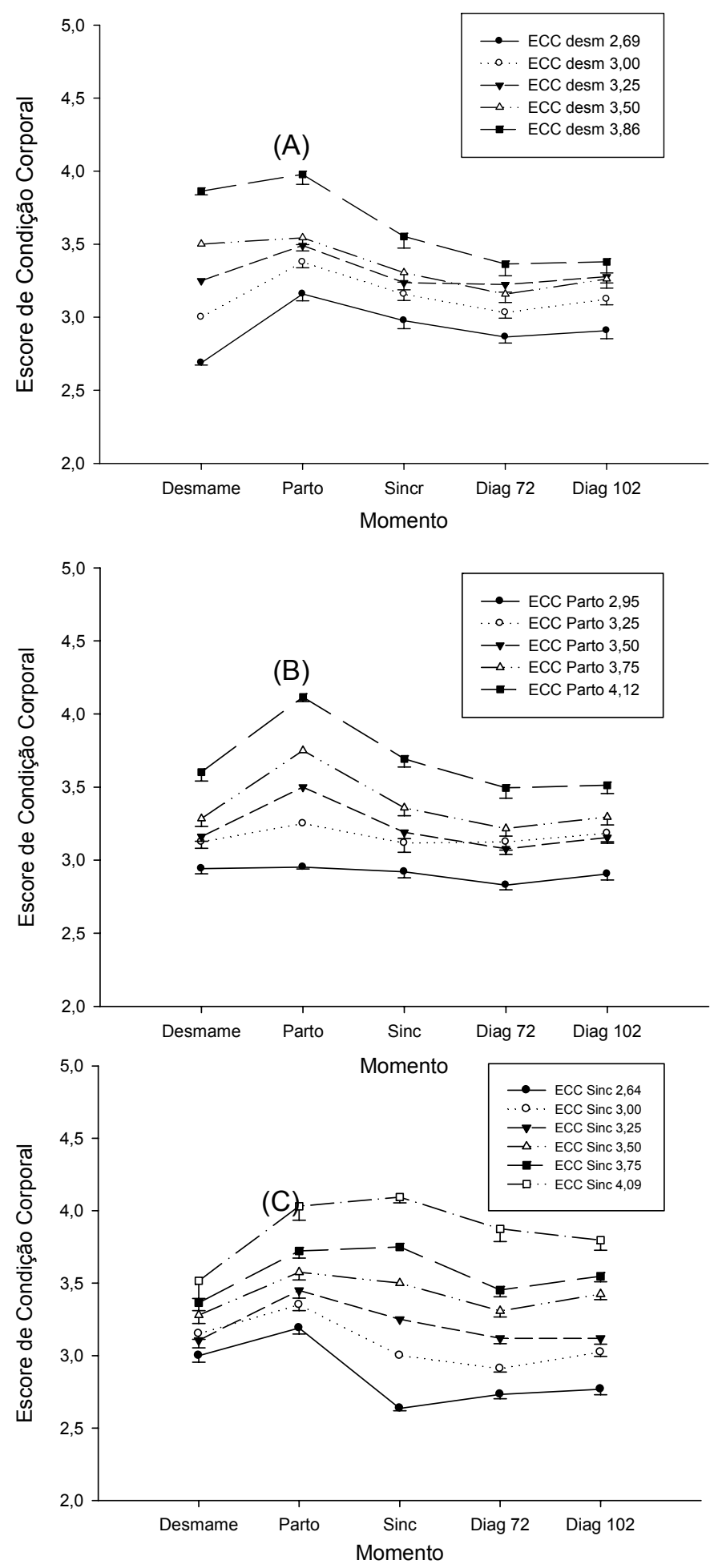

ECC - escore de condição corporal; Desm - desmame; Sinc - sincronização

Figura 22 - Representação gráfica da evolução do escore de condição corporal segundo cada classe e o momento de classificação em vacas Nelore (Bos indicus): (A) no desmame; (B) próximo ao parto; (C) na sincronização 


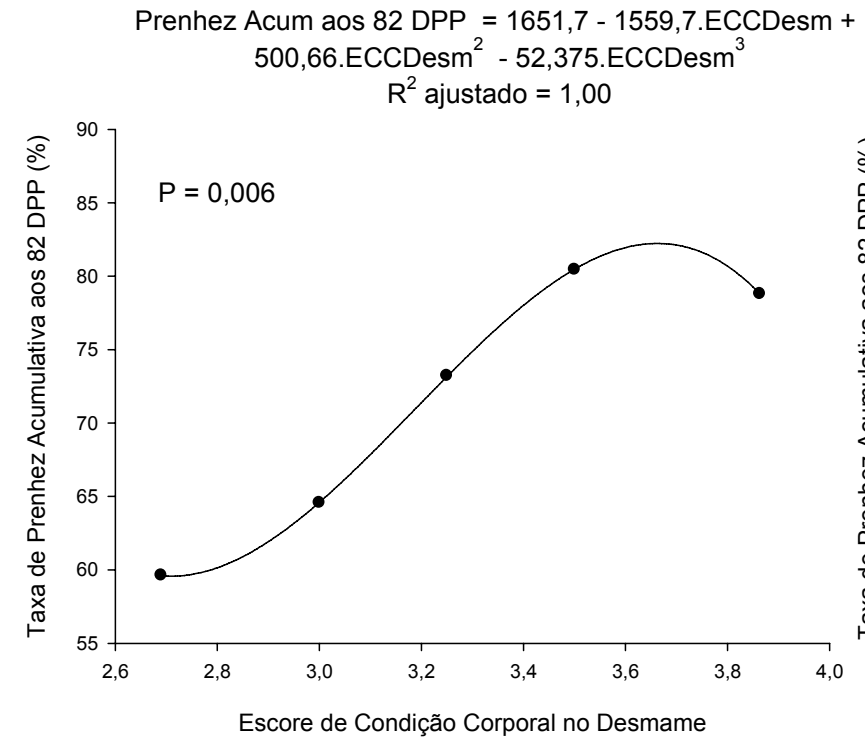

(A)
Prenhez Acum aos 82 DPP $=-15,147+24,497$. ECCParto $R^{2}=0,98$

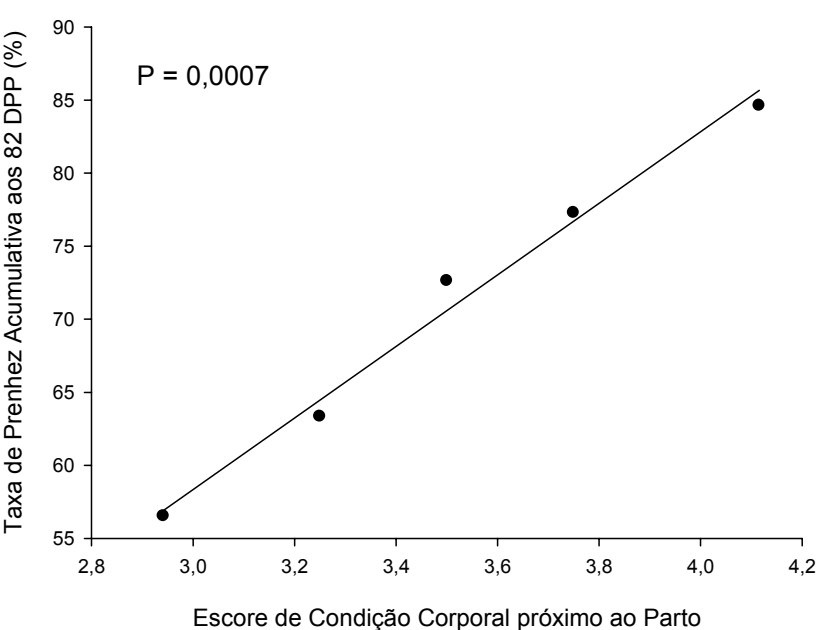

(B)
Prenhez Acum aos 82 DPP $=38,644+10,018$.ECCSinc $R^{2}=0,16$

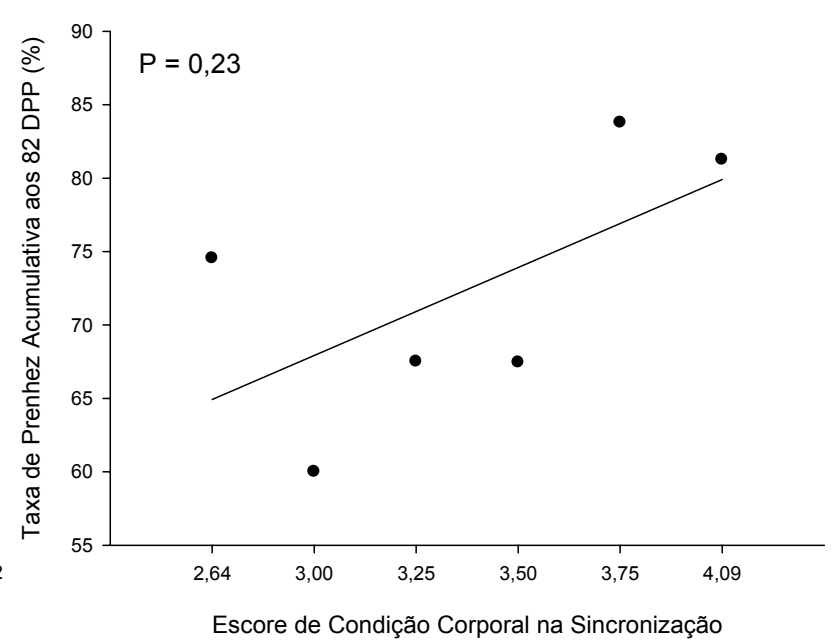

(C)

ECC - escore de condição corporal; Desm - desmame; Sinc - sincronização

Figura 23 - Gráfico de dispersão e reta de regressão do escore de condição corporal e taxa de prenhez acumulada aos 82 dias pós-parto em vacas Nelore (Bos indicus): (A) escore de condição corporal no desmame; (B) escore de condição corporal próximo ao parto; (C) escore de condição corporal na sincronização 
Tabela 12 - Diferença de escore de condição corporal entre o desmame e o parto em vacas Nelore (Bos indicus)

\begin{tabular}{ccc}
\hline ECC no Parto & N & Diferença de ECC entre o desmame e o parto \\
\hline 2,94 & 69 & $0,01 \pm 0,04^{\mathrm{c}}$ \\
3,25 & 30 & $0,13 \pm 0,04^{\mathrm{c}}$ \\
3,50 & 84 & $0,34 \pm 0,03^{\mathrm{b}}$ \\
3,75 & 44 & $0,47 \pm 0,05^{\mathrm{ab}}$ \\
4,12 & 39 & $0,51 \pm 0,05^{\mathrm{a}}$ \\
\hline
\end{tabular}

ECC - escore de condição corporal; $a \neq b \neq c ; P<0,05$

Tabela 13 - Diferença de escore de condição corporal entre o parto e a sincronização em vacas Nelore (Bos indicus)

\begin{tabular}{ccc}
\hline ECC no Parto & $\mathrm{N}$ & Diferença de ECC entre o parto e a sincronização \\
\hline 2,94 & 69 & $-0.03 \pm 0.04^{\mathrm{c}}$ \\
3,25 & 30 & $-0.13 \pm 0.06^{\mathrm{bc}}$ \\
3,50 & 84 & $-0.31 \pm 0.04^{\mathrm{ab}}$ \\
3,75 & 44 & $-0.39 \pm 0,05^{\mathrm{a}}$ \\
4,12 & 39 & $-0.42 \pm 0,05^{\mathrm{a}}$ \\
\hline
\end{tabular}

ECC - escore de condição corporal; $a \neq b \neq c ; P<0,05$

Com o propósito de verificar uma possível causa da diferença de ECC ao desmame, foi analisado o efeito do intervalo em dias entre o desmame e o parto $(0,83)$, do número de dias pós-parto $(0,20)$, da idade da vaca $(0,68)$, da raça do bezerro anterior $(0,43)$ e do peso aos 240 dias do bezerro anterior $(P=0,90)$ sobre 0 ECC das vacas ao desmame, nas diferentes classes de escore ao parto, porém não foi notada diferença entre os grupos. 


\section{DISCUSSÃO}

\subsection{EFEITOS GERAIS}

Com base nos resultados apresentados no Capítulo 1 desta dissertação e nos resultados expostos na tabela 9 do Capítulo 2, pôde-se notar que o peso corporal foi um mal preditor das reservas corpóreas e também da eficiência reprodutiva. Esse fato pode ser explicado, uma vez que é sabido que o peso corporal pode ser influenciado por diversas variáveis, entre elas altura, perímetro torácico, constituição óssea, raça e idade. Dessa forma, isoladamente, o peso traz pouca informação sobre o animal (NORTHCUTT et al. 1992; BEEF IMPROVEMENT FEDERATION, 2002; ROCHA et al., 2003).

Parte do aumento de peso, que normalmente se observa no terço final da gestação e que pode atingir de 40 a $50 \mathrm{~kg}$, é resultado do crescimento do feto, do desenvolvimento das membranas fetais e do acúmulo de líquidos fetais, bem como do aumento do próprio útero. Portanto, o animal pode ter apresentado aumento de peso sem ter melhorado a sua condição corporal ou mesmo pode ter tido perda de condição corporal (OLIVEIRA et al., 2006). Entretanto, se o estudo fosse realizado com animais do mesmo grupo genético, da mesma idade, na mesma fase de criação e com medidas corpóreas semelhantes, o peso poderia ter uma alta correlação com as reservas corpóreas e a eficiência reprodutiva.

Os resultados da tabela 6 demonstram que a idade média dos animais trabalhados está dentro da realidade encontrada hoje no Brasil, se tratando de animais relativamente jovens (segunda ou terceira cria no momento do desmame). Ainda, podemos notar que os animais foram manejados com o objetivo de realizar a sincronização da ovulação no período do pós-parto precoce (ao redor de 45 dias pós-parto). Nesse contexto, Rodrigues et al. (2004a) e Penteado et al. (2006) demonstraram que ao se utilizar eCG é possível iniciar o programa de sincronização da ovulação entre 40 e 49 dias pós-parto, sem a ocorrência de comprometimento na taxa de concepção do programa de IATF. Sabe-se que no caso do presente experimento, o eCG foi utilizado. 
Os dados apresentados na tabela 7 demonstram que os animais do presente estudo estavam em boa condição corporal, peso e quantidade de gordura, evidenciando assim o bom manejo nutricional da fazenda. Isto pode ser comprovado pela da taxa de ciclicidade dos animais ao início do protocolo (38,7 \%). Além disso,,foi possível notar que este dado não está de acordo com os relatos nacionais de literatura e da realidade brasileira, pois em diversos estudos as taxa encontradas são bem inferiores (BARUSELLI et al.,2003, 24,3\%; RODRIGUES et al., 2004b, 21,2 \%; PERES et al., 2007, 26,2 \%; SÁ FILHO et al., 2007, 23,8\%; SALES et al., 2007; $6,1 \%)$.

A realização da IATF em duas etapas distintas não afetou a taxa de concepção aos $30(P=0,38)$ e $60(P=0,15)$ dias de gestação, nem a taxa de prenhez acumulada aos 82 dias pós-parto $(0,75)$. Porém, a taxa de ciclicidade foi afetada pela etapa de sincronização $(P<0,0001)$. Por este motivo, a data do parto também apresentou efeito na taxa de ciclicidade (Figura 8), sendo que animais que pariam entre 15/12/2005 e 15/01/2006 (segunda etapa) apresentaram menor ciclicidade (18,2 \%) em comparação aos animais que paririam entre 15/11/2005 e 14/12/2005 (primeira etapa; 53,2 \%). Entretanto, o ECC dos animais da segunda etapa $(3,21 \pm 0,04)$ foi maior que a dos animais da primeira $(3,14 \pm 0,03$; Tabela 11$)$, sem apresentar interação entre etapa e ECC na sincronização. Assim, pode-se inferir que na segunda etapa os animais apresentaram maior ECC, o que pode ter influenciado a maior ciclicidade.

Como não houve interação entre etapas de sincronização e ECC na sincronização a combinação dos dados demonstra que, de fato, animais ciclando (3.28 \pm 0.04$)$ possuem maior ECC que animais em anestro $(3.17 \pm 0.03 ; P=0,0002)$. Isto também pode ser comprovado pela figura 7 , na qual se verifica efeito do ECC na sincronização na probabilidade de ocorrência de ciclicidade. Ainda, os dados de ciclicidade apresentaram efeito de classe de ECC $(P=0,002)$ e EGPU $(P=0,009)$ no momento da sincronização. Estes dados estão em conformidade com os relatos de literatura que mostram que quanto maior o ECC na sincronização, maior a taxa de ciclicidade (AYRES et al., 2007).

A taxa de concepção à IATF aos 30 dias de gestação $(60,5 \%)$ também pôde ser classificada como elevada, quando comparada às taxas brasileiras de animais mantidos em condições experimentais semelhantes (período pós-parto e protocolo hormonal; 52,8 \% de PENTEADO et al., 2006; 42,9 \% de RODRIGUES et al. 2004a). 
Pode-se pressupor que esta taxa de concepção foi alcançada devido a utilização da eCG, pois há trabalhos (BARUSELLI et al., 2004; RODRIGUES et al., 2004; SILVA et al., 2004) que demonstram que vacas no pós-parto precoce e/ou com baixo ECC (<3,0, na escala de 1 a 5$)$ apresentam comprometimento das taxas de concepção quando a eCG não é utilizada. O aumento da fertilidade observado em vacas tratadas com eCG pode ser explicados por três principais efeitos: 1) aumento do diâmetro do folículo dominante de vacas em anestro; 2) aumento da taxa de ovulação das vaca em anestro e 3) aumento da concentração plasmática de progesterona na fase luteínica seguinte (MARQUES et al., 2003; BARUSELLI et al., 2004). Portanto, supõe-se que a alta taxa de concepção e a ausência de efeito negativo do baixo escore de condição corporal em algumas avaliações realizadas no presente experimento possa ser devido ao fato da eCG incrementar as taxas de concepção de vacas no pós-parto precoce e, principalmente, incrementar as taxas de vacas em anestro e/ou com comprometimento da condição corporal.

\subsection{EFEITOS EM PERÍODOS ESPECÍFICOS}

\subsubsection{Desmame}

Analisando-se o comportamento da reta de regressão apresentado na figura 23, pôde-se verificar efeito do ECC $(P=0,01)$ no desmame sobre a taxa de prenhez acumulada aos 82 dias pós-parto. Assim, torna-se evidente que o aumento do ECC e, consequentemente da EGPU $(P=0,03)$ e do peso $(P=0,01)$, têm efeito positivo sobre a prenhez, o que pode ser confirmado pelo valor de $\mathrm{P}(0,006)$ do modelo de regressão. Se desconhece dados na atual literatura que corrroborem com estes achados. 


\subsubsection{Intervalo Desmame - Parto}

No período entre o desmame e o parto os animais que apresentaram maior deposição de tecido adiposo obtiveram maiores taxas de concepção $(P=0,06)$ e menores taxas de perda gestacional $(P=0,046)$. Isto pode estar relacionado ao fato destes animais conseguirem armazenar maior quantidade de energia, a qual pôde ser consumida no período pós-parto (período de balanço energético negativo) e, assim, não comprometer o desempenho reprodutiva do animal. Este fato pôde ser claramente observado na análise da figura 22B.

Entretanto, quando o efeito da diferença de peso neste período é analisado, pôde-se constatar que os animais que obtiveram os maiores ganhos de peso foram os animais que apresentaram menor taxa de prenhez acumulada aos 82 dias pósparto. O que pode ser suposto, neste caso, é que os animais os quais ganharam mais peso entre o desmame e o parto podem ter tido fetos que cresceram mais no terço final da gestação, uma vez que foi notado aumento do peso corporal não acompanhado por aumento de ECC ou EGPU. Esta suposição esta de acordo com os dados de Oliveira et al. (2006), onde foi apresentado que o animal no terço final da gestação pôde apresentar aumento de peso sem ter melhorado a sua condição corporal ou até mesmo ter sofrido perda do ECC.

Mais estudos são necessários para verificar a repetibilidade destes dados.

\subsubsection{Parto}

O parto foi o momento que apresentou maior número de variáveis influenciando a eficiência reprodutiva do animal $(29,4 \%$ das observações estatísticas). Pôde-se notar claramente que os animais que apresentaram maior quantidade de reservas corporais ao parto tiveram melhores taxas de prenhez acumulada aos 112 dias pós-parto. Este é um dado que está amplamente discutido na literatura. Lopes-Gatius et al. (2003) demonstrou em um estudo de meta-análise, 
que animais com baixo ECC ao parto apresentavam redução (9 \%) significativa na taxa de prenhez em relação à animais com condição intermediária. A maior parte dos estudos que verificaram a ação do ECC ao parto e no pós-parto está ligada ao prolongamento do anestro pós-parto, o qual leva a um atraso da primeira ovulação, que por sua vez afeta a eficiência reprodutiva dos animais (LÓPEZ-GATIUS et al., 2003; BEAM; BUTLER, 1999; BUTLER; SMITH, 1989; dentre outros). Porém, a análise do efeito do ECC ao parto sobre a taxa de ciclicidade, mostrou que este parâmetro não foi capaz de alterar essa taxa $(P=0,35)$. Ainda, ao se comparar as classes de animais com ECC $\leq 3$ ou $>3$ ao parto foi constatada mesma porcentagem de animais cíclicos para ambos os grupos (33,3\% vs 40,6\%; $P=0,29)$.

\subsubsection{Intervalo Parto - Sincronização}

Ao se analisar os dados obtidos entre o parto e sincronização, surpreendentemente, pôde-se verificar que animais que apresentaram maior perda de ECC e EGPU neste período tenderam a aumentar a taxa de concepção aos 112 dias $(P=0,09$ e $P=0,06$, respectivamente) e aumentaram a taxa de prenhez á IATF aos 112 dias pós-parto (30 dias de gestação; ECC, $P=0,03$ ). Porém, como esperado, a taxa de perda gestacional também tendeu a diminuir nos animais com menor perda de peso $(P=0,09)$.

Diversos estudos têm apontado que animais com moderada perda de condição corporal entre o parto e a primeira IA apresentam melhores taxas de concepção que animais com maiores perdas (FERGUSON, 1991; DOMECQ et al., 1997b; BUTLER; SMITH, 1989; FERGUSON; OTTO, 1989; RUEGG; MILTON, 1995). Entretanto, Looper et al. (2003) concluíram que a atividade luteínica e o primeiro estro de vacas em boa condição corporal ao parto não sofreram influência da mudança de peso e de ECC no período pós-parto. Ainda, após o parto, as vacas que tiveram alto ECC ao parto apresentaram maior perda de condição corporal e maior mobilização lipídica do que as vacas magras (BERNABUCCl et al., 2005; LOOPER et al.,2003; TREACHER et al., 1986; ). 
Ao se analisar a figura 22B, pôde-se notar que os animais com inferior ECC ao parto foram aqueles que apresentaram menor perda desse escore $(-0,03 \pm 0,03$ unidades de ECC, $\mathrm{P}<0,0001$ ) entre o parto e a sincronização e foram também os animais que apresentaram menor taxa de prenhez acumulada aos 82 dias pós-parto (56,6 \%, Figura 23B). Além disso, estes também foram os animais que apresentaram o menor ECC ao desmame $(2,94 \pm 0,04$ unidades de ECC; $P<0,0001)$ e menor ganho de ECC e EGPU entre o desmame e o parto $(0,01 \pm 0,04$ unidades de ECC e $0,07 \pm 0,02 \mathrm{~cm}$ de EGPU, $\mathrm{P}<0,0001)$. Fato semelhante foi observado por Frood $\mathrm{e}$ Croxton (1978). No estudo conduzido por esses autores, vacas com baixo ECC ao parto (1,5 na escala 1-5) não perderam condição corporal durante o início da lactação e vacas com moderado $\operatorname{ECC}(3,0)$ tiveram maior perda de ECC até o segundo mês após o parto.

Com o objetivo de estudar a possível causa para a classe de baixo escore ao parto ter tido menor ECC ao desmame e, ainda, não ter tido incremento satisfatório entre o desmame e o parto foram realizadas análises a fim de se verificar a diferença entre os grupos quanto: a idade da vaca $(P=0,62)$, o intervalo entre o desmame e o parto $(P=0,83)$, os dias pós-parto $(P=0,20)$, o peso do bezerro anterior aos 240 dias $(P=0,14)$, a data do parto $(P=0,90)$ e a influência da raça do bezerro anterior no ECC ao desmame $(P=0,14)$. Porém, nenhuma destas variáveis exerceu influência sobre a diferença de ECC ao parto.

Ainda, pode-se supor que o grupo de animais com maior ECC ao parto foi o que apresentou maior ganho de ECC entre o desmame e o parto $(0,51 \pm 0,05$ unidades de ECC) e também o que apresentou maior perda $(-0,42 \pm 0,05$ unidades de ECC) entre o parto e a sincronização. Ainda, estes são os mesmos animais que apresentaram maior taxa de prenhez acumulada aos 82 dias pós-parto $(84,6 \%)$.

\subsubsection{Intervalo entre 82 e 112 dias pós-parto}

Foi verificado apenas efeito significativo do ECC no diagnóstico aos 82 dias pós-parto influenciando a taxa de perda gestacional $(P=0,046)$. Ao se classificar os animais por perda ou não da gestação, pôde-se verificar que os animais que 
apresentaram perda gestacional apresentaram menor ECC $(2,81 \pm 0,10$ vs 3,12 \pm 0,03; $P=0,04)$. Fato semelhante ocorreu na avaliação aos 112 dias pós-parto.

López-Gatius et al. (2002) demonstraram que a perda de 1 (uma) unidade de condição corporal (ECC; escala 1-5) entre o parto e 30 dias após o parto aumentou a chance de perda gestacional em 2,43 vezes. Similarmente, Silke et al. (2002) observaram que vacas que perderam condição corporal entre 28 e 56 dias de gestação tiveram 3,2 vezes mais chance de perda gestacional. Estas observações embasam a inferência que o status metabólico das vacas, evidenciado pela mudança de ECC, afetaria a sobrevivência embrionária e fetal. Entretanto, no presente estudo, a diferença de ECC, de EGPU ou mesmo de peso entre os diversos intervalos após o parto não afetou a taxa de perda gestacional. Portanto, pode-se pressupor que as perdas gestacionais ocorridas no presente estudo devem estar ligadas mais a fatores ambientais ou infecciosos, os quais refletiram em menor ECC no momento dos diagnósticos e não tanto ao balanço energético do animal.

Ao se analisar os resultados como um todo, fica evidente a importância do ECC ao parto, além do seu monitoramento durante os períodos de desmame, parto e no momento de sincronização. Entretanto, a nutrição e, consequentemente, o ECC no período pós-parto apresentaram resultados inconsistentes na eficiência reprodutiva. Esta inconsistência pode ser devida às interações entre a nutrição pré e pós-parto, balanço energético negativo, produção de leite e amamentação, bem como outros fatores ambientais (MONTIEL; AHUJA, 2005).

Além disso, outro trabalho mostra que vacas com ECC > 6 ou $<5$ (escala de 1-9) que foram manejadas para perder ou ganhar condição durante o último trimestre de gestação e, desta maneira atingirem um ECC de 5 ao parto, apresentaram desempenho reprodutivo posterior igual as vacas que mantiveram ECC durante o pré-parto (MORRISON et al., 1999). Portanto, pode-se supor que o desempenho reprodutivo de vacas que apresentam moderado ECC ao parto não é influenciado por grandes mudanças nas reservas energéticas durante o último trimestre da prenhez. Ainda, sabe-se que o nível de alimentação pós-parto tem pouco efeito na atividade reprodutiva das vacas com boa condição corporal ao parto, mas tem influência marcante quando o nível nutricional pré-parto é baixo (OLIVEIRA et al., 2006). Assim, se fosse necessário a escolha de um único momento para aferição do ECC, o ponto que melhor poderia predizer a eficiência reprodutiva futura seria o ECC ao parto. 


\section{CONCLUSÕES}

As hipóteses iniciais do presente estudo foram parcialmente comprovadas. Vacas com maior ECC, EGPU e ganho destas medidas entre o desmame e o parto apresentaram melhor eficiência reprodutiva. A avaliação do peso apresentou baixa correlação com a eficiência reprodutiva, confirmando a hipótese inicial desse estudo. Porém, a hipótese de que a menor perda de escore de condição corporal e gordura subcutânea entre o parto e a sincronização melhoraria a eficiência reprodutiva foi rejeitada. A avaliação do escore de condição corporal e da espessura da gordura subcutânea no momento do parto demonstrou ter maior impacto na eficiência reprodutiva de vacas Nelore submetidas à IATF e repasse com touro.

Porém, mais experimentos são necessários para elucidar melhor os possíveis mecanismos fisiológicos pelos quais a menor perda de escore de condição corporal, e gordura subcutânea entre o parto e a sincronização não melhoram a eficiência reprodutiva. 


\section{IMPLICAÇÕES}

Esta seqüência de estudos teve como objetivo estabelecer uma ferramenta prática (ECC) e consistente de monitoramento do status energético do animal, visando facilitar o manejo nutricional e otimizar o desempenho reprodutivo e produtivo do rebanho.

Portanto, consideramos que os achados desta dissertação podem ser utilizados por produtores, pesquisadores e profissionais que trabalham em fazendas de corte com o intuito de melhorar a eficiência reprodutiva e, principalmente, estabelecer uma rotina de monitoramento a ser seguida sistematicamente na fazenda.

Assim, tem a possibilidade de associar o uso do ECC com a rotina da fazenda, realizando a sua aferição nos diversos momentos do sistema de cria. Juntamente com o emprego dessa tecnologia, julgamos importante também promover treinamento contínuo do técnico envolvido na execução de toda a rotina, seja ela reprodutiva (aplicação de hormônios corretos, na dose correta, para as vacas corretas, nos horários corretos), ou produtiva (manejo de desmama, de préparto e de pós-parto).

O uso de protocolos de IATF + sistematização do monitoramento do ECC podem certamente ajudar o produtor a aumentar a taxa de prenhez e manter os índices reprodutivos da fazenda em níveis adequados. Por exemplo, alguns índices reprodutivos a serem buscados por produtores e técnicos seriam: manter o intervalo médio entre partos próximo aos 12 meses; taxa de concepção maior que 45\%; elevada taxa de prenhez no início da estação de monta; taxa de prenhez no final de estação maior que $80 \%$.

Consideramos que os futuros experimentos para melhoria da eficiência reprodutiva de bovinos de corte devem focar o estabelecimento de técnicas ligadas à nutrição e manejo dos animais. Além disso, elucidar melhor os mediadores que sinalizam ao sistema reprodutivo o status nutricional do animal.

Além disso, mais experimentos são necessários para elucidar melhor os possíveis mecanismos fisiológicos pelos quais a menor perda de escore de condição 
corporal, peso e gordura subcutânea entre o parto e a sincronização não melhoram a eficiência reprodutiva. 


\section{REFERÊNCIAS}

ADAMS, G. P.; MATTERI, R. L.; KASTELIC, J. P.; KO, J. C. H.; GINTHER, O. J. Association between surges of follicle-stimulating hormone and the emergence of follicular waves in heifers. Journal of Reproduction and Fertility, v. 94, p. 177-188, 1992.

ALLEN, W. R.; MOOR, R. M. The origin of the equine endometrial cups. I. Production of the PMSG by fetal trofoblast cells. Journal of Reproduction Fertility, v. 29, p. 313-316, 1972.

ARREGUIN, J. A. A.; SANTOS, R. E.; VILLA-GODOY, A.; ROMÁN-PONCE, H. Dinámica folicular ovárica en vacas Cebú con diferente condición corporal y frecuencia de amamantamiento durante el periodo anovulatorio posparto. In: CURSO INTERNACIONAL DE REPRODUCCIÓN BOVINA 7., 1997, México, Anais... 1997. p. $210-240$.

AYRES, H.; PENTEADO, L.; TORRES-JUNIOR, J. R. S.; FERREIRA, R. M.; BARUSELLI, P. S. Escore de condição corporal e espessura da gordura subcutânea como preditores de ciclicidade em vacas Nelore (Bos indicus) no período pós-parto. Acta Scientiae Veterinariae, v. 35, p. s1051, 2007.

BARROS, C. M.; FIGUEIREDO, R. A.; PINHEIRO, O. L. Estro, ovulação e dinâmica folicular em zebuínos. Revista Brasileira de Reprodução Animal, v. 19, p. 9-12, 1995.

BARUSELLI, P. S.; AYRES, H.; SOUZA, A. H.; MARTINS, C. M.; GIMENES, L. U.; TORRES-JUNIOR, J. R. S. Impacto da IATF na eficiência reprodutiva em bovinos de corte. In: INTERNATIONAL CONGRESS ON ANIMAL REPRODUCTION-ICAR, 1., 2004, Porto Seguro. Proceedings... 2004. v. 2, p. 117. 
BARUSELLI, P. S.; REIS, E. L.; CARVALHO, N. A. T.; CARVALHO, J. B. P. eCG increase ovulation rate and plasmatic progesterone concentration in Nelore (Bos indicus) heifers treated with progesterone releasing device. In: SIMPÓSIO INTERNACIONAL DE REPRODUÇÃO ANIMAL APLICADA, 2., 2006, Londrina. Proceedings... 2006. v. 1, p. 113-132.

BEAM, S. W.; BUTLER, W. R. Effects of energy balance on follicular development and first ovulation in postpartum dairy cows. Journal Reproduction and Fertility, v. 54, p. 411-424. 1999. Supplemenent.

BEEF IMPROVEMENT FEDERATION. Guidelines 2002. Disponível em: $<$ http://www.beefimprovement.org/library/06guidelines.pdf >. Acesso em: 21 maio 2008.

BERNABUCCI, U.; RONCHI, B.; LACETERA, N.; NARDONE, A. Influence of body condition score on relationships between metabolic status and oxidative stress in periparturient dairy cows. Journal of Dairy Science, v. 88, p. 2017-2026, 2005.

BINELLI, M.; THATCHER, W. W.; MATTOS, R.; BARUSELLI, P. S. Anti-luteolytic strategies to improve fertility in cattle. Theriogenology, v. 56, n. 9, p. 1451-1463, 2001.

BÓ, G. A. Sincronizacion de celos para programas de inseminacion artificial y transferencia de embriones bovinos. In: SIMPÓSIO SOBRE O CONTROLE FARMACOLÓGICO DO CICLO ESTRAL EM RUMINANTES, 1., 2000, São Paulo. Anais... São Paulo: Fundação da Faculdade de Medicina Veterinária e Zootecnia, USP, 2000, p. 35-60.

BÓ, G. A.; ADAMS, G. P.; CACCIA, M.; MARTINEZ, M.; PIERSON, R. A.; MAPLETOFT, R. J. Ovarian follicular wave emergence after treatment with progestogen and estradiol in cattle. Animal Reproduction Science, v. 39, n. 1, p. 193-204, 1995b. 
BÓ, G. A.; ADAMS, G. P.; NASSER, L. F.; PIERSON, R. A.; MAPLETOFT, R. J. Effect of estradiol valerate on ovarian follicles, emergence of follicular waves and circulating gonadotropins in heifers. Theriogenology, v. 40, n. 2, p. 225-239, 1993.

BÓ, G. A.; ADAMS, G. P.; PIERSON, R. A.; MAPLETOFT, R. J. Exogenous control of follicular wave emergence in cattle. Theriogenology, v. 43, n. 1, p. 31-40, 1995.

BO, G. A.; ADAMS, G. P.; PIERSON, R. A.; TRIBULO, H. E.; CACCIA, M.; MAPLETOFT, R. J. Follicular wave dynamics after estradiol-17ß treatment of heifers with or without a progestogen implant. Theriogenology, v. 41, p. 1555-1569, 1994.

BÓ, G. A.; BARUSELLI, P. S.; MARTINEZ, M. F. Pattern and manipulation of follicular development in Bos indicus cattle. Animal Reproduction Science, v. 78, n. 3-4, p. 307-326, 2003.

BÓ, G. A.; PIERSON, R. A.; MAPLETOFT, R. J. The effect of estradiol valerate on follicular dynamics and superovulatory response in cows with Syncro-Mate-B implants. Theriogenology, v. 36, n. 2, p. 169-183, 1991.

BOUSFIELD, G. R.; BUTNEV, V. Y.; GOTSCHALL, R. R.; BAKER, V. L.; MOORE, W. T. Structural features of mammalian gonadotropins. Molecular and Cellular Endocrinology, v. 125, p. 3-19, 1996.

BRAUN, R. K.; DONOVAN, G. A.; TRAN, T. Q.; SHEARER, J. K.; BLISS, E. L.; WEBB, D. W.; BEEDE, D. K.; HARRIS, B. Body condition scoring dairy cows as a herd management tool. Compendium on Continuing Education for the Practicing Veterinarian, v. 8, p. F62-F67, 1986.

BRETHOUR, J. R. The repeatability and accuracy of ultrasound in measuring backfat of cattle. Journal of Animal Science v. 70, p. 1039-1044, 1992.

BRUCKMAIER, R. M.; GREGORETTI, L.; JANS, F.; FAISSLER, D.; BLUM, J. W. Longissimus dorsi muscle diameter, backfat thickness, body condition scores and skinfold values related to metabolic and endocrine traits in lactating dairy cows fed 
crystalline fat or free fatty acids. Journal of Veterinary Medicine Series A, v. 45, p. 397-410, 1998.

BUTLER, W. R.; SMITH, R. D. Interrelationships between energy balance and postpartum reproductive function in dairy cows. Journal of Dairy Science, v. 72, p. 767-783, 1989.

CACCIA, M.; BO, G. A. Follicle wave emergence following treatment of CIDR-B implanted beef heifers with estradiol benzoate and progesterone. Theriogenology, v. 49 , p. 341,1998 . Abstract.

CANFIELD, R. W.; BUTLER, W. R. Energy balance and pulsatile LH secretion in early postpartum dairy cattle. Domestic Animal Endocrinology, v. 7, n. 3, p. 323330, 1990.

CARVALHO, J. B. P. Sincronização da ovulação com dispositivo intravaginal de progesterona (CIDR $®$ ) em novilhas Bos indicus, Bos indicus $x$ Bos taurus $\mathrm{e}$ Bos taurus. 2004. 124 f. Tese (Doutorado em Mediciana Veterinária) - Faculdade de Medicina Veterinária e Zootecnia, Universidade de São Paulo, São Paulo, 2004.

CARVALHO, J. B. P.; REIS, E. L.; CARVALHO, N. A. T.; NICHI, M.; BARUSELLI, P. S. Follicular wave and luteal function in Bos taurus, Bos indicus and Bos taurus $\mathrm{x}$ Bos indicus heifers treated with progesterone device. In: INTERNATIONAL CONGRESS ON ANIMAL REPRODUCTION-ICAR, 1., 2004, Porto Seguro. Proceedings... Belo Horizonte: Colégio Brasileiro de Reprodução Animal, 2004, p. 112.

CAVALIERI, J.; RUBIO, I.; KINDER, J. E.; ENTWISTLE, K. W.; FITZPATRICK, L. A. Synchonization of estrus and ovulation and associated endocrine changes in Bos indicus cows. Theriogenology, v. 47, p. 801-814, 1997.

CLARKE, I. J. The GnRH/gonadotropin axis in the ewe, cow and sow. Domestic Animal Endocrinology, v. 6, n. 1, p. 1-14, 1989. 
CONFEDERAÇÃO DA AGRICULTURA E PECUÁRIA DO BRASIL. CNA. 2008.

Disponível em: <http://www.cna.org.br> Acesso em: 24 maio 2008.

COLAZO, M. G.; KASTELIC, J. P.; MAPLETOFT, R. J. Effects of estradiol cypionate (ECP) on ovarian follicular dynamics, synchrony of ovulation, and fertility in CIDRbased, fixed-time Al programs in beef heifers. Theriogenology, v. 60, n. 5, p. 855865, 2003.

COLE, H. H.; HART, G. H. Potency of blood serum of mares in progressive stages of pregnancy in effecting the sexual maturity of the immature rat. American Journal of Physiology, v. 93, p. 57-58, 1930.

CRUZ, L. C.; VALLE, E. R.; KESLER, D. J. Effect of prostaglandin and gonadotrofin releasing hormone-induced luteinizing hormone releases on ovulation and corpus luteum function of beef cows. Animal Reproduction Science, v. 49, n. 2, p. 135142, 1997.

DAELS, P. F.; ALBRECHT, B. A.; MOHAMMED, H. O. Equine Chorionic Gonadotropin regulates luteal steroidogenesis in pregnant mares. Biology Reproduction, v. 59, p. 1062-1068, 1998.

DEMETRIO C. G. B. Modelos lineares generalizados. In: REUNIÃO ANUAL DA RBRAS, 46., 2001, Piracicaba. Anais... 2001. p. 113.

DISKIN, M. G.; AUSTIN, E. J.; ROCHE, J. F. Exogenous hormonal manipulation of ovarian activity in cattle. Domestic Animal Endocrinology, v. 23, n. 1-2, p. 211-228, 2002.

DOMECQ, J. J.; SKIDMORE, A. L.; LLOYD, J. W.; KANEENE, J. B. Relationship between body condition scores and conception at first artificial insemination in a large dairy herd of high yielding Holstein cows. Journal of Dairy Science, v. 80, p. 113120, 1997. 
DOMECQ, J. J.; SKIDMORE, A. L.; LLOYD; J. W.; KANEENE, J. B. Validation of Body Condition Scores with Ultrasound Measurements of Subcutaneous Fat of Dairy Cows. Journal of Dairy Sciencie, v. 78, p. 2308-2313, 1995.

DUNN, T. G.; KALTENBACH, C. C. Nutrition and the postpartum interval of the ewe, sow and cow. Journal of Animal Science, v. 51, p. 29-37, 1980. Supplement 2.

DUNNE, L. D.; DISKIN, M. G.; SREENAN, J. M. Embryo and foetal loss in beef heifers between day 14 of gestation and full term. Animal Reproduction Science, v. 58, n. 1-2, p. 39-44, 2000.

DZIUK, P.J.; BELLOWS, R. A. Management of reproduction in beef cattle, sheep and pigs. Journal of Animal Science, v. 57, p. 355-362, 1983. Supplement 2.

EDMONSON, A. J.; LEAN, I. J.; WEAVER, L. D.; FARVER, T.; WEBSTER, G. A body condition scoring chart for Holstein dairy cows. Journal of Dairy Science, $v$. 72, p. 68-78, 1989.

FALLAS, M. R.; ZARCO, Q. L.; GALINA, C. S.; BASURTO, H. Efecto del amamantamiento sobre la actividad ovárica posparto en vacas F1 (Holstein $\times$ Indobrasil) en dos tipos de pasto. In: REUNIÓN DE INVESTIGACIÓN PECUARIA EN MÉXICO, 1987. México. Anais... 1987. p. 348-349.

FANNING, M. D.; SPITZER, J. C.; BURNS, G. L.; PLYLER, B. B. Luteal function and reproductive response in suckled beef cows after metestrus administration of a norgestomet implant and injection of estradiol valerate with various dosages of injectable norgestomet. Journal of Animal Science, v. 70, n. 5, p. 1352-1356, 1992.

FERGUSON, J. D.; GALLIGAN, D. T.; THOMSEN, N. Principal descriptors of body condition score in Holstein cows. Journal of Dairy Sceince, v. 77, p. 2695-2703, 1994. 
FORTUNE, J. E.; RIVERA, G. M.; YANG, M. Y. Follicular development: the role of the follicular microenvironment in the selection of the dominant follicle. Animal Reproduction Science, v. 82-83, p. 109-126, 2004.

FRONK, T. J.; SCHULTZ, L. H.; HARDIE, A. R. Effect of dry period over conditioning on subsequent metabolic disorders and performance of dairy cows. Journal of Dairy Science, v. 63, p. 1080-1090, 1980.

FROOD, M. J.; CROXTON, D. The use of condition scoring in dairy cows and its relationship with milk yield and live weight. American Society of Animal Production. v. 27, p. 285, 1978.

GALINA, C. S.; MURCIA, C.; BEATTY, A.; NAVARRO-FIERRO, R.; PORRAS, A. Reproductive performance of Zebu cattle in Mexico. In: FINAL RESEARCH COORDINATION MEETING OF THE FAO/IAEA, 1989, Bogotá. Proceedings... Bogotá: FAO/IAEA, Colombia, 1989.

GALINA, C. S.; ARTHUR, G. H. Review of cattle reproduction in the tropics. 3. Puerperium. Animal Breeding Abstracts, v. 57, p. 889-910, 1989.

GARCIA-WINDER, M.; IMAKAWA K.; DAY, M. L.; ZALESKY, D. D.; KITTOK, R. J.; KINDER, J. E. Effect of suckling and ovariectomy on the control of luteinizing hormone secretion during the postpartum period in beef cows. Biology Reproduction, v. 31, n. 4, p. 771-778, 1984.

GARNSWORTHY, P. C.; TOPPS, J. H. The effect of body condition of dairy cows at calving on their food intake and performance when given complete diets. Animals Prodution, v. 35, p. 113-119, 1982.

GEARHART, M. A.; CURTIS, C. R.; ERB, H. N.; SMITH, R. D.; C. J. SNIFFEN,; CHASE, L. E.; Cooper; M. D. Relationship of changes in condition score to cow health in Holsteins. Journal of Dairy Science, v. 73, p. 3132-3140, 1990. 
GILLUND, P.; REKSEN, O.; GRÖHN, Y. T.; KARLBERG, K. Body condition related to ketosis and reproductive performance in Norwegian dairy cows. Journal of Dairy Science, v. 84, n. 6, p. 390-396, 2001.

GINTHER, O. J. Selection of the dominant follicle in cattle and horses. Animal Reproduction Science, v. 60-61, n. 1, p. 61-79, 2000.

GINTHER, O. J.; BERGFELT, D. R.; BEG, M. A.; KOT, K. Follicle selection in cattle: role of luteinizing hormone. Biology of Reproduction, v. 64, n. 1, p. 197-205, 2001.

GINTHER, O. J.; KNOPF, L.; KASTELIC, J. P. Temporal associations among ovarian events in cattle during oestrus cycle with two and three follicular waves. Journal of Reproduction and Fertility, v. 8 , n. 1, p. 223-230, 1989.

GINTHER, O. J.; WILTBANK, M. C.; FRICKE, P. M.; GIBBONS, J. R.; KOT, K. Selection of the dominant follicle in cattle. Biology of Reproduction, v. 55, n. 2, p. 1187-1194, 1996.

GONZALEZ-MENICO, F.; MANNS, J.; MURPHY, B. D. FSH and LH activity of PMSG from mares at different stages of gestation. Animals Reproduction Sciencie, v. 1, p. 137-144, 1978.

GOSPODAROWICS, D. Purification and physiochemical properties of the pregnant mare serum gonadotropin (PMSG). Endocrinology, v. 91, p. 101-106, 1972.

GREINER, S. P.; ROUSE, G. H.; WILSON, D. E.; CUNDIFF, L. V.; WHEELER, T. L.; The relationship between ultrasound measurements and carcass fat thickness and longissimus muscle area in beef cattle; Journal of Animal Science, v. 81, n. 3, p. 676-82, 2003.

GRIFFIN, D. B.; SAVELL, J. W.; RECIO, H. A.; GARRETT, R. P.; CROSS, H. R. Predicting carcass composition of beef cattle using ultrasound technology; Journal of Animal Science, v. 77, n. 4, p. 889-892, 1999. 
HANSEL, W.; MALVEN, P. V.; BLACK, D. L. Estrous cycle regulation in the bovine. Journal of Animal Science, v. 20, p. 621, 1961.

HASLER, M.; EIGENMANN, U.; JANETT, F.; THUN, R. Korperkondition und Haufigkeit von Ovarialzysten bei Braunviehku"hen wa"hrend der ersten 40 Laktationstage. Schweiz Arch Tierheilkd, v. 146, p. 213-221, 2004.

HEINRICHS, A. J.; ROGERS, G. W.; COOPER, J. B. Predicting body weight and wither height in Holstein heifers using body measurements. Journal of Dairy Science, v. 75, p. 3576-3581, 1992.

HEUWIESER, W.; MANSFELD, R. Beurteilung der Korperkondition bei Milchkuhen. Teil 2. Milchpraxis v. 30, p. 10-14, 1992.

HOUGHTON, P. L.; LEMENAGER, R. P.; MOSS, G. E.; HENDRIX, K. S. Prediction of postpartum beef cow body composition using weight to height ratio and visual body condition score. Journal of Animal Science, v. 68, p. 1429-1437, 1990.

HOUGHTON, P. L.; TURLINGTON, L. M. Application of ultrasound for feeding and finishing animals: a review. Journal of Animal Science, v. 70, p. 930, 1992.

HUMBOLT, P.; HOLM, P.; LONERGAN, P.; WRENZYCKI, C.; LEQUARRÉ, A. S.; JOLY, C. G.; HERRMANN, D.; LOPES, A.; RIZOS, D.; NIEMANN, H.; CALLESEN, $H$. Effect of stage of follicular growth during superovulation on developmental competence of bovine oocytes. Theriogenology, v. 63, p. 1140-1166, 2005

INSTITUTO BRASILEIRO DE GEOGRAFIA E ESTATÍSTICA. IBGE. Brasília: IBGE; 2008. Disponível em: < http://www.ibge.gov.br>. Acesso em: 24 maio 2008.

JACKSON, P. S.; JOHNSON, C. T.; FURR, B. J.; BEATTIE, J. F. Influence of stage of oestrous cycle on the time to oestrus following cloprostenol treatment in the bovine. Theriogenology, v. 12, p. 153-167, 1979. 
JOLLY, P. D. Physiological and nutritional aspects of postpartum acyclicity in bos indicus cows. 1992. 137 f. Thesis (Ph.D.) - James Cook University of North Queensland, Townsville, 1992.

JOLLY, P. D.; MCDOUGALL, S.; FITZPATRICK, L. A.; MACMILLAN, K. L.; ENTWISTLE, K. W. Physiological effects of undernutrition on postpartum anoestrus in cows. Journal of Reproduction and Fertility, v. 49, p. 477-492, 1995.

Supplement.

KASTELIC, J. P.; GINTHER, O. J. Factors affecting the origin of the ovulatory follicle in heifers with induced luteolysis. Animal Reproduction Science, v. 26, n. 1-2, p. 13-24, 1991.

KASTELIC, J. P.; KNOPF, L.; GINTHER, O. J. Effect of day of prostaglandin $\mathrm{F}_{2 \alpha}$ treatment on selection and development of the ovulatory follicle in heifers. Animal Reproduction Science, v. 23, n. 3, p. 169-180, 1990.

KEMP, D. J.; HERRING, W. O.; KAISER, C. J. Genetic and environmental parameters for steer ultrasound and carcass traits. Journal of Animal Science, v. 80 , p. 1489-1496, 2002.

KLAWUHN, D. Vergleich der Ruckenfettdicke mit dem uber die Gesamtkorperwasserbestimmung ermittelten Korperfettgehalt bei Rindern. 1992. 142 f. Dissertação (Mestrado) - Humboldt-Universaty, Berlin, 1992.

KUNZ, P. L.; BLUM, J. W.; HART, I. C.; BICKEL, H.; LANDIS, J. Effects of different energy intakes before and after calving on food intake, performance and blood hormones and metabolites in dairy cows. Animal Production, v. 40, p. 219-231, 1985.

LARSON, L. L.; BALL, P. J. H. Regulation of estrous cycles in dairy cattle: a review. Theriogenology, v. 38, n. 2, p. 255-267, 1992. 
LASSEN, J.; HANSEN, M.; SØRENSEN, M. K.; AAMAND, G. P.; CHRISTENSEN, L. G.; MADSEN, P. Genetic analysis of body condition score in first-parity Danish Holstein cows. Journal of Dairy Science, v. 86, p. 4123-4128, 2003.

LAVERDIERE, G.; ROY, G. L.; PROULX, J.; LAVOIE, D.; DUFOUR, J. J. Estrus synchronization efficiency of $\mathrm{PGF}_{2 \alpha}$ injection in Shorthorn-Hereford and crossbred Charolais cattle not having exhibited estrus at 4 or 7 days prior to treatment. Theriogenology, v. 43, n. 5, p. 899-911, 1995.

LEGARDINIER, S.; CAHOEAU, C.; KLETT, D.; COMBARNOUS, Y. Involvement of equine chorionic gonadotropin (eCG) carbohydrate side chains in its bioactivity: lessons from recombinant hormone expressed in insect cells. Reproduction Nutrition Development, v. 45, p. 255-259, 2005.

LOOPER, M. L.; LENTS, C. A.; WETTEMANN, R. P. Body condition at parturition and postpartum weight changes do not influence the incidence of short-lived corpora lutea in postpartum beef cows. Journal of Animal Science, v. 81, p. 2390-2394, 2003.

LÓPEZ-GATIUS, F.; SANTOLARIA, P.; YÁNIZ, J.; RUTLLANT, J.; LÓPEZ-BÉJAR, M. Factors affecting pregnancy loss from gestation day 38 to 90 in lactating dairy cows from a single herd. Therioenology, v. 57, p. 1251-1261, 2002.

LÓPEZ-GATIUS, F.; YA' NIZ, J.; MADRILES-HELM, D. Effects of body condition score and score change on the reproductive performance of dairy cows: A metaanalysis. Theriogenology, v. 59, p. 801-812, 2003.

LOTTHAMMER, K. H. Influence of nutrition on reproductive performance of the milking/gestating cow in the tropics. In: SPEEDY, A.; SANSDUCY, P. (Ed.). Feeding dairy cows in the tropics. Roma: FAO, 1991. p. 36-47.

MACIEL, A. B. M. Proposta de avaliação da condição corporal em vacas Holandesa e Nelore. 2006. 58 f. Dissertação (Mestrado em Zootecnia) - Faculdade 
de Medicina Veterinária e Zootecnia, Universidade Estadual Paulista, Campus Botucatu, São Paulo, 2006.

MACMILLAN, K. L.; BURKE, C. R. Effects of oestrous cycle control on reproductive efficiency. Animal Reproduction Science, v. 42, n. 1-4, p. 307-320, 1996.

MACMILLAN, K. L.; CLAYTON, D. G. Factors influencing the interval to post-partum oestrus, conception date and empty rate in an intensively managed dairy herd. New Zealand Society of Animal Production, v. 40, p. 236-239, 1980.

MAPLETOFT, R. J.; BÓ, G. A.; ADAMS, G. P. Avanços na manipulação do ciclo estral de doadoras e receptoras nos programas de transferência de embriões em bovinos. In: REUNIÃO ANUAL DA SOCIEDADE BRASILEIRA DE TECNOLOGIA DE EMBRIÕES, 15., 2003, Caldas Novas. Anais... Porto Alegre: UFRGS, 2004. p. 2451.

MARLOWE, T. J.; FREUND, R. J.; GRAHAM, J. B. Influence of age, breed, flesh condition, nursing, and season on weight and grade of beef cattle. Journal of Animal Science, v. 21, p. 346-354, 1962.

MARQUES, M. O.; REIS, E. L.; CAMPOS FILHO, E. P.; BARUSELLI, P. S. Efeitos da administração de eCG e de benzoato de estradiol para sincronização da ovulação em vacas Bos taurus taurus x Bos taurus indicus no período pós-parto. In: SIMPOSIO INTERNACIONAL DE REPRODUCCIÓN ANIMAL, 5., 2003, Córdoba. Anais... Córdoba: Instituto de Reproducción Animal de Córdoba, 2003. p. 392.

MARTINEZ, M. F.; ADAMS, G. P.; BERGFELT, D. R.; KASTELIC, J. P.; MAPLETOFT, R. J. Effect of LH or GnRH on the dominant follicle of the first follicular wave in beef heifers. Animal Reproduction Science, v. 57, n. 1-2, p. 23-33, 1999.

MARTINUK, S. D.; MANNING, A. W.; BLACK, W. D.; MURPHY, B. D. Effects of carbohydrates on the pharmacokinetics and biological activity of equine chorionic gonadotropin in vivo. Biology Reproduction, v. 45, p. 598-604, 1991. 
MCCRACKEN, J. A. Prostaglandins and luteal regression - a review.

Prostaglandins, v. 1, n. 1, p. 1-4, 1972.

MCCRACKEN, J. A.; CUSTER, E. E.; LAMSA, J. C.; ROBINSON, A. G. The central oxytocin pulse generator: a pacemaker for luteolysis. Advances in Experimental Medicine and Biology, v. 395, n. 1-2, p. 133-154, 1995.

MCDOUGALL, S.; BURKE, C. R.; MACMILLAN, K. L.; WILLIAMSON , N. B. Patterns of follicular development during periods of anovulation in pasture-fed dairy cows after calving. Research in Veterinary Science, v. 58, p. 212-216, 1995.

MENZER, C.; SCHAMS, D. Radioimmunoassay for PMSG and its application to in vivo studies. Journal Reproduction Fertility, v. 55, p. 339-345, 1979.

MONTIEL, F.; AHUJA, C. Body condition and suckling as factors influencing the duration of postpartum anestrus in cattle: A review. Animal Reproduction Science, v. 85, p.1-26, 2005.

MORENO, I. Y. D.; GALINA, C. S.; ESCOBAR, F. J.; RAMÍREZ, B.; NAVARROFIERRO, R. Evaluation of the lytic response of prostaglandin F2 alpha in Zebu cattle based on serum progesterone. Theriogenology, v. 25, n. 3, p. 413-421, 1986.

MORO, J.; CASTAŃEDA, O. G.; RUIZ, F.; ROMÁN, H. Aplicación de un sistema de registro de la producción en ganader'ýas de doble propósito. In: REUNIÓN CIENTÍFICA DEL SECTOR AGROPECUARIO Y FORESTAL DEL ESTADO DE VERACRUZ, 7., 1994, Veracruz, México. Anais... 1994.

MORRISON, D. G.; SPITZER, J. C.; PERKINS, J. L. Influence of prepartum body condition score change on reproduction in multiparous beef cows calving in moderate body condition. Journal of Animal Science, v. 77, p. 1048-1054, 1999.

MORROW, D. A. Fat cow syndrome. Journal of Dairy Science, v. 59, p. 16251629, 1976. 
MORROW, D. A.; HILLMAN, D.; DADE, A. W. Clinical investigation of a dairy herd with the fat cow syndrome. Journal of the American Veterinary Medical Association. v. 174, p. 161-167, 1979.

MORROW, D. A.; ROBERTS, S. J.; MCENTEE, K. Pospartum ovarian activity and involution of the uterus and cervix in dairy cattle. II. Involution of uterus and cervix. Cornell Veterinary, v. 59, p. 190-198, 1969.

MURPHY, B. D.; MARTINUK, S. D. Equine chorionic gonadotrophin. Endocrine Rewiews, v. 12, n. 1, p. 27-44, 1991.

MURPHY, M. G.; BOLAND, M. P.; ROCHE, J. F. Pattern of follicular growth and resumption of ovarian activity in post-partum beef suckler cows. Journal of Reproduction and Fertility, v. 90, p. 523-533, 1990.

MOSENFECHTEL, S.; EIGENMANN, U.J.; WANNER, M.; RUSCH, P. Ruckenfettdicke und Fruchtbarkeit bei Braunviehkuhen. Schweiz Arch Tierheilkd, v. 142, p. 679-689, 2000.

NISWENDER, G. D.; JUENGEL, J. L.; SILVA, P. J.; ROLLYSON, M. K.; MCINTUSH, E. W. Mechanisms controlling the function and life span of the corpus luteum.

Physiological Reviews, v. 80, n. 1, p. 1-29, 2000.

NORTHCUTT, S. L.; WILSON, D. E.; WILLHAM, R. L. Adjusting weight for body condition score in Angus cows. Journal Animal Science, v. 70, p. 1342-1345, 1992.

NORTHEY, D. L.; FRENCH, L. R. Effect of embryo removal and intra-uterine infusion of embryonic homogenates on the lifespan of the bovine corpus luteum. Journal of Animal Science, v. 50, n. 2, p. 298-302, 1980.

ODDE, K. G. A review of synchronization of estrus in postpartum cattle. Journal of Animal Science, v. 68, n. 3, p. 817-830, 1990. 
OKUDA, K.; MIYAMOTO, Y.; SKARZYNSKI, D. J. Regulation of endometrial prostaglandin $\mathrm{F}_{2 \alpha}$ synthesis during luteolysis and early pregnancy in cattle. Domestic Animal Endocrinology, v. 23, n. 1-2, p. 255-264, 2002.

OLIVEIRA, R. L.; BARBOSA, M. A. A. F.; LADEIRA, M. M.; SILVA, M. M. P.; ZIVIANI, A. C.; BAGALDO, A. R. Nutrição e manejo de bovinos de corte na fase de cria. Revista Brasileira de Saúde e Produção Animal, v. 7, n. 1, p. 57-86, 2006.

OYEDIPE, E. O.; BUVANENDRAN, V.; EDUVIE, L. O. Some factors affecting the reproductive performance of White Fulani (Bunaji) cattle. Tropical Agriculture, v. 59, p. 231-234, 1982.

PARFET, J. R.; SMITH, C. A.; COOK, D. L.; SKYER, D. M.; YOUNGQUIST, R. S.; GARVERICK, H. A. Secretory patterns of LH and FSH and follicular growth following administration of $\mathrm{PGF}_{2 \alpha}$ during the early luteal phase in cattle. Theriogenology, $\mathrm{v}$. 31, n. 3, p. 513-524, 1989.

PENTEADO, L.; AYRES, H.; TORRES-JUNIOR, J. R. S.; SOUZA, A. H.; BARUSELLI, P. S. Taxa de concepção de vacas Nelore. Acta Scientieae Veterinariae, v. 34, p. 401, 2006.

PERES, R. F. G.; MENEGHETTI, M.; CARDOSO, B. L.; CLARO JUNIOR, I.; PIRES, A.V.; VASCONCELOS, J. L. M. Efeito do momento da aplicação da prostaglandina em protocolo de IATF na taxa de prenhez de vacas Nelore paridas. Acta Scientiae Veterinariae, v. 35, p. s1140, 2007.

PERKINS, T. L.; GREEN, R. D.; HAMLIN, K. E. Evaluation of ultrasonic estimates of carcass fat thickness and longissimus muscle area in beef cattle. Journal of Animal Science, v. 70, n. 4, p. 1002-1010, 1992.

PERRY, R. C.; CORAH, L. R.; COCHRAN, R. C.; BEAL, W. E.; STEVENSON, J. S.; MINTON, J. E.; SIMMS, D. D.; BRETHOUR, J. R. Influence of dietary energy on follicular development, serum gonadotrophins, and first postpartum ovulation in suckled beef cows. Journal of Animal Science, v. 69, p. 3762-3773, 1991. 
PETERS, A. R. Reproductive activity of the cow in the post-partum period. I. Factors affecting the length of the post-partum acyclic period. British Veterinary Journal, v. 140, p. 76-84, 1984.

PIMENTEL, C. A.; DESCHAMPS, J. C.; OLIVEIRA, J. A. F.; CARDELINO, R.; PIMENTEL, M. A. Effects of early weaning on reproductive efficiency in beef cows. Theriogenology, v. 11, p. 421-427, 1979.

PIERSON, R. A.; GINTHER, O. J. Ultrasonic imaging of the ovaries and uterus in cattle. Theriogenology, v. 29, n. 1, p. 21-37, 1988.

PIERSON, R. A.; GINTHER, O. J. Ultrasonographic appearance of the bovine uterus during the estrous cycle. Journal American Veterinary Medical Association, v. 190 n. 8, p. 995-1001, 1987.

PRATT, S. L.; SPITZER, J. C.; BURNS, G. L.; PLYLER; B. B. Luteal function, estrous response, and pregnancy rate after treatment with Norgestomet and various dosages of estradiol valerate in suckled cows. Journal of Animal Science, v. 69, p. 27212726, 1991.

PRYCE, J. E.; COFFEY, M. P.; SIMM, G. The relationship between body condition score and reproductive performance. Journal of Dairy Science, v. 84, p. 15091515, 2001.

RAE, D. O.; KUNKLE, W . E.; CHENOWETH, P. J.; SAND, R. S.; TRAN, T. Body condition: influences on beef cattle reproductive performance. In: CONGRESO NACIONAL DE BUIATRIA, 10., 1996, Acapulco, Gro., México. Anais... 1996, p. 339343.

RATHBONE, M. J.; KINDER, J. E.; FIKE, K.; KOJIMA, F.; CLOPTON, D.; OGLE, C. R.; BUNT, C. R. Recent advances in bovine reproductive endocrinology and physiology and their impact on drug delivery system design for the control of the 
estrous cycle in cattle. Advance Drug Delivery Reviews, v. 50, n. 3, p. 277-320, 2001.

REFSAL, R. K.; SEGUIN, B. E. Effect of stage of diestrus and number of cloprostenol (ICI 80,996) injections on interval to estrus, LH peak and ovulation in heifers. Theriogenology, v. 14, n. 1, p. 37-48, 1980.

REID, J. T.; ROBB, J. Relationship of body composition to energy intake and energetic efficiency. Journal of Dairy Science, v. 54, n. 553-564, 1971.

REIST, M.; ERDIN, D.; VON EUW, D.; TSCHUEMPERLIN, K.; LEUENBERGER, H.; CHILLIARD, Y.; HAMMON, H. M.; MOREL, C.; PHILIPONA, C.; ZBINDEN, Y.; KUENZI, N.; BLUM, J. W. Estimation of energy balance at the individual and herd level using blood and milk traits in high-yielding dairy cows. Journal of Dairy Science, v. 85, p. 3314-3327, 2002.

REVAH, I.; BUTLER, W. R. Prolonged dominance of follicles and reduced viability of bovine oocytes. Journal of Reproduction and Fertility, v. 106, n. 1, p. 39-47, 1996.

RHODES, J. M.; DE'ATH, G.; ENTWISTLE, K. W. Animal and temporal effects on ovarian follicular dynamics in Brahman heifers. Animal Reproduction Science, v. 38, n. 4, p. 265-277, 1995.

RICHARDS, M. W.; SPITZER, J. C.; WARNER, M. B. Effect of varying levels of postpartum nutrition and body condition at calving on subsecuent reproductive performance in beef cattle. Journal of Animal Science, v. 62, p. 300-306, 1986.

RHODES, F. M.; MCDOUGALL, S.; BURKE, C. R.; VERKERK, G. A.; MACMILLAN, K. L. Invited review: Treatment of cows with an extended postpartum anestrous interval. Journal of Dairy Science, v. 86, p. 1876-1894, 2003.

ROBINSON, D. L., MCDONALD,C. A.; HAMMOND, K.; TURNER, J. W. Live animal measurement of carcass traits by ultrasound: Assessment and accuracy of sonographers. Journal of Animal Science, v. 70, p. 1667-1676, 1992. 
ROCHA, E. D.; ANDRADE, V. J.; EUCLIDES FILHO, K.; NOGUEIRA, E.;

FIGUEIREDO, G. R. Tamanho de vacas Nelore adultas e seus efeitos no sistema de produção de gado de corte. Arquivo Brasileiro de Medicina Veterinária e Zootecnia. v. 55, n. 4, p. 255-267, 2003.

ROCHE, J. R.; DILLON, P. G.; STOCKDALE, C. R.; BAUMGARD, L. H.; VANBAALE, M. J. Relationships among international body condition scoring systems. Journal of Dairy Science, v. 87, p. 3076-3079, 2004.

RODRIGUES, C. A.; AYRES, H.; REIS, E. L.; MADUREIRA, E. H.; BARUSELLI, P. $S$. Aumento da taxa de prenhez em vacas Nelore acíclicas tratadas com eCG para inseminação artificial em tempo fixo. Acta Scientiae Veterinariae, v. 32, p. 222, 2004b.

RODRIGUES, C. A.; AYRES, H.; REIS, E. L.; MADUREIRA, E. H.; BARUSELLI, P. $S$. Aumento da taxa de prenhez em vacas Nelore inseminadas em tempo fixo com o uso de eCG em diferentes períodos pós parto. Acta Scientiae Veterinariae, v. 32, p. 220, 2004a.

ROUSE, G. H.; WILSON, D. E.; DUELLO D. A. The accuracy of real-time ultrasound scans taken serially on small-, medium-, and large-frame steers and bulls slaughtered at three endpoints. In: Beef \& sheep research report. Ames: lowa State University, 1992. p. 14-19.

RUBIANES, E.; BEARD, A.; DIERSCHKE, D. J.; BARTLEWSKI, P.; ADAMS, G. P.; RAWLINGS, N. C. Endocrine and ultrasound evaluation of the response to PGF and $\mathrm{GnRH}$ given at different stages of the luteal phase in cyclic ewes. Theriogenology, v. 48, p. 1093-1104, 1997.

RUEGG, P. L.; MILTON, R. L. Body condition scores of Holstein cows on Prince Edward Island, Canada: relationships with milk yield, reproductive performance, and disease. Journal of Dairy Science, v. 78, p. 552-564, 1995. 
SÁ FILHO, M. F.; AMARAL, J. P. B.; MANTOVANI, A. P.; REIS, E. L.; NICHI, M.; BARUSELLI, P. S. Effect of synthetic progesterone (Afisterone ${ }^{\circledR}$ ) administration at the moment of $\mathrm{CIDR}^{\circledR}$ insertion on follicular wave emergence in beef heifers. In: INTERNATIONAL CONGRESS ON ANIMAL REPRODUCTION, 1., 2004, Porto Seguro. Proceedings... Belo Horizonte: Colégio Brasileiro de Reprodução Animal, 2004, p. 127.

SÁ FILHO, O. G.; VALARELLI, R. L.; MENEGHETTI, M.; VASCONCELOS, J. L. M. Taxas de prenhez ao longo de 70 dias de estação de monta em vacas Nelore pósparto tratadas com acetato de melengestrol associado ou não com cipionato de estradiol. Acta Scientiae Veterinariae, v. 35, p. s971, 2007.

SAINZ, R. D.; ARAÚJO, F. R. C. Uso de tecnologias de ultra-som no melhoramento do produto final carne. In: CONGRESSO BRASILEIRO DAS RAÇAS ZEBUÍNAS, 5., 2002, Uberaba. Anais... 2002. Disponível em: < http://www.avalonline.com.br/artigostecnicos/artigos/ABCZ_2002_final.pdf>. Acesso em: 21 maio 2008.

SALES, J. N. S.; SOUZA, A. H.; BENEDITO, T. B.; ARAÚJO, T. P. B.; PENTEADO, L.; SÁ FILHO, M. F.; CREPALDI, G. A.; BARUSELLI, P. S. Efeito da suplementação com Megalac-E® SOBRE a taxa de prenhez de vacas Nelore primíparas insemindas em tempo fixo. Acta Scientiae Veterinariae, v. 35, p. s1127, 2007.

SANTOS, J. E.; THATCHER, W. W.; CHEBEL, R. C.; CERRI, R. L. A.; GALVÃO, K. $N$. The effect of embryonic death rates in cattle on the efficacy of estrus synchronization programs. Animal Reproduction Science, v. 82-83, n. 1, p. 513535, 2004.

SARTORI, R.; FRICKE, P. M.; FERREIRA, J. C.; GINTHER O. J.; WILTBANK, M. C. Follicular deviation and acquisition of ovulatory capacity in bovine follicles. Biology Reproduction, v. 65, n. 5, p. 1403-1409, 2001.

SAS STATISTICAL ANALISYS SYSTEM. SAS User's Guide: Statistics. Version 9.1 SAS Ins. Cary: SAS, 2002-2003. 
SAVIO, J. D.; KEENAN, L.; BOLAND, M. P.; ROCHE, J. F. Patter of growth of dominant follicles during oestrus cycle in heifers. Journal of Reproduction and Fertility, v. 83, n. 2, p. 663-671, 1988.

SAVIO, J. D.; KEENAN, L.; BOLAND, M. P.; ROCHE, J. F. Pattern of growth of dominant follicles during the oestrous cycle of heifers. Journal of Reproduction and Fertility, v. 83, p. 663-671, 1988.

SCHILLO, K. K. Effects of dietary energy on control of luteinizing hormone secretion in cattle and sheep. Journal of Animal Science, v. 70, p. 1271-1282, 1992.

SCHRODER, U. J.; STAUFENBIEL, R. Methods to Determine Body Fat Reserves in the Dairy Cow with Special Regard to Ultrasonographic Measurement of Backfat Thickness. Journal of Dairy Science, v. 89, p. 1-14, 2006.

SELK, G. E.; WETTEMANN, R. P.; LUSBY, K. S.; OLTJEN, J. W.; MOBLEY, S. L.; RASBY, R. J.; GARMENDIA, J. C. Relationship among weight change, body condition and reproductive performance of range beef cows. Journal of Animal Science, v. 66, p. 3153-3159, 1988.

SHORT , R. E.; BELLOWS, R. A.; STAIGMILLER, R. B.; BERARDINELLI, J. G.; CUSTER, E. E. Physiological mechanisms controlling anestrous and infertility in post partum beef cattle. Journal Animal Science, v.68, p.799-816, 1990.

SILKE, V.; DISKIN, M. G.; KENNY, D. A.; BOLAND, M. P.; DILLON, P.; MEE, J. F.; SREENAN, J. M. Extent, pattern and factors associated with late embryonic losses in dairy cows. Animal Reproduction Science, v. 71, p. 1-12, 2002.

SILVA, R. C. P.; RODRIGUES, C. A.; MARQUES, M. O.; AYRES, H.; REIS, E. L.; NICHI, M.; MADUREIRA, E. H.; BARUSELLI, P. S. Efeito do eCG e do GnRH na taxa de prenhez de vacas Nelore lactantes inseminadas em tempo fixo. Acta Scientiae Veterinariae, v. 32, p. 221, 2004. 
SILVA, S. L.; LEME, P. R.; FIGUEIREDO, L. G. G. Correlações entre características de carcaça obtidas "in vivo" por ultra-sonografia e na carcaça "post mortem" em novilhos nelore. In: REUNIÃO ANUAL DA SOCIEDADE BRASILEIRA DE ZOOTECNIA, 38., 2001, Piracicaba. Anais... Piracicaba: Sociedade Brasileira de Zootecnia, 2001. p.1206-1208.

SILVA, S. L.; LEME, P. R.; PUTRINO, S. M.; MARTELLO, L. S.; LIMA, C. G.; LANNA, D.P.D. Estimativa do peso e do rendimento de carcaça de tourinhos Brangus e Nelore, por medidas de ultra-sonografia1. Revista Brasileira de Zootecnia, v.32(5), 2003

SIROIS, J.; FORTUNE, J.E. Ovarian follicular dynamics during the estrous cycle in heifers monitored by real-time ultrasonography. Biology of Reproduction, v. 39, p. 308-317, 1988.

SOUZA, A. H. Inseminação artificial em tempo fixo em vacas holandesas de alta produção. 2008. $152 \mathrm{f}$. Tese (Doutorado em Mediciana Veterinária) - Faculdade de Medicina Veterinária e Zootecnia, Universidade de São Paulo, São Paulo, 2008.

SPELBRING, M. C.; MARTIN, T. G.; DREWRY; K. J. Maternal productivity of crossbred Angus $x$ Milking Shorthorn cows. I. Cow and calf weights and scores. Journal of Animal Science, v. 45, p. 969-975, 1977.

STAUFENBIEL, R.; STAUFENBIEL, B.; ROSSOW, N.; WIEDEMANN; F. 1993. Energie-und Fettstoffwechsel des Rindes - Vergleich der Aussage der Ruckenfettdicke mit anderen Untersuchungsgroßen. Mh. Vet. Med, v. 48, p. 167174.

STAUFENBIEL, R. Energie- und Fettstoffwechsel des Rindes.

Untersuchungskonzept und Messung der Ruckenfettdicke. Mh. Vet. Med. v. 47, p. 467-474, 1992. 
STAUFENBIEL, R. Konditionsbeurteilung von Milchkuhen mit Hilfe der sonographischen Ruckenfettdickenmessung. Prakt Tierarzt Coll Vet v. 27, p. 8792, 1997.

STEVENSON, J. S.; JOHNSON, S. K.; Milliken, G. A. Incidence of postpartum anestrus in suckled beef cattle: treatments to induce estrus, ovulation, and conception. Prof Animal Science v. 19, p. 124-134, 2003.

STOUFFER, J. R.; CROSS, H. R. Evaluation of beef cattle with real-time array ultrasound. Journal of Animal Science, v. 61, p. 144, 1985. Abstract.

TANABE, T. Y.; HANN, R. C. Synchronized estrus and subsequent conception in dairy heifers treated with prostaglandin $F_{2} \alpha$. I. Influence of stage of cycle at treatment. Journal of Dairy Science, v. 58, n. 4, p. 805-811, 1984.

TREACHER, R. J.; REID, I. M.; ROBERTS, C. J. Effect of body condition at calving on the health and performance of dairy cows. Animal Production, v. 43, p. 1-6, 1986.

URWIN, V. E.; ALLEN, W. R. Pituitary and chorionic gonadotrophic control of ovarian function during early pregnancy in equids. Journal Reproduction Fertility, v. 32, p. $371,1982$.

VACA, L. A.; GALINA, C. S.; FERNANDEZ-BACA, S.; ESCOBAR, F. J.; RAMÍREZ, B. Oestrous cycles, oestrus and ovulation of the Zebu in the Mexican tropics. The Veterinary Record, v. 117, n. 26, p.434-437,1985.

VASCONCELOS, J. L. M.; SILCOX, R. W.; ROSA, G. J. M.; PURSLEY, J. R.; WILTBANK, M. C. Synchronization rate, size of the ovulatory follicle and pregnancy rate after synchronization of ovulation beginning on different days of the estrous cycle in lactating dairy cows. Theriogenology, v. 52, n. 6, p. 1067-1078, 1999.

WAGNER, J. J.; LUSBY, K. S.; OLTJEN, J. W.; RAKESTRAW, J.; WETTEMANN, R. P.; WALTERS, L. E. Carcass composition in mature hereford cows: Estimation and 
effect on daily metabolizable energy requirement during winter. Journal of Animal Science, v. 66, p. 603-612, 1988.

WARD, D. N.; MOORE JR, W. T. Comparative study of mammalian glycoprotein hormones. In: ANIMAL MODELS FOR RESEARCH IN FERTILITY AND CONTRACEPTION. Baltimore: Harper and Row, 1979. p. 151.

WILDMAN, E. E.; JONES, G. M.; WAGNER, P. E.; BOWMAN, R. L.; TROUTT, H. F.; LESCH, T. N. A dairy cow body condition scoring system and its relationship to selected production characteristics. Journal of Dairy Science, v. 65, p. 495, 1982.

WILLIAMS, G. L. Suckling as a regulator of postpartum rebreeding in cattle: a review. Journal of Animal Science, v. 68, p. 8331-852, 1990.

WILLIAMS, G. L.; GAZAL, O. S.; GUZMÁN VEGA, G. A.; STANKO, R. L. Mechanisms regulating suckling-mediated anovulation in the cow. Animal of Reproduction Science, v. 42, p. 289-297, 1996.

WILSON, D. E. Aplication of ultrasound for genetic improvement. Journal of Animal Science, v. 70, p. 973-983, 1992.

WILTBANK, J. N.; ZIMMERMAN, D. R.; INGALLS, J. E.; ROWDEN, W. W. Use of progestacional compounds alone or in combination with estrogen for synchronization of estrus. Journal of Animal Science, v. 24, p. 990-994, 1965.

WILTBANK, M. C. How information of hormonal regulation of the ovary has improved understanding of timed breeding programs. Theriogenology, v. 48, n. 1, p. 83-97, 1997.

WILTBANK, M.C.; GÜMEN, A.; SARTORI, R. Physiological classification of anovulatory conditions in cattle Theriogenology, v. 57, p. 21-52, 2002. 
WITTEK, T.; FÜRLL, M. Untersuchungen zu Korperkondition und abdominalen Fettdepots in Beziehung zur Fettmobilisation bei an Labmagenverlagerung erkrankten. Kuhen Tierarztl Umsch, v. 57, p. 302-309, 2002.

WRIGHT, I. A.; RHIND, S. M.; RUSSEL, A. J. F.; WHYTE, T. K.; MCBEAN, A. J.; MCMILLEN, S. R. Effects of body condition, food intake and temporary calf separation on the duration of the post-partum anoestrus period and associated $\mathrm{LH}$, FSH and prolactin concentrations in beef cows. Animal Production, v. 45, p. 395402, 1987.

WRIGHT, I. A.; RHIND, S. M.; WHYTE, T. K.; SMITH, A. J. Effects of body condition at calving and feeding level after calving on LH profiles and the duration of the postpartum anoestrous period in beef cows. Animal Production, v. 55, p. 41-46, 1992.

YAAKUB, H.; O'CALLAGHAN, D.; BOLAND, M. P. Effect of type and quantity of concentrates on superovulation and embryo yield in beef heifers. Theriogenology, $v$. 51, p. 1259-1266, 1999.

YAVAS, Y.; WALTON, J. S. Postpartum acyclicity in suckled beef cows: a review. Theriogenology, v. 54, p. 25-55, 2000. 